\title{
Fragilidade gama e variância robusta: extensões do modelo semiparamétrico de Cox
}

Nivea da Silva Matuda

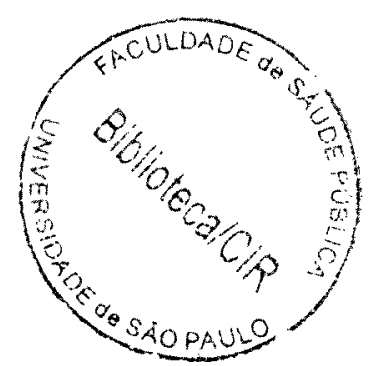

Tese apresentada ao Programa de Pós-Graduação em Saúde Pública da Faculdade de Saúde Pública da Universidade de São Paulo, para obtenção do título de Doutor em Saúde Pública.

Área de concentração: Epidemiologia

Orientador: Prof. Dr. José Maria Pacheco de Souza 


\section{AGRADECIMENTOS}

Agradeço ao meu Deus por ter me sustentado e pela esperança de melhores conquistas.

Ao meu orientador, Professor José Maria, por seu desprendimento e bom senso que foram essenciais para que eu chegasse até aqui. Admiro muito sua habilidade de tornar o ambiente acadêmico extremamente agradável e quero levar adiante para meus alunos.

A minha família pelo apoio emocional e compreensão.

Quero agradecer aos meus colegas do departamento de Estatística da UFPR por acreditarem em mim e ao apoio financeiro do PICDT-UFPR/CAPES.

Sou grata a todos os amigos do IME e FSP pelo prazer de estudarmos e divertirmos juntos, em especial Iracema e Gizelton sempre prontos a me socorrer; Giana, Sandra, Juliana, Dionísia e Suzana pela maravilhosa convivência; Professoras Denise e Sabina pela atenção que demonstraram; e secretárias Beth e Regina e funcionários da biblioteca da FSP por toda ajuda essencial. 


\section{RESUMO}

Matuda, NS. Fragilidade gama e variancia robusta: extensões do modelo semiparamétrico de Cox. São Paulo; 2005. [Tese de Doutorado - Faculdade de Saúde Pública da USP]

Objetivo. Apresentar, metodologicamente, as abordagens de variancia robusta e de fragilidade em modelos semiparamétricos para analisar dados univariados e multivariados de sobrevida; e compará-las, empiricamente, estimando razões de taxas de falha na análise de dados reais da área biomédica. Métodos. A formulação dos modelos com fragilidade e com variancia robusta são descritos e diferentes modelos para analisar falhas múltiplas são apresentados. Cinco conjuntos de dados são considerados na comparação, dois de eventos agrupados e três de eventos recorrentes. Considerou-se a $1^{a}$ falha dos eventos recorrentes para a análise de dados univariados de sobrevida, em que a fragilidade representa a heterogeneidade não observada e a variancia robusta melhora a variablidade dos estimadores quando o modelo não está especificado corretamente. Resultados. A abordagem de variância robusta apresentou um bom desempenho computacional. Os ajustes com fragilidade e com variância robusta foram afetados de maneira similar pelos modelos para falhas múltiplas. Conclusões. As duas abordagens podem levar a diferentes ajustes nos modelos para eventos recorrentes. As análises para $1^{\mathrm{a}}$ falha podem diferir das análises com eventos recorrentes. A não ser que haja interesse em testar independência, o modelo de variância robusta parece ser o mais indicado, enquanto modelos de fragilidade com suposições menos restritivas e com razoável desempenho computacional não estiverem disponíveis em programas flexíveis. No momento, o S-Plus é o melhor programa para aplicar a fragilidade gama, seguido do Stata; o uso de uma macro do SAS mostrou-se desvantajoso. Os três programas são equivalentes para analisar modelos de variância robusta.

Descritores: Análise de Dados Multivariados de Sobrevida. Modelos de Fragilidade Compartilhada. Eventos Agrupados. Eventos Recorrentes. Extensão do Modelo Semiparamétrico de Cox. 


\section{SUMMARY}

Matuda, NS. Gamma frailty and robust variance: extensions of the semiparametric Cox model. São Paulo; 2005. [Phd Thesis - Faculdade de Saúde Pública da Universidade de São Paulo, Brazil]

Objectives. To present methodologically, the robust variance and gamma frailty approaches applied to semiparametric models for univariate and multivariate survival analyses; and to compare them, empirically, adjusting the models for real data. Methods. The formulation of the models with frailty and with robust variance is described and different models to analyze multiple failures are presented. Five data sets are considered in the comparisons, two of cluster events and three of recurrent events. The first failure of the recurrent events was considered for the univariate survival analysis, where the frailty represents heterogeneity unobserved and robust variance improves the variance of the estimators when the model is not specified correctly. Results. The robust variance approach presented a good computational performance. The adjustments with frailty and with robust variance were affected in similar way by the models for multiple failures. Conclusions. The two approaches can produce different adjustments in the models for recurrent events. The analyses for first failure can differ from the analyses with recurrent events. When there is not interest in testing independence, the robust variance model is the indicated, while models of frailty with less restrictive assumptions and reasonable computational performance are not available in flexible programs. At the moment, S-Plus is indicated for gamma frailty, followed by Stata; the use of a SAS macro is disadvantageous. The three programs are equivalent for robust variance.

Descriptors: Multivariate Survival Analysis. Shared Frailty Models. Cluster Events. Recurrent Events 


\section{INDICE}

1 INTRODUÇĀO 1

1.1 Características dos dados multivariados de sobrevida . . . . . . 4

1.2 Conceitos básicos da análise de sobrevida . . . . . . . . . . 6

1.2.1 Funções do tempo de falha . . . . . . . . . . . 7

1.2.2 Modelos para dados univariados de sobrevida . . . . . 8

1.2.3 Estimação dos modelos de riscos proporcionais . . . . . . 10

1.2.4 Modelo de Cox com a presença de empates . . . . . . . 15

1.2.5 Modelo de Cox estratificado . . . . . . . . . . . 16

1.3 Modelos para dados multivariados de sobrevida . . . . . . . 17

2 OBJETIVOS $\quad 20$

3 MATERIAL E MÉTODOS 21

3.1 Descrição dos conjuntos de dados . . . . . . . . . . . . 22

3.1.1 Estudo 1: ninhada de ratos ............ 22

3.1.2 Estudo 2: retinopatia em diabéticos ........... 23

3.1.3 Estudo 3: recorrência de tumor em pacientes com câncer de bexiga ....................... 23

3.1.4 Estudos 4 e 5: febre e morbidades infantis . . . . . . . 24

4 APRESENTAÇÃo METODOLÓGICA 26

4.1 Extensões do modelo de Cox para dados multivariados de sobrevida 26 
4.1.1 Fragilidade .................. 27

4.1.2 Estimação do modelo de fragilidade gama . . . . . . . . 30

4.1.3 Variância robusta ................ 36

4.1.4 Estruturas de intervalo de risco e tipos de conjunto de risco para falhas múltiplas . . . . . . . . . . . 39

4.2 Aspectos computacionais . . . . . . . . . . . . . 50

5 COMPARAÇĀO EMPIRICA 55

5.1 Comparação dos modelos por estudo . . . . . . . . . . 55

5.2 Comparação dos programas computacionais . . . . . . . . 87

6 DISCUSSÃo $\quad 89$

7 CONCLUSÕES $\quad 94$

8 REFERENCIAS 95 


\section{INTRODUÇÃO}

Em análise de sobrevida, a variável resposta é o tempo de falha. Entende-se por falha a ocorrência de um evento de interesse em um individuo e tempo de falha é o tempo até o evento ocorrer, medido a partir de um instante de tempo inicial pré-estabelecido. Existe uma complexidade para analisar-se dados de tempos de falha porque, quase nunca, é possivel observar o tempo de falha em todos os indivíduos pertencentes ao estudo, por causa principalmente da interrupção do acompanhamento em indivíduos que ainda não falharam. Se o tempo de falha não pôde ser observado, é registrado o período de tempo em que o indivíduo ficou sob observação, e só é possível determinar que o tempo de falha do indivíduo é superior ao período de observação; essa informação parcial é caracterizada como censura à direita, como descrito em KALBFLEISCH e PRENTICE (2002).

Dados de tempos de falha com possiveis censuras são encontrados em estudos epidemiológicos para estabelecer estratégias de prevenção (LIANG e col. 1995); por exemplo, o tempo até o desmame precoce, para a qual os pesquisadores buscam identificar fatores que aceleram a taxa de ocorrência do desmame. Em ensaios clínicos, um novo tratamento pode ser declarado mais efetivo que o tratamento padrão se for mostrado, por exemplo, que prolonga mais o tempo de vida de pacientes com leucemia. Estudos que têm, como variável de interesse, o tempo até a morte, motivaram o desenvolvimento de uma metodologia estatística para tratar as censuras, fazendo com que esta área ficasse conhecida como análise de sobrevida. Dentre esses desenvolvimentos, encontram-se os trabalhos de CUTLER e EDERER (1958) e de KAPLAN e MEIER (1958) para estimar a probabilidade de sobrevida em função do tempo.

Embora sejam comuns na prática, as censuras não permitem o uso de técnicas estatísticas convencionais, tais como o teste $t$, para comparação de dois tratamen- 
tos. Sem a presença de censuras, metodologias estatísticas clássicas poderiam ser utilizadas, provavelmente aplicando-se uma transformação na resposta, para satisfazer a suposição de distribuição normal. Por outro lado, como discutido em ALLISON (1984), desprezar as observações censuradas pode causar graves distorções nos resultados, levando a vícios sérios por perda de informaçōes. MANTEL (1966) propôs uma estatística, conhecida como log-rank, para comparar duas distribuiçōes de sobrevida.

A aplicação de modelos de regressão na análise de sobrevida também necessita de técnicas específicas para tratar as censuras, e comparativamente aos modelos de regressão para respostas não censurados, são mais complexas. O uso da modelagem em estudos prospectivos ficou popular após a publicação e aceitação do artigo original de COX (1972), que propôs um modelo semiparamétrico para avaliar o efeito das covariáveis sobre a taxa de falha. Este modelo ficou conhecido como modelo semiparamétrico de Cox ou modelo de riscos proporcionais de Cox.

A análise de tempos de falha ou análise de sobrevida é uma das áreas da Estatística que experimentou um rápido crescimento durante a última metade do século XX (FLEMING e LIN 2000). Um fator que contribuiu para a aplicação intensa desses métodos em diversas áreas do conhecimento foi a sua implementação em programas computacionais flexíveis. Uma indicação deste sucesso é o número elevado de aplicações na área biomédica que se obtém de uma simples pesquisa bibliográfica sobre a análise de sobrevida neste período e em anos ainda mais recentes. Usando a base de dados Medline/PubMed, foram encontrados 3820 artigos que continham nos campos de "title" e/ou "abstract" o termo "survival analysis", entre os artigos publicados no período de 1992 a 2003 . Em um período anterior, 1980 a 1991 , a mesma pesquisa relacionou 586 artigos.

A partir do último quarto do século XX, foram publicados muitos livros-textos descrevendo métodos tradicionais e modernos, que variam em sua sofisticação matemática, como MILLER e col. (1981), LAWLESS (1982), COX e OAKES (1984), KALBFLEISCH e PRENTICE (2002), COLLETT (2003), KLEIN e MOESCHBERGER (2003), e LEE e WANG (2003), os quatro últimos, reedições. Livros mais recentes têm tratado de temas específicos da análise de sobrevida, como o de THERNEAU e GRAMBSCH (2000), sobre extensões do modelo semiparamétrico de Cox e o de IBRAHIM e col. (2001), para a análise de sobrevida com enfoque 
bayesiano.

FLEMING e HARRINGTON (1991) e ANDERSEN e col. (1993) tratam da aplicação da teoria probabilística de processos de contagem na análise de sobrevida, em uma estrutura de processos estocásticos. $\mathrm{O}$ uso desta teoria tem permitido avanço substancial na formulação de modelos para análise de sobrevida e na derivação rigorosa das propriedades estatísticas de estimadores e testes estatísticos destes modelos, tendo como base a teoria de martingale para tempos contínuos.

Muitos modelos estatísticos de sobrevida assumem independência entre os tempos de falha, em que a ocorrência dos eventos é influenciada por características mensuráveis dos indivíduos e de seu ambiente. Essa suposição, no entanto, nem sempre ocorre na prática. Em algumas situações, há interesse em observar a ocorrência de um único tipo de falha mais de uma vez em cada individuo envolvido na análise; nestes casos, os tempos de falha intra-indivíduo não são independentes, seja pela ordenação das falhas, seja por características inerentes à variável tempo de falha, em que a ocorrência de uma falha pode influenciar na taxa de ocorrência de falhas posteriores. Quando são considerados diferentes tipos de falha não ordenados no mesmo indivíduo, os tempos de falha intra-individuo podem estar correlacionados, já que a ocorrência de uma falha pode influenciar na taxa de ocorrência de outros tipos de falhas. Em outras situações, as unidades experimentais são compostas por mais de um indivíduo; nestes casos, possivelmente, os tempos de falha intra-grupo estão correlacionados porque os indivíduos têm algo em comum. Em todas as situações descritas, autores como KALBFLEISCH e PRENTICE (2002) e HOUGAARD (2000) denominam esses dados de sobrevida como tempos de falha multivariados ou dados multivariados de sobrevida. Em geral, tempos de falha multivariados não são independentes. Uma das complexidades na análise de dados multivariados de sobrevida é a suposta violação da independência entre os tempos de falha.

$\mathrm{Na}$ literatura estão, em plena discussão, a formulação e o ajuste dos modelos de regressão para a análise de tempos de falha multivariados (FLEMING e LIN 2000; HOUGAARD 2000). Análises estatísticas para os tempos de falha multivariados em que uma específica distribuição multivariada é usada na estimação por máxima verossimilhança, são uma extensão da metodologia paramétrica para 
tempos de falha independentes. Como extensão do modelo semiparamétrico de Cox, destacam-se as abordagens de fragilidade e variância robusta, que permitem uma forma arbitrária para as distribuições marginais dos tempos de falha multivariados. No modelo com fragilidade, a correlação intra-indivíduo ou intragrupo é caracterizada parametricamente. No modelo com variância robusta, esta correlação não é especificamente modelada, mas leva-se em consideração na estimação robusta da matriz de variância dos estimadores de $\beta$, vetor que contém os parâmetros do modelo.

As análises estatísticas para dados multivariados de sobrevida baseadas em modelos semiparamétricos têm sido cada vez mais aplicadas na área biomédica, desde que os métodos de estimação para os parâmetros dos modelos estão implementados em programas computacionais de distribuição comercial como SAS, S-Plus e Stata, bem como no programa $R$, de distribuição livre.

\subsection{Características dos dados multivariados de so- brevida}

Tempos de falha multivariados são obtidos quando:

- dois ou mais eventos, do mesmo tipo ou de tipos diferentes, ocorrem no mesmo indivíduo;

- eventos ocorrem em indivíduos que estão agrupados pelo planejamento usado no estudo, e existe razão para assumir uma possível estrutura de correlação entre os tempos de falha de indivíduos do mesmo grupo, sendo que há independência entre os grupos.

Há diferentes classificações para dados multivariados de sobrevida (HOUGAARD 2000; KALBFLEISCH e PRENTICE 2002). Ao selecionar os modelos mais apropriados para análise dos dados, THERNEAU e GRAMBSCH (2000) sugeriram que as falhas sejam classificadas em ordenadas e não ordenadas, podendo as falhas não ordenadas ser de tipos diferentes ou do mesmo tipo:

a) falhas ordenadas são os eventos recorrentes que surgem quando cada indivíduo em observação está sujeito a experimentar o mesmo evento várias vezes, 
como um estudo que registre os tempos de ocorrência do primeiro e do segundo enfarto do miocárdio. São falhas ordenadas porque um indivíduo só estará em risco de experimentar a segunda falha se teve a primeira;

b) falhas não ordenadas de tipos diferentes são os eventos de diferentes tipos, em que cada indivíduo pode passar por diferentes estados em qualquer ordem. Podem ser encontrados em estudos que acompanham a evolução da diabetes em que se registram os tempos até as ocorrências de algumas seqüelas de interesse, como retinopatia, nefropatia, microangiopatia e neuropatia. Uma característica desses dados é que cada tipo de falha pode ocorrer somente uma vez para o mesmo indivíduo, não permitindo eventos recorrentes;

c) falhas não ordenadas de mesmo tipo ocorrem em indivíduos que pertencem a algum tipo de agrupamento (eventos agrupados), como os estudos de famílias, em que cada membro da família está sob o risco de ter o evento de interesse. Os tempos de falha de uma mesma família podem estar relacionados porque os seus membros compartilham fatores genéticos e possivelmente fatores ambientais; outro exemplo, è de eventos ocorrendo em órgãos similares de um mesmo indivíduo, como o tempo até o início de perda visual em cada olho.

Outros dois termos usados na literatura para tempos de falha multivariados são:

d) modelo de riscos competitivos, quando um único evento ocorre no indivíduo dentre vários possíveis eventos, ou seja, há interesse em mais de um tipo de falha mas a ocorrência da primeira inibi as outras falhas, como o estudo de mortalidade por causa do óbito.

e) modelo multiestado, quando permite a ocorrência de eventos de diferentes tipos ou iguais, no mesmo indivíduo, ou seja, a ocorrência de um tipo de falha não inibi a recorrência do mesmo tipo de falha e nem a ocorrência de outro tipo de falha. Um exemplo, é o estudo para analisar os tempos até infecção por fungos, bactérias ou vírus em transplantados; 
O Quadro 1.1 contém um esquema que resume o uso de diferentes termos para as possíveis formas de apresentação dos dados de sobrevida. Destacam-se os diferentes formatos de dados multivariados de sobrevida, incluindo os eventos agrupados e o modelo de riscos competitivos que tratam de uma falha por individuo. Os demais formatos de dados multivariados são de falhas múltiplas, quando há mais de uma falha por indivíduo; sendo que o modelo multiestado é o formato mais geral, permitindo tanto falhas ordenadas como falhas não ordenadas de tipos diferentes.

Quadro 1.1 - Resumo dos termos usados para dados de sobrevida

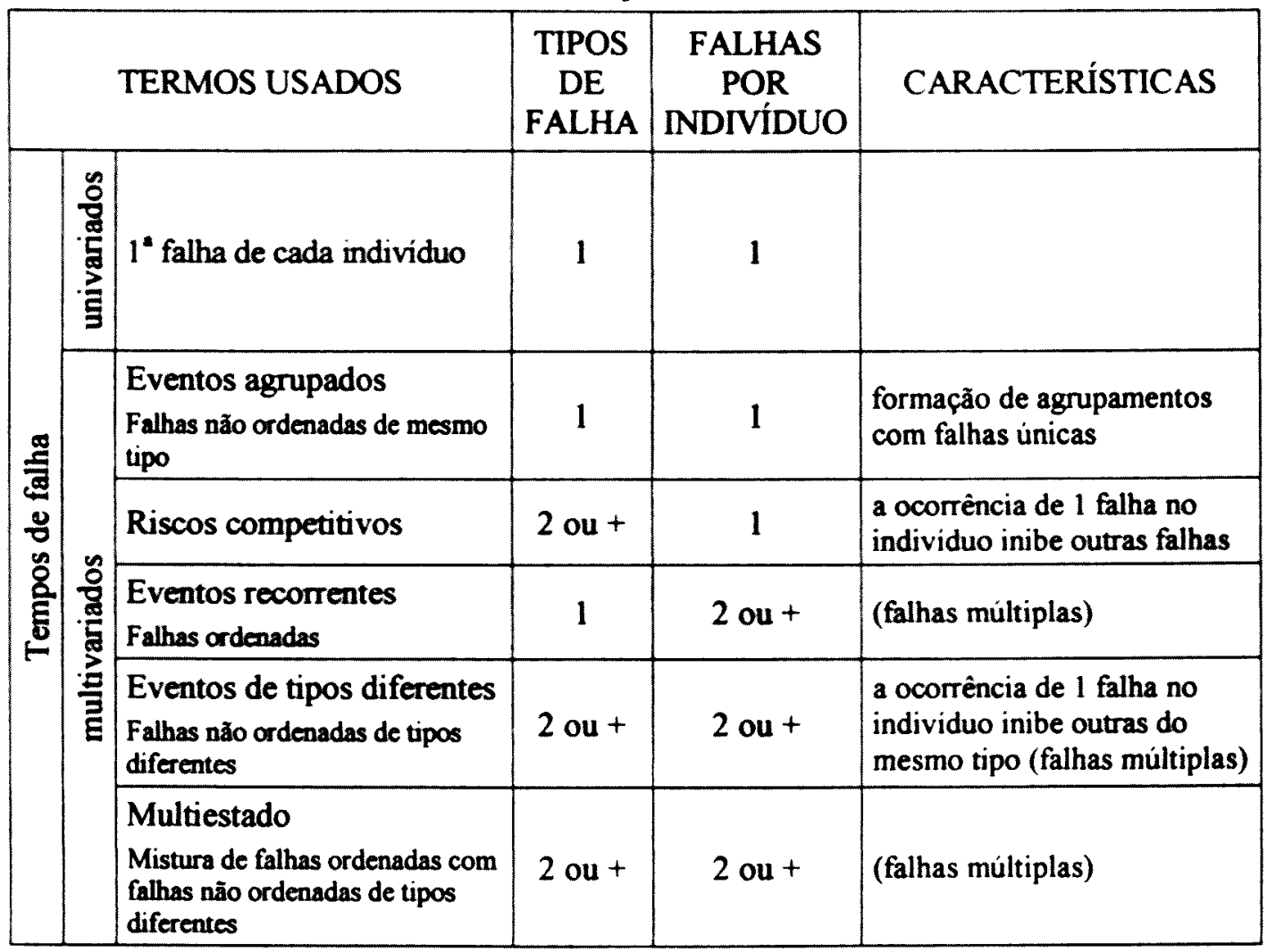

Neste trabalho, é enfatizada a análise de eventos agrupados e a de eventos recorrentes, assumindo que no instante seguinte à ocorrência do evento, o indivíduo está sob o risco de falhar novamente.

\subsection{Conceitos básicos da análise de sobrevida}

Nesta seção são apresentados alguns aspectos dos fundamentos estatísticos para analisar dados univariados de sobrevida, que são relevantes na extensão para dados multivariados. 


\subsubsection{Funções do tempo de falha}

Considere-se, inicialmente, um modelo estatístico para dados univariados de sobrevida, em que cada indivíduo pode experimentar um único evento. $O$ tempo de falha do indivíduo é representado por uma variável aleatória não-negativa, $T$, e suponha-se que $T$ é contínuo.

A função de sobrevida, $S(t)$, é definida como a probabilidade de um indivíduo não falhar até um tempo $t$, ou seja, a probabilidade do tempo de falha ser maior que $t$

$$
S(t)=\operatorname{Pr}(T>t)
$$

A função taxa de falha ("hazard function") é um conceito chave em análise de sobrevida. Considerando um intervalo de tempo $[t, t+\Delta t)$ e tornando $\Delta t$ bem pequeno, tem-se que a função taxa de falha, $h(t)$, é definida como a taxa instantânea de falha no tempo $t$, condicionada à sobrevida até antes de $t$. Assim, para tempos contínuos, a função taxa de falha no tempo $t$ é expressa por

$$
h(t)=\lim _{\Delta t \rightarrow 0} \frac{\operatorname{Pr}(t<T \leq t+\Delta t \mid T>t)}{\Delta t}
$$

Outras nomenclaturas como taxa de transição, taxa de risco e força de mortalidade são encontradas em diferentes aplicações da função taxa de falha.

A função taxa de falha acumulada, $H(t)$, é obtida pela integração de $h(t)$

$$
H(t)=\int_{0}^{t} h(u) d u
$$

Pode-se mostrar que a relação entre as funções de sobrevida e taxa de falha são dadas por

$$
S(t)=\exp \left[-\int_{0}^{t} h(u) d u\right]=\exp \{-H(t)\}
$$

e

$$
h(t)=\frac{f(t)}{S(t)}=-\frac{d}{d t} \log S(t)
$$

em que $f(t)$ é a função densidade de probabilidades de $T$.

Nos indivíduos censurados, o seu tempo de falha $T$ não é observado e registrase o tempo de censura $C$. A causa da censura pode ser aleatória, isto é, os indivíduos estão sujeitos a outros eventos aleatórios que não são de interesse 
mas podem impedir a observação do evento de interesse. No caso de censura aleatória, $C$ representa uma variável aleatória não-negativa com uma distribuição de probabilidades.

Como descrito por KLEIN e MOESCHBERGER (2003, p.76), pode-se pensar que para cada indivíduo há duas variáveis aleatórias $T$ e $C$, mas somente uma delas é observada. Para representar de uma forma simples o conjunto de dados observados, são definidos o tempo observado $t_{i}$ e o indicador de censura $\delta_{i}$ do indivíduo $i(i=1,2, \ldots, n)$ para uma amostra de $n$ indivíduos independentes. Supondo censura aleatória à direita, considere-se para cada indivíduo $i$

$$
t_{i}=\min \left(T_{i}, C_{i}\right)
$$

e

$$
\delta_{i}=\left\{\begin{array}{l}
1, \text { se } T_{i} \leq C_{i} \\
0, \text { se } T_{i}>C_{i}
\end{array}\right.
$$

em que $T_{i}$ e $C_{i}$ são os tempos de falha e censura do indivíduo $i$, respectivamente. Assim, $t_{i}$ é o tempo de falha ou o tempo de censura do indivíduo $i$ e $\delta_{i}$ é igual a 0 se $t_{i}$ for tempo de censura ou é igual a 1 , caso contrário.

Com os pares $\left(t_{i}, \delta_{i}\right),(i=1,2, \ldots, n)$, é possível estimar os parâmetros da distribuição dos tempos de falha e testar as hipóteses de interesse sobre os parâmetros da distribuição, usando, por exemplo, o método de máxima verossimilhança.

\subsubsection{Modelos para dados univariados de sobrevida}

Em adição ao tempo de falha ou de censura, covariáveis são coletadas de cada individuo em estudo e um objetivo importante da análise estatística é verificar o efeito dessas covariáveis sobre a função taxa de falha.

$\mathrm{Na}$ análise de dados univariados de sobrevida, para cada indivíduo $i$, os dados consistem de $\left(t_{i}, \delta_{i}, \mathbf{x}_{i}\right)$, sendo que $\mathbf{x}_{i}^{\prime}=\left(x_{1 i}, x_{2 i}, \ldots, x_{p i}\right)$ é um vetor dos valores de $p$ covariáveis do indivíduo $i$ que são consideradas para predizer o evento; $(i=1,2, \ldots, n)$.

Admitindo que os tempos observados $t_{i}(i=1,2, \ldots, n)$ são contínuos e independentes, uma formulação geral conhecida como modelo de riscos proporcionais 
assume que a função taxa de falha do indivíduo $i$ no tempo $t$ é dada por

$$
h\left(t \mid \mathbf{x}_{i}\right)=h_{0}(t) \Psi\left(\mathbf{x}_{i}\right)
$$

sendo que $h_{0}(t)$ é uma função do tempo $t$ e $\Psi(\mathbf{x})$ é uma função positiva de $\mathbf{x}$. Este modelo é conhecido como modelo de riscos proporcionais porque para quaisquer dois indivíduos, a razão de suas taxas de falha independe do tempo, ou seja, a razão das taxas de falha dos dois indivíduos é constante ao longo do tempo.

Assume-se neste modelo que as covariáveis têm um efeito multiplicativo sobre a função taxa de falha, suposição que parece ser razoável em muitas situações. COX e OAKES (1984) apresentam três formulações para $\Psi(\mathbf{x})$. A que se tornou mais popular é a forma $\Psi(\mathbf{x})=\exp \left(\boldsymbol{\beta}^{\prime} \mathbf{x}\right)$ garantindo valores não-negativos para a taxa de falha, sendo que $\boldsymbol{\beta}^{\prime}=\left(\beta_{1}, \beta_{2}, \ldots, \beta_{p}\right)$ é o vetor de coeficientes do modelo, que são parâmetros desconhecidos, sendo que $-\infty<\beta_{k}<\infty(k=1,2, \ldots, p)$. Assim, tem-se uma forma funcional para o modelo de riscos proporcionais definida como

$$
h\left(t \mid \mathbf{x}_{i}\right)=h_{0}(t) \exp \left(\boldsymbol{\beta}^{\prime} \mathbf{x}_{i}\right)
$$

$O$ vetor $\boldsymbol{\beta}$ representa os efeitos das covariáveis sobre a taxa de falha. Assim, se $\beta_{1}$ for positivo (negativo), um aumento no valor de $x_{1}$ acelera (desacelera) a taxa de falha. Assume-se que esses efeitos são constantes no tempo.

A função $h_{0}(t)$ é conhecida como um risco basal ou de referência, já que $h\left(t \mid \mathbf{x}_{i}=\mathbf{0}\right)=h_{0}(t)$. Para ser consistente com a definição de risco basal, é necessário incorporar ao modelo uma variável indicadora para cada nível das covariáveis categóricas, exceto para a categoria a ser considerada como basal.

Usando a propriedade de riscos proporcionais para interpretar os coeficientes do modelo, em um caso simples de covariável categórica com duas categorias, para a comparação de dois grupos, por exemplo, a covariável $x_{l}$ é definida como $x_{l i}=0$, se o indivíduo $i$ é do grupo de controle e $x_{l i}=1$, se o indivíduo $i$ é do grupo de tratamento. Então, mantidas fixas as demais covariáveis, tem-se que no tempo $t$, a razão das taxas de falha de dois indivíduos, $i$ e $j$, é dada por

$$
H R=\frac{h\left(t \mid x_{l i}=1\right)}{h\left(t \mid x_{l j}=0\right)}=\exp \left(\beta_{l}\right)
$$

indicando que a taxa de falha para tratamento é $\exp \left(\beta_{l}\right)$ vezes a taxa de falha 
para controle.

No caso de uma covariável contínua $l$, a razão das taxas de falha de dois indivíduos, $i$ e $j$, idênticos exceto pelo valor da covariável contínua $l$,

$$
H R=\frac{h\left(t \mid \mathbf{x}_{i}\right)}{h\left(t \mid \mathbf{x}_{j}\right)}=\exp \left[\beta_{l}\left(x_{l i}-x_{l j}\right)\right]
$$

portanto, $H R=\exp \left(\beta_{l}\right)$, se $x_{l i}-x_{l j}=1$. As estimativas da razão de taxas de falhas apresentadas pelos programas estatísticos são relativas, em geral, a $H R=\exp \left(\beta_{l}\right)$. No caso de covariáveis contínuas, corresponde a um $H R$ entre individuos que são diferentes somente na covariável $l$, e essa diferença é de uma unidade de medida.

A análise estatística sobre o conjunto de dados depende de se assumir ou não uma forma específica para $h_{0}(t)$ em (1.3). Em geral, uma especificação da função $h_{0}(t)$ é equivalente à especificação da distribuição dos tempos contínuos de falha e nota-se que, sob o modelo de riscos proporcionais, os parâmetros dessas distribuições são funções do vetor de covariáveis $\mathbf{x}_{i}$. Entretanto, em várias situações, não há bases teóricas ou empíricas suficientes para escolher entre especificações alternativas para $h_{0}(t)$.

COX (1972) propôs um modelo de riscos proporcionais em que não há a necessidade de uma forma específica para $h_{0}(t)$, conhecido como modelo semiparamétrico de Cox. Em parte é paramétrico porque em (1.3) especifica-se um modelo de regressão com forma funcional exclusiva, assumindo que as covariáveis atuam multiplicativamente sobre a taxa de risco mediante $\exp \left(\boldsymbol{\beta}^{\prime} \mathbf{x}_{i}\right)$; é em parte não-paramétrico porque não assume uma distribuição de probabilidades para os tempos de falha.

\subsubsection{Estimação dos modelos de riscos proporcionais}

Para estimar os parâmetros do modelo de riscos proporcionais em (1.3), o método de máxima verossimilhança permite usar a informação que se tem nos casos de censura. O método combina as observações censuradas e não-censuradas de tal modo que produz, sob certas condições de regularidade, estimativas consistentes e assintoticamente normais.

O método de máxima verossimilhança é certamente uma das técnicas mais 
utilizadas na estimação paramétrica, quando a forma da distribuição geradora dos dados é conhecida. Uma desvantagem da estimação por máxima verossimilhança é a exigencia de que se especifique a forma de $h_{0}(t)$ em (1.3). Para estimar os parâmetros do modelo semiparamétrico, é usada a função de verossimilhança parcial proposta por COX (1972) que, para estimar $\beta$, condicionou a verossimilhança, eliminando $h_{0}(t)$.

\section{Função de verossimilhança}

O primeiro passo para a estimação de (1.3) é construir a função de verossimilhança, cuja forma depende do tipo de censura. O tipo mais comum na área biomédica é a censura aleatória à direita. Neste caso, com $i=1,2, \ldots, n$ e sob a suposição de que $\left(T_{i}, C_{i}\right)$ são independentes e que $T_{i}$ é independente de $C_{i}$, a função de verossimilhança para $\left(t_{i}, \delta_{i}, \mathbf{x}_{i}\right)$ é então definida como

$$
L(\boldsymbol{\delta})=\prod_{i=1}^{n}\left[f_{T}\left(t_{i} \mid \mathbf{x}_{i}\right) S_{C}\left(t_{i} \mid \mathbf{x}_{i}\right)\right]^{\delta_{i}}\left[f_{C}\left(t_{i} \mid \mathbf{x}_{i}\right) S_{T}\left(t_{i} \mid \mathbf{x}_{i}\right)\right]^{1-\delta_{i}}
$$

em que $f_{T}\left(t_{i} \mid \mathbf{x}_{i}\right)$ e $S_{T}\left(t_{i} \mid \mathbf{x}_{i}\right)$ são as funções de densidade e de sobrevida de $T_{i}$, respectivamente e $f_{C}\left(t_{i} \mid \mathbf{x}_{i}\right)$ e $S_{C}\left(t_{i} \mid \mathbf{x}_{i}\right)$ são as funções de densidade e de sobrevida de $C_{i}$, respectivamente. Aqui, $\delta$ é o vetor de todos os parâmetros desconhecidos (consistindo do vetor $\boldsymbol{\beta}$ e dos parâmetros da distribuição de $T_{i}$ ).

Supondo que as funções $f_{C}\left(t_{i} \mid \mathbf{x}_{i}\right)$ e $S_{C}\left(t_{i} \mid \mathbf{x}_{i}\right)$ não envolvem qualquer parâmetro de interesse, a função de verossimilhança em (1.4) pode ser simplificada para

$$
L(\boldsymbol{\delta})=\prod_{i=1}^{n}\left[f_{T}\left(t_{i} \mid \mathbf{x}_{i}\right)\right]^{\delta_{i}}\left[S_{T}\left(t_{i} \mid \mathbf{x}_{i}\right)\right]^{1-\delta_{i}}
$$

Duas suposições importantes em (1.5) são a de censura independente, ou seja, que os indivíduos censurados em $t_{i}$ são representativos de todos os indivíduos que estavam em risco no tempo $t_{i}$ (SZKLO e NIETO 2000) e a de censura nãoinformativa, em que os parâmetros de interesse estão associados somente com o tempo de falha.

É possível, por (1.1) e (1.2), escrever a função de verossimilhança em termos unicamente da função taxa de falha como

$$
L(\boldsymbol{\delta})=\prod_{i=1}^{n}\left[h\left(t_{i} \mid \mathbf{x}_{i}\right)\right]^{\delta_{i}} \exp \left[-\int_{0}^{t_{i}} h\left(u \mid \mathbf{x}_{i}\right) d u\right]
$$


Estimativas de máxima verossimilhança são obtidas substituindo em (1.6) a expressão apropriada para $h\left(t_{i} \mid \mathbf{x}_{i}\right)$, de acordo com a suposta distribuição de $T_{i}$, para então encontrar as estimativas de $\delta$ que maximizam (1.6) por meio da solução do sistema de equações

$$
\mathrm{U}(\boldsymbol{\delta})=\frac{\partial}{\partial(\boldsymbol{\delta})} \log L(\boldsymbol{\delta})=\mathbf{0}
$$

O vetor de derivadas $U(\cdot)$ é conhecido como vetor escore. Sob certas condições de regularidade pode ser mostrado que $\hat{\boldsymbol{\delta}}$, o estimador de máxima verossimilhança de $\delta$, é assintoticamente normal com média $\delta$ e matriz de variancias $I^{-1}(\delta)$ sendo que

$$
\mathbf{I}(\boldsymbol{\delta})=E\left[-\frac{\partial^{2}}{\partial \boldsymbol{\delta} \partial \boldsymbol{\delta}^{\prime}} \log L(\boldsymbol{\delta})\right]
$$

conhecida como matriz de informação esperada, que pode ser estimada pela matriz de informação observada, dada por

$$
\mathbf{i}(\hat{\boldsymbol{\delta}})=\left.\left[-\frac{\partial^{2}}{\partial \boldsymbol{\delta} \partial \boldsymbol{\delta}^{\prime}} \log L(\boldsymbol{\delta})\right]\right|_{\boldsymbol{\delta}=\hat{\boldsymbol{\delta}}}
$$

Em geral, os estimadores de máxima verossimilhança não podem ser expressos analiticamente; necessita-se de um processo iterativo para a obtenção das estimativas como, por exemplo, o conhecido método de Newton-Raphson. Após obter as estimativas, é possível, pelas propriedades dos estimadores de máxima verossimilhança, construir intervalos de confiança e fazer testes de hipóteses sobre os parâmetros em $\boldsymbol{\delta}$ e sobre as razões das taxas de falha, $H R$.

\section{Função de verossimilhança parcial}

Considere-se que $t_{1}^{*}<t_{2}^{*}<\ldots<t_{D}^{*}$ referem-se a $D$ tempos distintos de falha; $D \leq n$ indivíduos da amostra. Seja $\mathbf{x}_{i}$ o vetor de covariáveis para o indivíduo que falhou no tempo $t_{i}^{*}(i=1,2, \ldots, D)$. Uma maneira simples de entender a forma da verossimilhança parcial é considerar, para $\Delta t$ pequeno, que

$$
\operatorname{Pr}\left(\text { um indivíduo falhar no tempo } t_{i}^{*}, \text { dado que está em risco) } \approx \Delta t h\left(t_{i}^{*} \mid \mathbf{x}_{i}\right)\right.
$$

Seja o conjunto de risco $R_{i}=\left\{j: t_{j} \geq t_{i}^{*}\right\},(i=1,2, \ldots, D),(j=1,2, \ldots, n)$, representando os índices de todos os indivíduos da amostra que estão em "risco" 
no instante de falha $t_{i}^{*}$, ou seja, $R_{i}$ discrimina todos individuos que ainda não falharam e nem foram censurados até $t_{i}^{*}$.

Então,

$\operatorname{Pr}\left(\right.$ ocorrer falha no tempo $t_{i}^{*}$, entre todos os individuos em risco $) \approx \Delta t \sum_{j \in \boldsymbol{R}_{i}} h\left(t_{i}^{*} \mid \mathbf{x}_{j}\right)$

Logo, a probabilidade condicional de um indivíduo falhar em $t_{i}^{*}$, dado o conjunto de risco em $t_{i}^{*}$, é dada por

$$
\frac{h\left(t_{i}^{*} \mid \mathbf{x}_{i}\right)}{\sum_{j \in R_{i}} h\left(t_{i}^{*} \mid \mathbf{x}_{j}\right)}=\frac{h_{0}\left(t_{i}^{*}\right) \exp \left(\beta^{\prime} \mathbf{x}_{i}\right)}{\sum_{j \in R_{i}} h_{0}\left(t_{i}^{*}\right) \exp \left(\beta^{\prime} \mathbf{x}_{j}\right)}=\frac{\exp \left(\boldsymbol{\beta}^{\prime} \mathbf{x}_{i}\right)}{\sum_{j \in R_{i}} \exp \left(\boldsymbol{\beta}^{\prime} \mathbf{x}_{j}\right)}
$$

A função de verossimilhança parcial $P L(\beta)$ é então formada pelo produto de todos os termos em (1.7) associados aos distintos tempos de falha

$$
P L(\boldsymbol{\beta})=\prod_{i=1}^{D} \frac{\exp \left(\boldsymbol{\beta}^{\prime} \mathbf{x}_{i}\right)}{\sum_{j \in R_{i}} \exp \left(\boldsymbol{\beta}^{\prime} \mathbf{x}_{j}\right)}=\prod_{i=1}^{n}\left(\frac{\exp \left(\boldsymbol{\beta}^{\prime} \mathbf{x}_{i}\right)}{\sum_{j \in R_{i}} \exp \left(\boldsymbol{\beta}^{\prime} \mathbf{x}_{j}\right)}\right)^{\delta_{i}}
$$

Os tempos de censura não são incorporados diretamente na verossimilhança parcial, mas os indivíduos censurados contribuem para $P L(\beta)$ por meio do conjunto de risco $R_{i}$ somente enquanto permanecem em risco. Em LACHIN (2000), foi mostrado que (1.8) é uma parte da verossimilhança completa, sendo que a outra parte envolve tanto o vetor de parâmetros $\beta$ como o risco basal $h_{0}(t)$.

A verossimilhança parcial pode também ser expressa por

$$
P L(\boldsymbol{\beta})=\prod_{i=1}^{n}\left(\frac{\exp \left(\boldsymbol{\beta}^{\prime} \mathbf{x}_{i}\right)}{\sum_{j=1}^{n} Y_{j}\left(t_{i}\right) \exp \left(\boldsymbol{\beta}^{\prime} \mathbf{x}_{j}\right)}\right)^{\delta_{i}}
$$

sendo que $Y_{i}(t)$ indica se o indivíduo $i(i=1,2, \ldots, n)$ está em "risco" no tempo $t$. Na análise de dados univariados de sobrevida com censura aleatória à direita, tem-se

$$
Y_{i}(t)=\left\{\begin{array}{l}
1, \text { se } \min \left(T_{i}, C_{i}\right) \geq t \\
0, \text { caso contrario }
\end{array}\right.
$$

A notação com $Y_{i}(t)$ é útil, pois pode ser generalizada para contemplar falhas múltiplas (Seção 4.1.4), quando admite-se que o indivíduo está, sucessivamente, em risco para mais de uma falha.

Os valores de $\beta$ que maximizam a função de verossimilhança parcial são 
obtidos resolvendo o sistema de equaçōes

$$
\mathcal{U}(\boldsymbol{\beta})=\frac{\partial}{\partial \boldsymbol{\beta}} \log P L(\boldsymbol{\beta})=\sum_{i=1}^{n} \delta_{i}\left[\mathbf{x}_{i}-\frac{\sum_{j \in R_{i}} \mathbf{x}_{j} \exp \left(\boldsymbol{\beta}^{\prime} \mathbf{x}_{j}\right)}{\sum_{j \in R_{i}} \exp \left(\boldsymbol{\beta}^{\prime} \mathbf{x}_{j}\right)}\right]=\mathbf{0}
$$

sendo que $U(\beta)$ é o vetor escore baseado na verossimilhança parcial. A solução de $\mathcal{U}(\beta)$ pode ser encontrada numericamente, usando um processo de NewtonRaphson ou algum outro método iterativo. Nota-se que (1.8) não depende do risco basal $h_{0}(t)$, tanto que inferências com relação aos efeitos das covariáveis sobre a taxa de falha podem ser feitas sem conhecer $h_{0}(t)$.

COX (1972) usou a função de verossimilhança parcial motivado heuristicamente, sem demonstrar que uma solução para as equações de estimação baseadas na verossimilhança parcial forneceria estimativas com as mesmas propriedades dos estimadores baseados na verossimilhança completa. COX (1972) aplicou simplesmente a teoria de máxima verossimilhança à verossimilhança parcial. Posteriormente, COX (1975), TSIATIS (1981) e outros citados por LACHIN (2000, p.388), sob suposições especificas, mostraram que os estimadores de máxima verossimilhança parcial eram assintoticamente normais. Uma justificativa rigorosa e mais geral foi obtida por ANDERSEN e GILL (1982). Eles propuseram uma generalização do modelo semiparamétrico de Cox, assumindo que os tempos de falha multivariados sāo processos de contagem multivariados com incrementos independentes, e usaram a teoria de martingales para mostrar que o estimador de máxima verossimilhança parcial é consistente e assintoticamente normal sob certas condições de regularidade.

Os resultados assintóticos do modelo de Cox permitem usar os testes da razão de verossimilhanças, de Wald e de escore para fazer inferências sobre os parámetros do modelo. Seja $\hat{\beta}$ o vetor das estimativas de máxima verossimilhança (parcial) de $\boldsymbol{\beta}$. Então, $\hat{\boldsymbol{\beta}}$ tem distribuição assintoticamente normal com média $\boldsymbol{\beta}$ e matriz de variâncias estimada por $\mathcal{I}(\hat{\beta})^{-1}$ com

$$
\mathcal{I}(\boldsymbol{\beta})=-\frac{\partial^{2}}{\partial \boldsymbol{\beta} \partial \boldsymbol{\beta}^{\prime}} \log P L(\boldsymbol{\beta})
$$

a matriz de informação observada da verossimilhança parcial. As respectivas estatísticas para testar $\mathrm{H}_{0}: \boldsymbol{\beta}=\boldsymbol{\beta}_{0}$, são dadas por

$$
\chi_{L R}^{2}=2\left[\log P L(\hat{\boldsymbol{\beta}})-\log P L\left(\boldsymbol{\beta}_{0}\right)\right]
$$




$$
\begin{gathered}
\chi_{W}^{2}=\left(\hat{\boldsymbol{\beta}}-\boldsymbol{\beta}_{0}\right)^{\prime} \mathcal{I}(\hat{\boldsymbol{\beta}})\left(\hat{\boldsymbol{\beta}}-\boldsymbol{\beta}_{0}\right) \\
\chi_{S}^{2}=\mathcal{U}^{\prime}\left(\boldsymbol{\beta}_{0}\right) \mathcal{I}\left(\boldsymbol{\beta}_{0}\right)^{-1} \mathcal{U}\left(\boldsymbol{\beta}_{0}\right)
\end{gathered}
$$

as quais têm distribuição assintótica qui-quadrada com $p$ graus de liberdade, sob a hipótese $\mathrm{H}_{0}$. As versões destes testes para testar $\mathrm{H}_{0}: \beta_{j}=\beta_{0}(j=1,2, \ldots, p)$ podem ser encontradas, por exemplo, em KLEIN e MOESCHBERGER (2003).

\subsubsection{Modelo de Cox com a presença de empates}

A função de verossimilhança parcial em (1.8) assume que os tempos de falha são contínuos e, portanto, não pressupõe a possibilidade de empates nos valores observados. Na prática, no entanto, podem ocorrer empates nos tempos de falha e de censura, devido à unidade de medida. Quando ocorrem empates entre falhas e censuras, convencionou-se para desempate que a censura ocorre após a falha, determinando assim, quais observações são incluídas no conjunto de risco $R_{i}$; quando há empate entre tempos de falha, a equação (1.8) deve ser modificada para incorporar as observações empatadas.

Há várias sugestões para aproximar a verossimilhança parcial na presença de empates entre os tempos de falha. Seja $d_{i}$ o número de falhas no tempo $t_{i}^{*}$ $(i=1,2, \ldots, D)$ e seja em que $t_{j}$ é o tempo observado (tempo de falha ou de censura) do indivíduo $j(i=1,2, \ldots, n)$. A aproximação proposta independentemente por PETO (1972) e BRESLOW (1974) é simples e se os empates não são muito numerosos é uma boa aproximação. É expressa como

$$
P L_{B P}(\boldsymbol{\beta})=\prod_{k=1}^{D} \frac{\sum_{t_{i}=t_{k}^{*}} \exp \left(\boldsymbol{\beta}^{\prime} \mathbf{x}_{i}\right)}{\left[\sum_{j \in R_{k}} \exp \left(\boldsymbol{\beta}^{\prime} \mathbf{x}_{j}\right)\right]^{d_{k}}}
$$

EFRON (1977), sugeriu uma verossimilhança parcial aproximada dada por

$$
P L_{E}(\boldsymbol{\beta})=\prod_{k=1}^{D} \frac{\sum_{t_{i}=t_{k}^{*}} \exp \left(\boldsymbol{\beta}^{\prime} \mathbf{x}_{i}\right)}{\prod_{j=1}^{d_{k}}\left[\sum_{l \in R_{k}} \exp \left(\boldsymbol{\beta}^{\prime} \mathbf{x}_{l}\right)-\frac{j-1}{d_{k}} \sum_{t_{i}=t_{k}^{*}} \exp \left(\boldsymbol{\beta}^{\prime} \mathbf{x}_{i}\right)\right]}
$$

Conforme KALBFLEISCH e PRENTICE (2002), para as verossimilhanças parciais de Breslow-Peto e Efron, os cálculos do vetor escore e da matriz de informação são simples; no entanto, o inverso da matriz de informação não produz, exatamente, um estimador consistente da variância de $\hat{\boldsymbol{\beta}}$. E ainda segundo 
KALBFLEISCH e PRENTICE (2002), a aproximação de Efron produz boas estimativas, melhores que as de Breslow-Peto, mesmo quando o número de empates é grande. A aproximação de Efron foi recomendada por THERNEAU e GRAMBSCH (2000), porém, mesmo assim, é a menos usada por requerer mais tempo computacional.

\subsubsection{Modelo de Cox estratificado}

Uma importante generalização do modelo semiparamétrico de Cox é assumir que a amostra de $n$ indivíduos está dividida em $s$ estratos e que há um risco basal específico para cada estrato. Se for assumido que os efeitos das covariáveis não variam entre os estratos, o modelo de Cox específico para o indivíduo $i$ do estrato $j$ é dado por

$$
h_{j}\left(t \mid \mathbf{x}_{i j}\right)=h_{0 j}(t) \exp \left(\boldsymbol{\beta}^{\prime} \mathbf{x}_{i j}\right)
$$

para $i=1,2, \ldots, n_{j}$ e $j=1,2, \ldots, s$; sendo que $n_{j}$ é o número de indivíduos no estrato $j$ e $h_{0 j}(t)$ é o risco basal arbitrário para o estrato $j$. É assumido que o vetor de parâmetros, $\beta$, é comum a todos os estratos, o que equivale à suposição de não interação entre estrato e covariáveis.

O modelo de Cox estratificado é útil quando a suposição de riscos proporcionais é violada, já que, neste caso, o modelo (1.3) não pode ser usado. Uma solução para o problema é estratificar a amostra, de modo que a suposição seja válida em cada estrato, e ajustar o modelo (1.9).

A estimação de $\boldsymbol{\beta}$ em (1.9) está baseada no produto das verossimilhanças parciais construídas para cada estrato. Assim, a verossimilhança parcial para o modelo de Cox estratificado é dada por

$$
P L(\beta)=\prod_{j=1}^{s} P L_{j}(\beta)
$$

com

$$
P L_{j}(\boldsymbol{\beta})=\prod_{i=1}^{n_{j}}\left(\frac{\exp \left(\boldsymbol{\beta}^{\prime} \mathbf{x}_{i j}\right)}{\sum_{l=1}^{n_{j}} Y_{l j}\left(t_{i j}\right) \exp \left(\boldsymbol{\beta}^{\prime} \mathbf{x}_{l j}\right)}\right)^{\delta_{i}}
$$

em que $Y_{i j}(t)$ é um indicador de risco para o indivíduo $i$ do estrato $j$ no tempo $t\left(i=1,2, \ldots, n_{j}\right)(j=1,2, \ldots, s)$.

Portanto, somente os $n_{j}$ individuos do estrato $j$ podem contribuir para ve- 
rossimilhança parcial, $P L_{j}(\boldsymbol{\beta})$. Como $P L(\beta)$ não envolve $h_{0 j}(t)$, o que muda na formulação da verossimilhança parcial do modelo de Cox estratificado é o uso de um conjunto de risco restrito ao estrato $j$, que considera somente os indivíduos do estrato $j$ para a construção de $P L_{j}(\beta)$. O conceito de conjunto de risco restrito é retomado na análise de falhas múltiplas na Seção 4.1.4.

Segundo COLOSIMO (1997), as propriedades assintóticas destes estimadores podem ser obtidas como extensão dos resultados assintóticos de ANDERSEN e GILL (1982).

\subsection{Modelos para dados multivariados de sobre- vida}

As extensões das análises de tempos de falha univariados para as análises de tempos de falha multivariados têm demonstrado ser uma tarefa difícil, devido principalmente ao fato de que há mais de um modo de levar em consideração a associação entre os tempos de falha ao modelar dados de sobrevida. Duas abordagens alcançaram bastante popularidade, generalizando o modelo semiparamétrico de Cox.

A primeira abordagem, denominada de variancia robusta, nāo considera, a princípio, que os tempos de falha estão associados. Nesta situação inicial, ajustase um modelo de riscos proporcionais, obtendo-se as estimativas dos parâmetros do modelo e da variancia dos estimadores desses coeficientes. Posteriormente, as variâncias estimadas são ajustadas de forma a considerar a correlação dos dados.

A estimação da variância robusta em modelos semiparamétricos, desenvolvida por LIN e WEI (1989), está disponível no SAS versão $9^{1}$, no Stata a partir da versão 7 e no S-Plus versão 6.1-professional.

$\mathrm{Na}$ segunda abordagem, um efeito aleatório, chamado de fragilidade, é introduzido no modelo de riscos proporcionais a fim de explicar a correlação entre os tempos de falha multivariados. Várias propostas têm sido feitas para introduzir efeitos aleatórios nos modelos para análise de dados multivariados de sobrevida (PICKLES e CROUCHLEY 1995; LIANG e col. 1995; HOUGAARD 2000),

\footnotetext{
${ }^{1}$ Apesar de não constar no manual online" da versão 8.02, o modelos de riscos proporcionais com variância robusta podem ser ajustados, usando os mesmos comandos da versão 9 .
} 
como o modelo de fragilidade compartilhada ("shared frailty model") discutidos em MATUDA (1998), em que é focalizado a análise de eventos agrupados. O modelo assume que os membros do grupo têm uma fragilidade em comum, $\omega$, as vezes representada por $z=\exp \omega$, que tem um efeito multiplicativo sobre a função taxa de falha, mas não é observada. Assume-se que $z$ tem uma distribuição entre os grupos. HOUGAARD (2000) apresenta algumas distribuições para a fragilidade. Este trabalho restringiu-se à análise de modelos em que a fragilidade $z$ tem distribuição gama com esperança 1 e variância desconhecida, $\theta$; suposição adotada em muitos estudos devido, principalmente, à conveniência computacional.

Métodos de estimação para o modelo de fragilidade gama são mais complexos que os modelos de riscos proporcionais porque além de $\beta$, o parâmetro $\theta$ deve ser estimado. Como o modelo é formado por uma parte observada e outra não (problema de dados incompletos), o algoritmo EM, um processo computacional iterativo para obtenção de estimativas de máxima verossimilhança, torna-se especialmente apropriado para estimar os parâmetros do modelo de fragilidade (KLEIN 1992). Entretanto, a convergência do algoritmo EM pode ser extremamente lenta, o que tem levado a uma certa resistência para ser implementado em programas estatísticos de distribuição comercial. Está disponível uma macro do SAS que implementa o algoritmo EM de KLEIN (1992). Uma forma alternativa de estimação, sugerida por THERNEAU e GRAMBSCH (2000), considera uma verossimilhança parcial penalizada, assim denominada porque uma função de penalidade, relacionada com a densidade da fragilidade, é incluída na log-verossimilhança parcial. Uma vantagem da maximização por verossimilhança parcial penalizada é que tende a reduzir o número de iterações quando comparado com o algoritmo EM. Métodos de maximização por verossimilhança parcial penalizada estão implementados no S-Plus versão 6.1-professional e Stata versão 8.2 .

BOX-STEFFENSMEIER e DE BOEF (2002) comentam que a correlação entre tempos de falha multivariados pode surgir sob, pelo menos, dois modos: as mensurações podem não ser independentes entre eventos, ou seja, a ocorrência de uma falha influencia na ocorrência das demais; e/ou as mensurações podem não ser independentes entre indivíduos/grupos, devido a uma heterogeneidade não observada entre indivíduos/grupos. Seria interessante que os modelos para analisar 
tempos de falhas multivariados admitissem estas duas fontes de correlação.

Neste trabalho, as abordagens de fragilidade gama e variância robusta também foram aplicadas no modelo semiparamétrico de Cox para dados univariados de sobrevida, considerando a $1^{\mathrm{a}}$ falha nos estudos de eventos recorrentes. Esses modelos foram comparados com o modelo semiparamétrico de Cox e com os modelos semiparamétricos para eventos recorrentes.

Há mais de uma forma de construir os intervalos de tempo nos quais um indivíduo está em risco para cada falha, dentre as várias falhas a que está sujeito (falhas múltiplas). Por exemplo, pode-se considerar que o indivíduo está sob risco desde o instante inicial do acompanhamento, qualquer que seja a falha, ou considerar que o indivíduo está sob risco somente a partir do evento anterior. Devido à combinação de diferentes especificações de intervalos de risco e de conjuntos de risco, é possível formular sete modelos de riscos proporcionais para analisar falhas múltiplas (KELLY e LIM 2000), apesar de somente cinco deles serem conhecidos da literatura: PRENTICE e col. (1981), ANDERSEN e GILL (1982), WEI e col. (1989) e LEE e col. (1992). Seria interessante identificar os diferentes modelos semiparamétricos para falhas múltiplas e discutir a aplicação das abordagens de variância robusta e de fragilidade nesses modelos. 


\section{OBJETIVOS}

Apresentar, metodologicamente, as abordagens de variância robusta e de fragilidade em modelos semiparamétricos para analisar dados univariados e multivariados de sobrevida; e compará-las, empiricamente, estimando razões de taxas de falha para analisar dados reais da área biomédica. 


\section{MATERIAL E MÉTODOS}

As abordagens de fragilidade e com variancia robusta foram estudados sob dois aspectos: uma apresentação metodológica e uma comparação empírica. A apresentação metodológica é iniciada com as definições básicas para analisar tempos de falha multivariados. Os modelos com fragilidade e variância robusta são descritos, bem como a interpretação e processos de estimação dos seus parâmetros. As possíveis variações de modelos semiparamétricos para analisar falhas múltiplas são discutidas. Por último, algumas questões computacionais são levantadas.

Para a comparação empirica, cinco conjuntos de dados foram considerados. São estudos com eventos agrupados ou recorrentes e estão descritos na Seção 3.1. Os modelos com fragilidade e variância robusta foram ajustados com as aproximações de Breslow-Peto e de Efron para os empates. Nas análises de eventos recorrentes, foram aplicadas as sete possíveis variações de modelos semiparamétricos para falhas múltiplas do Quadro 4.1. Foram usados três programas para Windows: Stata versão 8.2, S-Plus versão 6.1-professional e SAS versão 8.02, para comparar o desempenho dos programas e verificar a robustez dos resultados entre os diferentes "softwares".

Foram ajustados modelos com fragilidade gama e variância robusta para a $1^{a}$ falha dos eventos recorrentes. Com tempos de falha univariados, a fragilidade individual é incluída no modelo para capturar o efeito da heterogeneidade não observada. Esse efeito é relevante, quando covariáveis importantes são omitidas do modelo. $\mathrm{Na}$ área biomédica, por exemplo, a herança genética e alguns fatores ambientais que não foram mensurados podem ser covariáveis importantes em estudos de mortalidade. A variância robusta é usada em dados univariados de sobrevida porque pode estimar, de forma mais eficiente, a variância dos estimadores do modelo semiparamétrico de Cox, quando o modelo não estiver 
especificado corretamente. Os modelos com fragilidade e variância robusta para dados univariados foram comparados com o modelo semiparamétrico de Cox e com os modelos semiparamétricos para eventos recorrentes.

Para a análise comparativa dos resultados, são apresentadas as estimativas pontual e de intervalo com $95 \%$ de confiança para a razão das taxas de falha ("hazard ratio"), HR, de cada modelo ajustado. Pelo tamanho do intervalo de confiança é verificada a precisão das estimativas e quando o intervalo contém o valor 1 , identifica-se um fator de risco (equivale ao intervalo de confiança de $\beta$ conter o valor 0 ). Para os modelos de fragilidade gama, são apresentados a estimativa de $\theta$, a variância da fragilidade gama, e o valor de $\mathrm{p}$ para $\mathrm{H}_{0}: \theta=$ 0 , considerando que $\mathrm{p} \leq 0,05$ é evidência forte contra $\mathrm{H}_{0}$. Os resultados são posteriormente comparados por meio de gráficos dos intervalos de confiança.

\subsection{Descrição dos conjuntos de dados}

Os dois primeiros estudos são exemplos de eventos agrupados (falhas não ordenadas do mesmo tipo). Os outros estudos correspondem a eventos recorrentes (falhas ordenadas). Os Estudos 4 e 5 são provenientes de um mesmo projeto. Em http://www.mayo.edu/hsr/people/therneau/book/book.html estão disponíveis os arquivos de dados dos Estudos 1 a 3; para os Estudos 4 e 5, ver http://www.fsp.usp.br/ jmpsouza/dados.html.

\subsubsection{Estudo 1: ninhada de ratos}

Para avaliar o possivel efeito cancerígeno de uma droga, foi realizado um experimento com ratos. Os dados estão em MANTEL e col. (1977) e referem-se a 50 ninhadas com 3 ratos cada uma, sendo que um rato recebeu aleatoriamente a droga e os outros dois receberam placebo. Devido à herança genética compartilhada pela descendência comum, os tempos de desenvolvimento do tumor de uma mesma ninhada podem estar associados. Entre os 150 ratos, 40 desenvolveram o tumor durante o estudo. 


\subsubsection{Estudo 2: retinopatia em diabéticos}

Em um estudo multicêntrico para avaliar a eficácia da fotocoagulação para retinopatia diabética, cada paciente teve um olho selecionado aleatoriamente para ser tratado com fotocoagulação, sendo que o outro olho não foi tratado. Assim, cada paciente serviu como seu próprio controle, contribuindo com duas observações. Foi medido em cada olho o tempo até a perda severa da acuidade visual. A covariável indicadora de tratamento foi considerada a principal e, para verificar efeito de confusão, foi incluída a covariável "tipo de diabetes" (juvenil, adulto). Foi analisado um subconjunto de 197 pacientes, que corresponde a uma amostra de $50 \%$ dos pacientes de alto risco (HUSTER e col. 1989). As censuras foram causadas por óbito, abandono ou fim do estudo. Das 394 observações (duas por indivíduo), 155 foram falhas que ocorreram durante o período de observação do estudo.

\subsubsection{Estudo 3: recorrência de tumor em pacientes com câncer de bexiga}

Em um estudo de câncer de bexiga, foram pesquisados 86 pacientes que tinham tumores de bexiga superficiais. Estes tumores foram removidos e os pacientes foram selecionados aleatoriamente para receber um dos tratamentos possíveis. WEI e col. (1989), avaliaram o efeito do tratamento "tiotepa" sobre os tempos de recorrência, com os do grupo placebo. Duas outras covariáveis foram incluídas no modelo: tamanho do maior tumor $(\mathrm{em} \mathrm{cm})$ e número de tumores $(0,1, \ldots, 7, \geq 8)$. Muitos pacientes tiveram recorrências múltiplas de tumores, sendo que os tumores novos eram removidos. Por causa da escassez de dados após a quarta recorrência, somente os primeiros 4 tempos de recorrência de tumor foram registrados. Devido a essa restrição no número de recorrências, o tempo de seguimento após a $4^{\text {a }}$ recorrência é desprezado (como se os indivíduos deixassem de ser observados após a $4^{\mathrm{a}}$ recorrência). Um dos pacientes teve tempo de seguimento igual a zero e foi retirado da amostra. A Tabela 3.1 mostra a distribuição do número de recorrências por paciente. 
Tabela 3.1 - Distribuição dos pacientes pelo número de recorrèncias de tumor de bexiga

\begin{tabular}{c|ccccc|c}
\hline $\begin{array}{c}\text { NÚMERO DE } \\
\text { RECORRÊNCIAS } \\
\text { POR PACIENTE }\end{array}$ & 0 & 1 & 2 & 3 & 4 & TOTAL \\
\hline $\begin{array}{c}\text { NÚMERO DE } \\
\text { PACIENTES }\end{array}$ & 38 & 18 & 7 & 8 & 14 & 85 \\
\hline
\end{tabular}

\subsubsection{Estudos 4 e 5: febre e morbidades infantis}

Este estudo faz parte do projeto matriz "Alimentação no primeiro ano de vida", desenvolvido no Departamento de Epidemiologia da Faculdade de Saúde Pública da Universidade de São Paulo, com financiamento FAPESP ( $n^{\circ}$ 96/060732). É uma coorte de mães e de seus filhos recém-nascidos, constituída entre 1998 e 1999 no Hospital Universitário da Universidade de São Paulo (HU). Após uma entrevista hospitalar com a mãe, cada criança foi acompanhada até completar 1 ano de idade, por meio de 7 visitas domiciliares realizadas aos 15, 30, 60, 90, 180, 270 e 360 dias de idade, respectivamente. Foram contactadas inicialmente 609 mães, das quais 103 foram excluídas por residirem fora da área de abrangência do $\mathrm{HU}$ ou porque seus endereços não foram encontrados, constituindo-se, assim, no início das visitas domiciliares, uma coorte efetiva de 506 crianças (BUENO e col. 2003).

Dados maternos, das condições da gestação e do parto, de características da criança ao nascer e de características familiares foram obtidos mediante consulta ao prontuário médico da mãe no dia do parto e a aplicação de questionários na entrevista hospitalar. Outras informações, como condição socioeconômica, posse de bens, tipo de residência, foram colhidas pelas entrevistadoras na primeira visita domiciliar. Na entrevista hospitalar, cada mãe recebeu um conjunto de três fichas com desenho de planilha para leitura ótica, com células para registro diário de eventos sobre ocorrência de morbidades e da prática alimentar, durante um período de 60 dias. Nas visitas domiciliares, estas fichas eram recolhidas e outras semelhantes eram entregues à mãe para a continuação dos registros. Foram considerados 24 tipos de morbidades/sintomas infantis, sendo que dor de barriga ou cólica, resfriado, vômito e febre foram os mais freqüentemente percebidos e registrados pelas mães. 
Para a análise de sobrevida, 56 crianças foram excluídas, pois a primeira planilha de registros diários não foi devolvida, restando 450 crianças que tinham ao menos a primeira planilha de registros diários (dos primeiros 60 dias de vida). Foram observados os tempos para as ocorrências dos vários tipos de morbidade/sintoma, segundo a percepção da mãe, até os 90 dias de idade. Havia interesse em verificar os efeitos devidos ao tipo de parto (normal, cesárea e fórceps) e ao hábito de fumar da mãe antes da gestação (não fumava, fumava) sobre a taxa de ocorrência de febre (Estudo 4) e sobre a taxa de ocorrência de qualquer morbidade (Estudo 5), ou seja, o tipo de morbidade/sintoma não foi levado em consideração; assim, a criança foi considerada como doente, independentemente de ter uma ou mais doenças diferentes no mesmo dia.

No Estudo 4, analisaram-se todas as ocorrências de febre até os 90 dias de vida. Com relação ao Estudo 5, foram desprezadas as ocorrências de qualquer morbidade após a $5^{\mathbf{a}}$ falha, por causa da escassez de dados.

As Tabelas 3.2 e 3.3 mostram a distribuição do número de ocorrências de febre e a distribuição do número de ocorrências de qualquer morbidade por criança, até os 90 dias de idade.

Tabela 3.2 - Distribuição das crianças pelo número de ocorrências de febre

\begin{tabular}{c|ccccc|c}
\hline $\begin{array}{c}\text { NÚMERO DE } \\
\text { OCORRÉNCIAS } \\
\text { POR CRIANÇA }\end{array}$ & 0 & 1 & 2 & 3 & 4 & TOTAL \\
\hline $\begin{array}{c}\text { NÚMERO DE } \\
\text { CRIANÇAS }\end{array}$ & 325 & 100 & 19 & 4 & 2 & 450 \\
\hline
\end{tabular}

Tabela 3.3 - Distribuição das crianças pelo número de ocorrências de morbidades infantis

\begin{tabular}{c|cccccccccc|c}
\hline $\begin{array}{c}\text { NÚMERO DE } \\
\text { OCORRENCIAS } \\
\text { POR CRIANÇA }\end{array}$ & 0 & 1 & 2 & 3 & 4 & 5 & 6 & 7 & 8 & $9-26$ & TOTAL \\
\hline $\begin{array}{c}\text { NÚMERO DE } \\
\text { CRIANCCAS }\end{array}$ & 60 & 117 & 76 & 58 & 32 & 27 & 24 & 13 & 16 & 27 & 450 \\
\hline
\end{tabular}




\section{APRESENTAÇÃO METODOLÓGICA}

\subsection{Extensões do modelo de Cox para dados mul- tivariados de sobrevida}

Seja $T_{i j}$, uma variável aleatória contínua e não-negativa representando o tempo da falha $i$ do grupo $j$, ou o tempo da falha $i$ do indivíduo $j$. É assumido que $T_{1 j}, T_{2 j}, \ldots, T_{n_{j}, j}$ estão correlacionados e que as censuras, $C_{i j}$, são aleatórias à direita $\left(i=1,2, \ldots, n_{j}\right),(j=1,2, \ldots, m)$.

No Estudo 1 com ninhadas de ratos, $T_{1 j}, T_{2 j}, T_{3 j}$ indicam os tempos até o desenvolvimento de tumor nos três ratos da ninhada $j$, e $n_{j}=3$ para $j=1,2, \ldots, 50$. No Estudo 3 de tratamento para câncer de bexiga, $T_{1 j}, \ldots, T_{n_{j}, j}$ são os tempos de recorrência de tumor do paciente $j$ e $1 \leq n_{j} \leq 4$ para $j=1,2, \ldots, 85$. Esta notação, portanto, serve tanto para falhas simples em agrupamentos de indivíduos como para falhas múltiplas do mesmo indivíduo. Por simplicidade, a palavra grupo é usada aqui para considerar tanto um conjunto de observações de diferentes indivíduos agrupados (eventos agrupados), como um conjunto de observações do mesmo indivíduo (falhas múltiplas).

$\mathrm{Na}$ análise de tempos de falha multivariados, pode-se modelar a distribuição conjunta de $\left(T_{1 j}, T_{2 j}, T_{3 j}\right)$, os tempos de falha do grupo $j$ no Estudo 1, por exemplo; pode-se também modelar a distribuição condicional de $T_{1 j}$ dado $\left(T_{2 j}, T_{3 j}\right)$. No entanto, a função taxa de falha conjunta, em geral, é bastante complexa quando os tempos de falha não são independentes, e a função taxa de falha condicionada não é unicamente definida. Seja $\mathbf{x}_{i j}$ o vetor de valores de $p$ covariáveis da observação $i$ do grupo $j\left(i=1,2, \ldots, n_{j}\right),(j=1,2, \ldots, m)$. A função taxa de falha 
marginal, $h_{i j}\left(t \mid \mathbf{x}_{i j}\right)$, da observação $i$ do grupo $j$, no tempo $t$, definida como

$$
h_{i j}\left(t \mid \mathbf{x}_{i j}\right)=\lim _{\Delta t \rightarrow 0} \frac{\operatorname{Pr}\left(t,<T_{i j} \leq t+\Delta t \mid T_{i j}>t, \mathbf{x}_{i j}\right)}{\Delta t}
$$

é usada como base para modelagem de tempos de falha multivariados, a fim de avaliar o efeito das covariáveis sobre a taxa de falha marginal. Para tanto, tem-se que levar em conta a correlação intra-grupo, para que $\beta$ seja estimado de forma consistente.

Duas propostas, fragilidade e variancia robusta, usam diferentes estratégias semiparamétricas para modelar a distribuição marginal de $T_{i j}$, como uma extensão do modelo semiparamétrico de Cox.

\subsubsection{Fragilidade}

Um modelo de fragilidade proposto na literatura, conhecido como modelo de fragilidade compartilhada, assume que a função taxa de falha marginal da observação $i$ do grupo $j$, é dada por

$$
h_{i j}\left(t \mid \mathbf{x}_{i j}, \mathbf{v}_{i}\right)=h_{0}(t) \exp \left(\boldsymbol{\beta}^{\prime} \mathbf{x}_{i j}+\omega^{\prime} \mathbf{v}_{i}\right)
$$

sendo que $h_{0}(t)$ é um risco basal; $\beta$ é o vetor de coeficientes; $\omega^{\prime}=\left(\omega_{1}, \omega_{2}, \ldots, \omega_{m}\right)$ é o vetor de $m$ efeitos aleatórios; $\mathbf{v}_{i}^{\prime}=\left(v_{i 1}, v_{i 2}, \ldots, v_{i m}\right)$ é um vetor de $m$ covariáveis indicadoras, com $v_{i j}=1$, se a observação $i$ pertence ao grupo $j$ e $v_{i j}=0$, caso contrário.

O efeito aleatório $\omega_{j}$ é conhecido como a fragilidade do grupo $j$. Note-se que $\omega_{j}=\boldsymbol{\omega}^{\prime} \mathbf{v}_{i}=\omega_{1} v_{i 1}+\omega_{2} v_{i 2}+\ldots+\omega_{m} v_{i m}$, se a observação $i$ pertence ao grupo j. O modelo de fragilidade compartilhada admite que as observações dentro do grupo estão correlacionadas porque compartilham a mesma fragilidade. Em (4.2), é admitido que a fragilidade tem uma distribuição entre os grupos.

Em outros contextos, pode ser útil adotar outras formulações para o modelo de fragilidade compartilhada

$$
h_{i j}\left(t \mid \mathbf{x}_{i j}, \omega_{j}\right)=h_{0}(t) \exp \left(\boldsymbol{\beta}^{\prime} \mathbf{x}_{i j}+\omega_{j}\right)
$$

e

$$
h_{i j}\left(t \mid \mathbf{x}_{i j}, z_{j}\right)=h_{0}(t) \exp \left(\boldsymbol{\beta}^{\prime} \mathbf{x}_{i j}\right) z_{j}
$$


sendo que $z_{j}=\exp \left(\omega_{i}\right)$ representa a fragilidade do grupo $j$ no modelo (4.4).

As funções taxa de falha em (4.3) e (4.4) são interpretadas como função taxa de falha marginal condicionada a $\Omega_{j}=\omega_{j}$ e função taxa de falha marginal condicionada a $Z_{j}=z_{j}$, respectivamente.

Em (4.4), supõe-se que $Z_{1}, Z_{2}, \ldots, Z_{j}$ são uma amostra independente de alguma distribuição com média 1 e variância desconhecida, $\theta$. Restrições nos parâmetros da distribuição da fragilidade são necessárias para que o modelo seja identificável. Valores grandes de $\theta$ refletem um grau de heterogeneidade maior entre os grupos e uma forte associação dentro dos grupos. Quando $\theta=0$, todos os $Z_{j}(j=1,2, \ldots, m)$ são iguais a 1 , e assim, (4.4) é reduzido ao modelo padrão de riscos proporcionais para $\sum_{j=1}^{m} n_{j}=n$ dados univariados de sobrevida. Esta interpretação para o parâmetro $\theta$ sugere testes estatísticos com $\mathrm{H}_{0}: \theta=0$, para verificar correlação intra-grupo.

Se for assumida a distribuição gama para a fragilidade $Z_{j} \operatorname{com} E\left(Z_{j}\right)=1 \mathrm{e}$ $\operatorname{Var}\left(Z_{j}\right)=\theta$, a função densidade de $Z_{j}$ é dada por

$$
f_{Z}(z)=\frac{\theta^{-1 / \theta}}{\Gamma(1 / \theta)} z^{\frac{1}{\theta}-1} \exp \left(\frac{-z}{\theta}\right)
$$

sendo que $\theta>0$.

A correspondente densidade de $\Omega_{j}(j=1,2, \ldots, m)$ é dada por

$$
f_{\Omega}(\omega)=\frac{\exp (\omega)^{1 / \theta} \exp [-\exp (\omega) / \theta]}{\theta^{1 / \theta} \Gamma(1 / \theta)}
$$

sendo que $\theta>0$.

Note-se que a interpretação para a razão das taxas de falha em (4.2), (4.3) e (4.4) é específica para um grupo $j$. Tomando como exemplo os dados do Estudo 2 e a covariável $x_{i j}$ indicadora de tratamento no olho $i$ do individuo $j$, tem-se que a razão das taxas de falha marginais condicionadas em (4.4), para o indivíduo $j$, é dada por

$$
H R=\frac{h_{i j}\left(t \mid x_{i j}=1, z_{j}\right)}{h_{k j}\left(t \mid x_{k j}=0, z_{j}\right)}=\exp \left(\beta_{l}\right)
$$

mostrando que $\exp \left(\beta_{l}\right)$ é a taxa de falha para perda visual de um olho tratado com fotocoagulação, relativa a taxa de falha para perda visual de um olho não tratado no mesmo indivíduo. 
Para obter a razão das taxas de falha entre dois grupos, é preciso determinar a função de taxa de falha marginal não-condicionada, $h_{i j}\left(t \mid \mathbf{x}_{i j}\right)$, conhecida como função de taxa de falha marginal observada.

KLEIN (1992), assumindo fragilidade gama com densidade (4.5), mostrou que sob (4.4), a função de sobrevida conjunta observada do grupo $j$ é dada por

$$
S_{j}\left(t_{1}, t_{2}, \ldots, t_{n_{j}} \mid \mathbf{x}_{i j}\right)=\left[1+\theta \sum_{i=1}^{n_{j}} H_{0}\left(t_{i j}\right) \exp \left(\boldsymbol{\beta}^{\prime} \mathbf{x}_{i j}\right)\right]^{-1 / \boldsymbol{\theta}}
$$

e a função taxa de falha marginal observada é dada por

$$
h_{i j}\left(t \mid \mathbf{x}_{i j}\right)=\frac{h_{0}(t) \exp \left(\boldsymbol{\beta}^{\prime} \mathbf{x}_{i j}\right)}{1+\theta H_{0}(t) \exp \left(\boldsymbol{\beta}^{\prime} \mathbf{x}_{i j}\right)}
$$

em que $H_{0}(t)$ é o risco basal acumulado no tempo $t$.

Sejam dois individuos $i$ e $k$, pertencentes aos grupos $j$ e $l$, com covariáveis $\mathbf{x}_{i j}$ e $\mathbf{x}_{k l}$, respectivamente. A razão das taxas de falha marginais observadas desses dois indivíduos, é dada por

$$
H R(t)=\frac{h_{i j}\left(t \mid \mathbf{x}_{i j}\right)}{h_{k l}\left(t \mid \mathbf{x}_{k l}\right)}=\exp \left[\boldsymbol{\beta}^{\prime}\left(\mathbf{x}_{i j}-\mathbf{x}_{k l}\right)\right] \frac{1+\theta H_{0}(t) \exp \left(\boldsymbol{\beta}^{\prime} \mathbf{x}_{k l}\right)}{1+\theta H_{0}(t) \exp \left(\boldsymbol{\beta}^{\prime} \mathbf{x}_{i j}\right)}
$$

Conforme (4.8), tem-se que a razão das taxas de falha observadas é uma função dependente do tempo, violando a suposição de riscos proporcionais.

É importante observar que para analisar (4.7) e (4.8) é preciso estimar $\beta$ e $\theta$; e se $h_{0}(t)$ não é especificado, pode-se estimar $H_{0}(t)$ pelo estimador de BRESLOW $(1972,1974)$ ou por um outro estimador encontrado na literatura.

O modelo (4.4) ainda permite que o tamanho dos grupos varie de um grupo para outro e permite grupos de tamanho 1. Modelos de fragilidade são também usados para fazer ajustamento da heterogeneidade não observada na análise de dados univariados de sobrevida. Neste caso, a fragilidade representa o efeito total das covariáveis individuais não observadas sobre a função taxa de falha. Para $i=1,2, \ldots, n$, tem-se então que o modelo de fragilidade para tempos de falha univariados é dado por

$$
h_{i}\left(t \mid \mathbf{x}_{i}, z_{i}\right)=h_{0}(t) \exp \left(\boldsymbol{\beta}^{\prime} \mathbf{x}_{i}\right) z_{i}
$$


Se é ignorado o efeito de importantes covariáveis omitidas do modelo, as funções taxa de falha estimadas podem estar distorcidas, como ilustrado em MATUDA (1998). Em THERNEAU e GRAMBSCH (2000), é comentado o potencial das fragilidades captarem os efeitos de importantes covariáveis de grupo que foram omitidas.

No modelo de fragilidade compartilhada, $h_{0}(t)$ pode não ser especificado (modelo semiparamétrico), como pode ser assumida uma forma paramétrica específica para o risco basal (modelo paramétrico), sendo que o processo de estimação para o modelo semiparamétrico é bem mais elaborado, comparado com o paramétrico. Uma outra suposição, ainda mais arbitrária, que não só influencia no processo de estimação como na interpretação das razões das taxas de falha, é sobre a escolha da distribuição para a fragilidade, em que há preferência histórica pela distribuição gama, devido principalmente a conveniências algébrica e computacional; com as restrições de média igual a 1 e variância desconhecida $\theta$. Para estimar o vetor de coeficientes $\beta$ e o parâmetro $\theta$ da fragilidade gama, são brevemente apresentados na próxima seção os processos de estimação para as modelagens paramétrica e semiparamétrica.

\subsubsection{Estimação do modelo de fragilidade gama}

Estão disponíveis na literatura alguns métodos de estimação para os modelos de fragilidade compartilhada. Estimar a variância dos estimadores dos parâmetros do modelo, especialmente a variância da fragilidade, em geral, é algo bem complexo (DUCHATEAU e col. 2002).

Para a observação $i$ do grupo $j\left(i=1,2, \ldots, n_{j}\right),(j=1,2, \ldots, m)$, os dados observados consistem de $\left(t_{i j}, \delta_{i j}, \mathbf{x}_{i j}\right)$ em que $t_{i j}$ é o tempo observado, $\delta_{i j}$ é o indicador de censura e $\mathbf{x}_{i j}$ é como antes. $O$ vetor de fragilidades, $\mathbf{Z}^{\prime}=\left(Z_{1}, Z_{2}, \ldots, Z_{m}\right)$, não é observável. A função de verossimilhança condicionada a $\mathbf{Z}$ (como se as fragilidades fossem observáveis), é dada por

$$
L(\boldsymbol{\beta}, \theta \mid \mathbf{z})=\prod_{j=1}^{m} \prod_{i=1}^{n_{j}}\left[h_{i j}\left(t_{i j} \mid \mathbf{x}_{i j}, z_{j}\right)\right]^{\delta_{i j}} S_{i j}\left(t_{i j} \mid \mathbf{x}_{i j}, z_{j}\right)
$$

em que $\mathbf{z}^{\prime}=\left(z_{1}, z_{2}, \ldots, z_{m}\right)$ é o vetor de valores não-observados de $\mathbf{Z}, h_{i j}\left(t \mid \mathbf{x}_{i j}, z_{j}\right)$ é como em (4.4) e $S_{i j}\left(t \mid \mathbf{x}_{i j}, z_{j}\right)$ é obtida de (4.4) pela relação (1.1). 
A função de verossimilhança completa (ou conjunta) é dada por

$$
L_{\text {comp }}(\boldsymbol{\beta}, \theta, \mathbf{z})=L(\boldsymbol{\beta}, \theta \mid \mathbf{z}) \prod_{j=1}^{m} f_{Z}\left(z_{j}\right)
$$

A estimação dos parâmetros do modelo de fragilidade compartilhada, na versão paramétrica, é baseada na função de verossimilhança observada (ou marginal), isto é, na função de verossimilhança não-condicionada, que se obtém ao integrar a função de verossimilhança completa, em relação a z. Seja $D_{j}=\sum_{i=1}^{n_{j}} \delta_{i j}$ o número de falhas no grupo $j$. Segundo KLEIN e MOESCHBERGER (2003), sob fragilidade gama com densidade (4.5) e usando (4.6), a log-verossimilhança observada é dada por

$$
\begin{aligned}
\log L_{o b s}(\boldsymbol{\beta}, \theta)= & \sum_{j=1}^{m} D_{j} \log \theta-\log \Gamma(1 / \theta)+\log \Gamma\left(1 / \theta+D_{j}\right) \\
& -\left(1 / \theta+D_{j}\right) \log \left[1+\theta \sum_{i=1}^{n_{j}} H_{0}\left(t_{i j}\right) \exp \left(\boldsymbol{\beta}^{\prime} \mathbf{x}_{i j}\right)\right] \\
& +\sum_{i=1}^{n_{j}} \delta_{i j}\left[\boldsymbol{\beta}^{\prime} \mathbf{x}_{i j}+\log h_{0}\left(t_{i j}\right)\right]
\end{aligned}
$$

em que $H_{0}(t)$ é o risco basal acumulado no tempo $t$.

Se é assumida uma forma paramétrica para $h_{0}(t)$, estimativas de máxima verossimilhança são viáveis por maximizar diretamente (4.10), por meio de um processo como de Newton-Raphson, por exemplo.

É desejável basear a inferência estatística sobre os dados observados, com a maximização de (4.10). No entanto, a verossimilhança observada é difícil de maximizar quando o risco basal, $h_{0}(t)$, não é especificado, pois assim, precisa ser estimado juntamente $\operatorname{com} \boldsymbol{\beta}$ e $\theta$.

Para estimar os parâmetros do modelo semiparamétrico com fragilidade gama, ou a função de verossimilhança completa é maximizada usando o algoritmo EM (KLEIN 1992) ou uma verossimilhança parcial penalizada é maximizada (THERNEAU e GRAMBSCH 2000). 


\section{Algoritmo EM para fragilidade gama}

O logaritmo da verossimilhança completa em (4.9) sob o modelo de fragilidade compartilhada (4.4), é expresso como

$$
\begin{aligned}
\log L_{\text {comp }}(\boldsymbol{\beta}, \theta, \mathbf{z})= & \sum_{j=1}^{m} \sum_{i=1}^{n_{j}} \delta_{i j}\left[\log h_{0}\left(t_{i j}\right)+\boldsymbol{\beta}^{\prime} \mathbf{x}_{i j}+\log z_{j}\right] \\
& -H_{0}\left(t_{i j}\right) \exp \left(\boldsymbol{\beta}^{\prime} \mathbf{x}_{i j}\right) z_{j}+\sum_{j=1}^{m} \log f_{Z}\left(z_{j}\right)
\end{aligned}
$$

E assim, como mostrado em KLEIN (1992), a log-verossimilhança completa com fragilidade gama pode ser escrita como

$$
\log L_{\text {comp }}\left(\boldsymbol{\beta}, \theta, \mathbf{z}, h_{0}\right)=\log L_{1}(\theta, \mathbf{z})+\log L_{2}\left(\boldsymbol{\beta}, h_{0}, \mathbf{z}\right)
$$

com

$$
\begin{aligned}
\log L_{1}(\theta, \mathbf{z})= & -m[(1 / \theta) \log \theta+\log \Gamma(1 / \theta)] \\
& +\sum_{j=1}^{m}\left[\left(1 / \theta+D_{j}-1\right) \log z_{j}-z_{j} / \theta\right]
\end{aligned}
$$

e

$$
\begin{aligned}
\log L_{2}\left(\boldsymbol{\beta}, h_{0}, \mathbf{z}\right)= & \sum_{j=1}^{m} \sum_{i=1}^{n_{j}} \delta_{i j}\left[\boldsymbol{\beta}^{\prime} \mathbf{x}_{i j}+\log h_{0}\left(t_{i j}\right)\right] \\
& -z_{j} H_{0}\left(t_{i j}\right) \exp \left(\boldsymbol{\beta}^{\prime} \mathbf{x}_{i j}\right)
\end{aligned}
$$

O valor $z_{j}(j=1,2, \ldots, m)$ das fragilidades em (4.11) e (4.12) é considerado como dado perdido ("missing"). O algoritmo EM é especialmente adequado para tratar o problema de dados incompletos. Em cada iteração do algoritmo, há duas etapas distintas: no passo $\mathrm{E}$ (esperança) o valor esperado de $\log L_{\text {comp }}$ é calculado sobre $\mathbf{Z}$, dados $\left(t_{i}, \delta_{i}\right),(i=1,2, \ldots, n),(j=1,2, \ldots, m)$ e as estimativas atualizadas de $\boldsymbol{\beta}, \theta$ e $h_{0}$; e no passo M (maximização) são obtidas as estimativas dos parâmetros que maximizam o valor esperado de $\log L_{\text {comp }}$ do passo E. Para a execução do passo E, KLEIN (1992) usou o fato que

$$
E\left(Z_{j} \mid t_{i j}, \delta_{i j}\right)=\frac{1 / \theta+D_{j}}{1 / \theta+\sum_{i=1}^{n_{j}} H_{0}\left(t_{i j}\right) \exp \left(\boldsymbol{\beta}^{\prime} \mathbf{x}_{i j}\right)}
$$




$$
E\left[\log \left(Z_{j}\right) \mid t_{i j}, \delta_{i j}\right]=\psi\left(D_{j}+1 / \theta\right)-\log \left[1 / \theta+\sum_{i=1}^{n_{j}} H_{0}\left(t_{i j}\right) \exp \left(\boldsymbol{\beta}^{\prime} \mathbf{x}_{i j}\right)\right]
$$

em que $\psi(\cdot)$ é a função digama.

Com as fragilidades fixadas e conhecidas, o passo $M$ reduz-se à maximização de uma verossimilhança parcial que é muito similar ao que se usa no modelo semiparamétrico de Cox com aproximação de Breslow-Preto para dados univariados de sobrevida; assim, a maximização é feita por um processo iterativo como o de Newton-Raphson. Mais detalhes podem ser encontrados em KLEIN e MOESCHBERGER (2003) e DUCHATEAU e col. (2002).

Segundo KLEIN e MOESCHBERGER (2003), as estimativas da variancia dos estimadores de $\beta, \theta$ e $h_{0}$ são obtidas invertendo a matriz de informação correspondente à função de verossimilhança observada (4.10), denotada por $\mathbf{i}_{\text {obs }}(\hat{\boldsymbol{\beta}}, \hat{\theta})$. MURPHY (1995) apresentou distribuições assintóticas para os estimadores obtidos pelo algoritmo EM proposto por NIELSEN e col. (1992) ${ }^{1}$, como também mostrou a consistência do estimador para as variancias assintóticas.

Sob o modelo (4.4) com fragilidade gama de média 1 e variância $\theta$, testar $\mathrm{H}_{0}$ : $\theta=0$ significa testar a hipótese de independência de $T_{1 j}, T_{2 j}, \ldots, T_{n_{j}, j}$. Os testes de razão de verossimilhanças, de Wald e de escore são os mais freqüentemente realizados para testar a hipótese de independência; e na prática, é conhecido que as estatísticas destes testes têm distribuição assintótica qui-quadrada com um grau de liberdade $\left(\chi_{1}^{2}\right)$, se $\mathrm{H}_{0}$ verdadeiro. Entretanto, a hipótese nula do teste é sobre um valor na borda do espaço paramétrico de $\theta$, tornando problemático o uso dos testes sem alguma modificação, já que por definição $\theta>0$.

As estatísticas dos testes de Wald e da razão de verossimilhanças são respectivamente,

$$
\chi_{W_{\theta}}^{2}=\frac{\hat{\theta}^{2}}{\hat{V} a r(\hat{\theta})}
$$

e

$$
\chi_{L R_{\theta}}^{2}=2\left[\log L\left(\hat{\boldsymbol{\beta}}, \hat{h}_{0}, \hat{\theta}\right)-\log L\left(\hat{\boldsymbol{\beta}}^{*}, \hat{h}_{0}^{*}\right)\right]
$$

\footnotetext{
${ }^{1}$ Segundo CHICARINO (1999), a principal diferença das propostas de KLEIN (1992) e NIELSEN e col. (1992) é que a primeira usa uma implementação completa do algoritmo EM, enquanto que a segunda usa uma busca unidimensional para estimar os parámetros do modelo de fragilidade. Como conseqüência. o algoritmo de KLEIN (1992) tem convergência mais lenta.
} 
em que $\hat{V} a r(\hat{\theta})$ é o elemento apropriado de $\mathbf{i}_{o b s}^{-1}(\hat{\boldsymbol{\beta}}, \hat{\theta})$ e $L\left(\boldsymbol{\beta}, h_{0}, \theta\right)$ é como em (4.9) sob fragilidade gama, sendo que $\hat{\beta}, \hat{h}_{0}(t)$ e $\hat{\theta}$ são as estimativas obtidas considerando o modelo (4.4); e, $\hat{\boldsymbol{\beta}}^{*}$ e $\hat{h}_{0}^{*}$ são as estimativas obtidas considerando o mesmo modelo (4.4) com $z_{j}=1(j=1,2, \ldots, m)$.

Para estimar $h_{0}(t)$, existem algumas propostas na literatura para estimar $H_{0}(t)$ após o ajuste do modelo, por exemplo, o estimador de Breslow (1972, 1974). Mas no caso do algoritmo EM, a estimativa de $H_{0}(t)$ faz parte do processo iterativo (KLEIN e MOESCHBERGER 2003).

O teste escore para testar a hipótese de independência foi desenvolvido por COMMENGES e ANDERSEN (1995) citados por KLEIN e MOESCHBERGER (2003, p.427). O teste pode ser usado também para verificar o efeito significativo de covariáveis omitidas em modelos para dados univariados de sobrevida e não é preciso supor uma distribuição para a fragilidade. A estatística de teste, $\chi_{S_{\theta}}^{2}$, necessita do cálculo de

$$
M_{i j}=\delta_{i j}-\hat{H}_{0}\left(t_{i j}\right) \exp \left(\hat{\boldsymbol{\beta}}^{\prime} \mathbf{x}_{i j}\right)
$$

o resíduo martingale da observação $i$ do grupo $j$. As estimativas de $H_{0}(t)$ e $\boldsymbol{\beta}$ são obtidas pelo ajuste do modelo de Cox para dados univariados de sobrevida, sendo que $\hat{H}_{0}(t)$ é a estimativa proposta por BRESLOW $(1972,1974)$. A fórmula da estatística $\chi_{S_{\theta}}^{2}$, que requer uma descrição extensa, pode ser encontrada em KLEIN e MOESCHBERGER (2003).

Além da hipótese $\mathrm{H}_{0}: \theta=0$, há interesse em testar hipóteses sobre o vetor dos coeficientes de regressão, como $\mathrm{H}_{0}: \boldsymbol{\beta}=\boldsymbol{\beta}_{0}$. Pode-se usar os testes de Wald e da razão de verossimilhanças. As respectivas estatísticas são dadas por

$$
\chi_{W_{\beta}}^{2}=\left(\hat{\beta}-\beta_{0}\right)^{\prime} I(\hat{\beta})\left(\hat{\beta}-\beta_{0}\right)
$$

e

$$
\chi_{L R_{\beta}}^{2}=2\left[\log L\left(\hat{\boldsymbol{\beta}}, \hat{h}_{0}, \hat{\theta}\right)-\log L\left(\beta_{0}, \hat{h}_{0}, \hat{\theta}\right)\right]
$$

em que $L\left(\beta, h_{0}, \theta\right)$ é a função de verossimilhança observada (4.10) e $I(\boldsymbol{\beta})$ é a submatriz apropriada da matriz de informação correspondente a verossimilhança em (4.10). As estatísticas desses testes têm distribuição assintótica qui-quadrado com $p$ graus de liberdade, sob $\mathrm{H}_{0}$, sendo $p=$ número de covariáveis no modelo. 


\section{Função de verossimilhança parcial penalizada para fragilidade gama}

Uma proposta alternativa de THERNEAU e GRAMBSCH (2000) para a verossimilhança, quando estimando os parâmetros $\beta$ e $\theta$ do modelo semiparamétrico com fragilidade gama, é usar a log-verossimilhança parcial penalizada

$$
\log P L_{p}(\beta, \theta, \omega)=\log P L(\beta, \omega)-\log L_{p e n}(\theta, \omega)
$$

sendo que $\omega$ é o vetor de efeitos aleatórios. Sejam $D$ o número de distintos tempos de falha, $t_{1}^{*}<t_{2}^{*}<\ldots<t_{D}^{*}$, e $d_{k}$ o número de falhas no tempo $t_{k}^{*}(k=1,2, \ldots, D)$. De DUCHATEAU e col. (2002), tem-se

$$
\log P L(\beta, \omega)=\sum_{k=1}^{D}\left[\sum_{t_{i j}=t_{k}^{*}} \eta_{i j}-d_{k} \log \sum_{t_{t_{q} \geq t_{k}^{*}}} \exp \left(\eta_{l q}\right)\right]
$$

com $\eta_{i j}=\boldsymbol{\beta}^{\prime} \mathbf{x}_{i j}+\omega_{j}$ e $t_{i j}$ é o tempo observado da observação $i$ do grupo $j$ $\left(i=1,2, \ldots, n_{j}\right),(j=1,2, \ldots, m)$; de fato, (4.13) é a log-verossimilhança parcial para o modelo (4.3) com a aproximação de Breslow-Peto; $\mathrm{e}^{2}$

$$
\begin{aligned}
\log L_{\text {pen }}(\theta, \omega) & =-\sum_{j=1}^{m} \log f_{\Omega}\left(\omega_{j}\right) \\
& =-\sum_{j=1}^{m} \frac{\omega_{j}-\exp \left(\omega_{j}\right)}{\theta}+m\left[\frac{\log \theta}{\theta}+\log \Gamma(1 / \theta)\right]
\end{aligned}
$$

A maximização da log-verossimilhança penalizada consiste de um "loop" interno e outro externo. No "loop" interno, o método de Newton-Raphson é usado na maximização de $\log P L_{p}(\boldsymbol{\beta}, \theta, \omega)$ para $\beta$ e $\omega$, dado um valor provisório de $\theta$. No "loop" externo, dadas a estimativa de $\beta$ e a previsão de $\omega$, uma logverossimilhança parcial (observada), similar a (4.10), é maximizada para $\theta$. É dada por,

$$
\begin{aligned}
\log P L_{o b s}= & \log P L(\beta, \omega)+\sum_{j=1}^{m}\left[\log \frac{\Gamma\left(D_{j}+1 / \theta\right)}{\Gamma(1 / \theta)}\right. \\
& \left.+1 / \theta \log \left(\frac{1 / \theta}{H_{j}+1 / \theta}\right)-D_{j} \log \left(D_{j}+1 / \theta\right)+D_{j}\right]
\end{aligned}
$$

$\operatorname{com} H_{j}=\sum_{i=1}^{n_{j}} H_{0}\left(t_{i j}\right) \exp \left(\boldsymbol{\beta}^{\prime} \mathbf{x}_{i j}\right)$.

\footnotetext{
${ }^{2}$ A expressão para $\log L_{\text {pen }}(\cdot)$ é diferente em DUCHATEAU e col. (2002), onde o primeiro termo entre colchetes aparece com o sinal trocado; e em THERNEAU e GRAMBSCH (2000), os termos entre colchetes não existem.
} 
O processo é iterado até a convergência. Para mais detalhes, ver DUCHATEAU e col. (2002) e THERNEAU e GRAMBSCH (2000).

Uma importante propriedade da fragilidade gama, estabelecida por THERNEAU e GRAMBSCH (2000), é que a solução para a maximização da logverossimilhança parcial penalizada coincide com a solução que KLEIN (1992) obteve usando o algoritmo EM, baseada na log-verossimilhança observada. Devido a este fato, THERNEAU e GRAMBSCH (2000) sugerem aplicar aos estimadores baseados na verossimilhança parcial penalizada a teoria assintótica desenvolvida por MURPHY (1995) para os estimadores baseados na log-verossimilhança observada de KLEIN (1992) e NIELSEN e col. (1992).

Segundo GRAY (1992) citado por THERNEAU e GRAMBSCH (2000, p.121), a matriz de segundas derivadas para a log-verossimilhança parcial penalizada é dada por

$$
\mathbf{H}(\beta, \theta, \omega)=\mathcal{I}-\left(\begin{array}{cc}
\mathbf{0} & \mathbf{0} \\
\mathbf{0} & -\log L_{\text {pen }}^{\prime \prime}
\end{array}\right)
$$

em que $\mathcal{I}$ é a matriz de informação do modelo semiparamétrico de Cox e

$$
\log L_{p e n}^{\prime \prime}=\frac{\partial^{2}}{\partial \omega \partial \omega^{\prime}} \log L_{p e n}(\theta, \omega)
$$

Assim, $\mathbf{H}^{-1}(\hat{\boldsymbol{\beta}}, \theta, \hat{\omega})$ é uma estimativa da matriz de variância para os estimadores de $\beta$, dado um valor fixado para $\theta$.

Uma desvantagem do uso da verossimilhança parcial penalizada é que a estimativa da matriz de variâncias do estimador de $\boldsymbol{\beta}$ são calculadas sob a suposição de $\theta$ conhecido. Como $\theta$ precisa ser estimado, os desvios padrão obtidos, segundo THERNEAU e GRAMBSCH (2000), são subestimados.

\subsubsection{Variância robusta}

Sob o modelo de fragilidade compartilhada (4.4), as distribuições marginais não-condicionadas de $T_{i j}\left(i=1,2, \ldots, n_{j}\right),(j=1,2, \ldots, m)$ não satisfazem à suposição de riscos proporcionais, quando a fragilidade tem distribuição gama, como visto em (4.8).

Um modelo alternativo para dados multivariados de sobrevida foi sugerido 
por LEE e col. (1992). Nesta abordagem, um modelo semiparamétrico de Cox é assumido para a função taxa de falha marginal

$$
h_{i j}\left(t \mid \mathbf{x}_{i j}\right)=h_{0}(t) \exp \left(\beta^{\prime} \mathbf{x}_{i j}\right)
$$

Para este modelo não é assumida uma forma para $h_{0}(t)$, então, estima-se $\boldsymbol{\beta}$ construindo a função de verossimilhança parcial para as $\sum_{j=1}^{m} n_{j}=n$ observações consideradas independentes, isto é

$$
P L(\boldsymbol{\beta})=\prod_{j=1}^{m} \prod_{i=1}^{n_{j}}\left(\frac{\exp \left(\boldsymbol{\beta}^{\prime} \mathbf{x}_{i j}\right)}{\sum_{l=1}^{m} \sum_{k=1}^{n_{l}} Y_{k l}\left(t_{i j}\right) \exp \left(\boldsymbol{\beta}^{\prime} \mathbf{x}_{k l}\right)}\right)^{\delta_{i}}
$$

Como as $n$ observações não são independentes dentro dos grupos, esta função de verossimilhança parcial não está corretamente especificada; contudo, LEE e col. (1992) mostraram que a estimativa de máxima verossimilhança parcial é consistente para $\beta$, desde que o modelo marginal (4.15) esteja especificado corretamente. Entretanto, a matriz de informação obtida desta verossimilhança parcial não fornece um estimador válido para a variancia do estimador de $\boldsymbol{\beta}$, sendo portanto necessário usar um estimador robusto.

Descreve-se a seguir um estimador robusto na situação de dados univariados de sobrevida, com $n$ indivíduos em uma amostra sem ocorrência de censuras. Um problema específico é o caso de uma estimativa de máxima verossimilhança baseada na função densidade $f\left(t_{i} \mid \mathbf{x}_{i}\right)$ para $T_{i}(i=1,2, \ldots, n)$, quando, de fato, $T_{i}$ são uma amostra da distribuição com função densidade $\mathrm{g}$. Tomando $L(\boldsymbol{\beta})=$ $\prod_{i=1}^{n} f\left(t_{i} \mid \mathbf{x}_{i}\right)$ tem-se, sob condições apropriadas, uma estimativa robusta para a matriz de covariancia de $\hat{\boldsymbol{\beta}}$ dada por

$$
\mathbf{i}(\hat{\boldsymbol{\beta}})^{-1}\left[\sum_{i=1}^{n} \mathbf{U}_{i}(\hat{\boldsymbol{\beta}}) \mathbf{U}_{i}^{\prime}(\hat{\boldsymbol{\beta}})\right] \mathbf{i}(\hat{\boldsymbol{\beta}})^{-1}
$$

sendo que $\mathrm{U}_{i}(\boldsymbol{\beta})$ é o vetor escore do indivíduo $i$ e $\mathrm{i}(\boldsymbol{\beta})$ é a matriz de informação observada. A origem dessa fórmula pode ser encontrada em HUBER (1967), citado por LACHIN (2000, p.489).

O estimador da variância robusto é conhecido como "estimador sanduíche" porque é semelhante a um sanduíche, onde as duas fatias de pão são a matriz de variâncias de $\hat{\boldsymbol{\beta}}$ e pode ser mostrado que o recheio é a matriz de variancias de $\sum_{i=1}^{n} \mathbf{U}_{i}(\hat{\beta})$. 
Com correlação intra-grupo e sob o modelo (4.15), uma modificação de (4.17), é obtida usando vetor escore para a observação $i$ do grupo $j$. É dada por

$$
\mathcal{U}_{i j}(\boldsymbol{\beta})=\frac{\partial \log P L_{i j}(\boldsymbol{\beta})}{\partial \boldsymbol{\beta}}=\delta_{i j}\left[\mathbf{x}_{i j}-\overline{\mathbf{x}}\left(t_{i j}, \boldsymbol{\beta}\right)\right]
$$

com

$$
\overline{\mathbf{x}}\left(t_{i j}, \boldsymbol{\beta}\right)=\left[\frac{\sum_{l=1}^{m} \sum_{k=1}^{n_{l}} Y_{k l}\left(t_{i j}\right) \mathbf{x}_{k l} \exp \left(\beta^{\prime} \mathbf{x}_{k l}\right)}{\sum_{l=1}^{m} \sum_{k=1}^{n_{l}} Y_{k l}\left(t_{i j}\right) \exp \left(\boldsymbol{\beta}^{\prime} \mathbf{x}_{k l}\right)}\right]
$$

sendo que o indicador de risco, $Y_{i j}(t)$, no caso de eventos agrupados, indica se o indivíduo $i$ do grupo $j$ está em risco no tempo $t$; e, no caso de falhas múltiplas, indica se o indivíduo $j$ está em risco para a falha $i$ no tempo $t$.

No entanto, como o modelo semiparamétrico (4.15) é estimado por uma função de verossimilhança parcial ao invés de uma completa, os vetores escores, $\mathcal{U}_{i j}(\beta),\left(i=1,2, \ldots, n_{j}\right),(j=1,2, \ldots, m)$ não são independentes e identicamente distribuídos com esperança zero. LIN e WEI (1989) descrevem um estimador sanduíche que fornece uma estimativa consistente para a matriz de variancia dos estimadores de $\boldsymbol{\beta}$, com correlação intra-grupo e a função de verossimilhança parcial em (4.16). Eles mostraram que uma estimativa robusta para a matriz de covariância do estimador de $\beta$ é

$$
\mathcal{I}(\hat{\boldsymbol{\beta}})^{-1}\left[\sum_{j=1}^{m} \sum_{i=1}^{n_{j}} \mathcal{W}_{i j}(\hat{\boldsymbol{\beta}}) \mathcal{W}_{i j}^{\prime}(\hat{\boldsymbol{\beta}})\right] \mathcal{I}(\hat{\boldsymbol{\beta}})^{-1}
$$

sendo

$$
\mathcal{W}_{i j}(\beta)=\mathcal{U}_{i j}(\beta)-\overline{\mathcal{U}}_{i j}(\beta)
$$

e

$$
\overline{\mathcal{U}}_{i j}(\boldsymbol{\beta})=\sum_{l=1}^{m} \sum_{k=1}^{n_{l}} \frac{Y_{i j}\left(t_{k l}\right) \exp \left(\boldsymbol{\beta}^{\prime} \mathbf{x}_{i j}\right)}{\sum_{s=1}^{m} \sum_{r=1}^{n_{s}} Y_{r s}\left(t_{k l}\right) \exp \left(\boldsymbol{\beta}^{\prime} \mathbf{x}_{r s}\right)} \delta_{k l}\left[\mathbf{x}_{i j}-\overline{\mathbf{x}}\left(t_{k l}, \boldsymbol{\beta}\right)\right]
$$

é uma média ponderada dos escores de todos os indivíduos com falhas antes do tempo $t_{i j}$ cujos pesos estão relacionados com o valor das covariáveis. Assim, tem-se que $\mathcal{W}_{i j}(\beta),\left(i=1,2, \ldots, n_{j}\right),(j=1,2, \ldots, m)$ são independentes e identicamente distribuídos.

A variancia em (4.18) produz limites de confiança robustos e testes de Wald e escore robustos para os parâmetros. 


\subsubsection{Estruturas de intervalo de risco e tipos de conjunto de risco para falhas múltiplas}

Nas Seções 4.1.1 e 4.1.3, as abordagens de fragilidade e variância robusta foram aplicadas à função taxa de falha marginal condicionada (4.4) e ao modelo de Lee-Wei-Amato (4.15), respectivamente. Além disso, essas duas abordagens podem também ser aplicadas a outros modelos propostos na literatura para modelar falhas múltiplas.

De acordo com a escala de tempo usada para medir os tempos de falha, é construido o intervalo de tempo em que o indivíduo está em "risco" para uma determinada falha, e este intervalo de risco pode ser formulado de três maneiras diferentes. No intervalo de risco com a estrutura de tempo total, considere-se que o indivíduo está sob risco desde o instante inicial do acompanhamento, qualquer que seja a falha. O intervalo de risco com tempo entre eventos ("gap time") determina que o indivíduo está sob risco a partir do evento anterior, "zerando" a contagem de tempo depois de cada evento. Isto provoca uma mudança na escala de tempo para $G_{i j}=T_{i j}-T_{i-1, j}$, em que $T_{1 j}<T_{2 j}<\ldots<T_{n_{j}, j}$. A formulação de processos de contagem mantém a mesma escala de tempo original, porém um indivíduo só está sob o risco de falhar após o evento anterior ter ocorrido. Além disso, a formulação de processos de contagem reconhece que um indivíduo pode ter uma entrada tardia ou período temporário de censura antes de estar novamente sob o risco de falhar.

Como descrito em KELLY e LIM (2000), a Figura 4.1 ilustra as três estruturas de intervalo de risco, usando dados hipotéticos de eventos recorrentes dos indivíduos $\mathrm{A}, \mathrm{B}$ e $\mathrm{C}$, os quais são acompanhados até a $3^{\mathbf{a}}$ falha ou término do acompanhamento. $O$ indivíduo $A$ teve duas falhas, a $1^{\mathrm{a}}$ no tempo 2 e a $2^{\mathrm{a}}$ no tempo 5 , sendo censurado no tempo 13. $O$ indivíduo $B$ teve três falhas nos tempos 7, 11 e 17. E o indivíduo $\mathrm{C}$ não teve falha sendo censurado no tempo 14. Para o individuo $\mathrm{A}$, por exemplo, os intervalos de risco para as três falhas, considerando tempo total, são $(0,2],(0,5]$ e $(0,13]$; na estrutura de tempo entre eventos, os intervalos de risco são $(0,2],(0,3]$ e $(0,8]$; e para formulação de processos de contagem são $(0,2],(2,5]$ e $(5,13]$.

O intervalo de risco para a primeira falha é o mesmo em todas as três estruturas de intervalos de risco, como mostrado na Figura 4.1. Portanto, não 
Figura 4.1 - Eventos recorrentes em 3 individuos e estruturas de intervalos de risco correspondentes

Tempos de falha ou censura

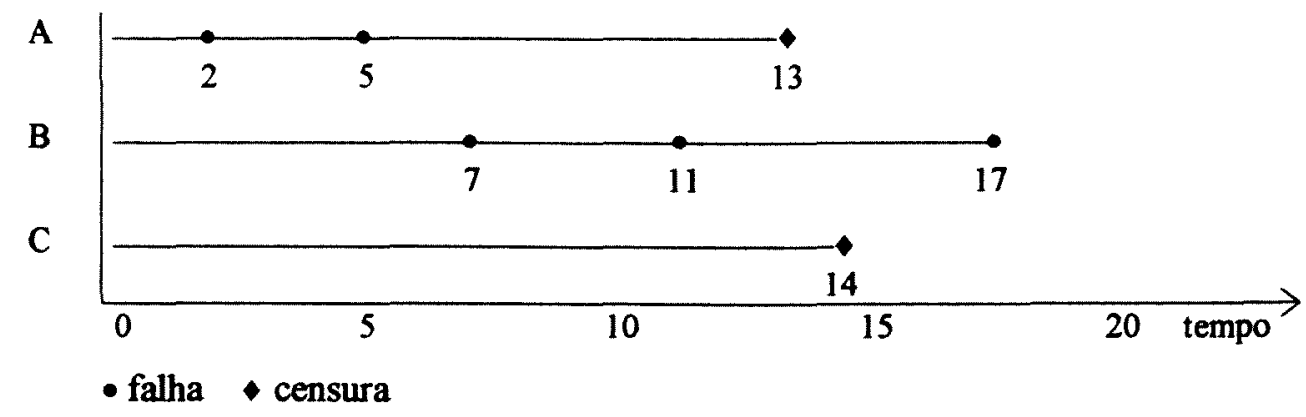

Intervalos de risco com a estrutura de tempo total

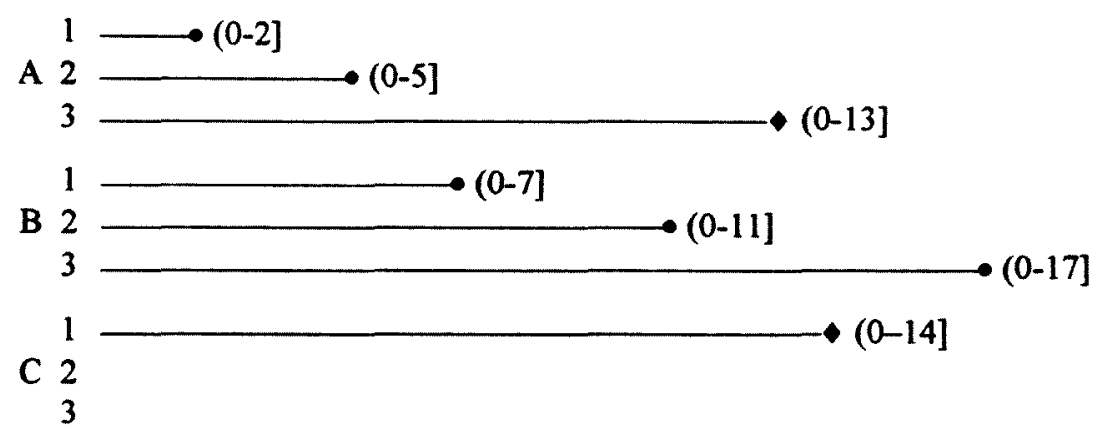

Intervalos de risco com a estrutura de tempo entre eventos

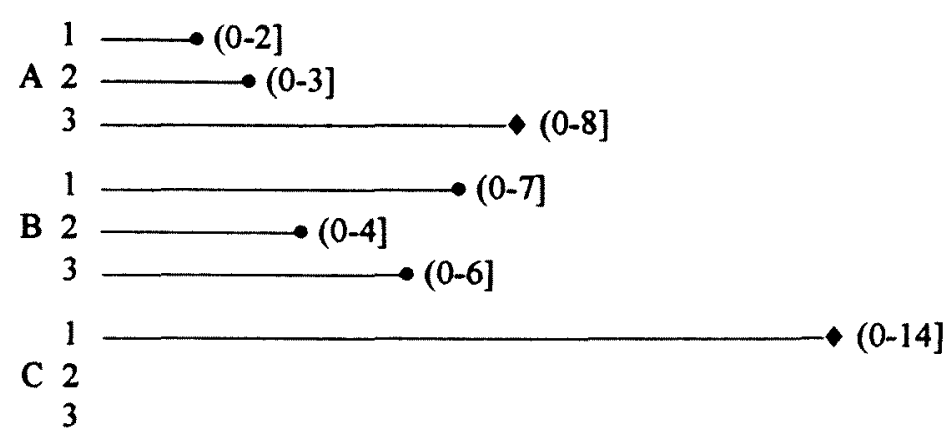

Intervalos de risco com a estrutura de processos de contagem

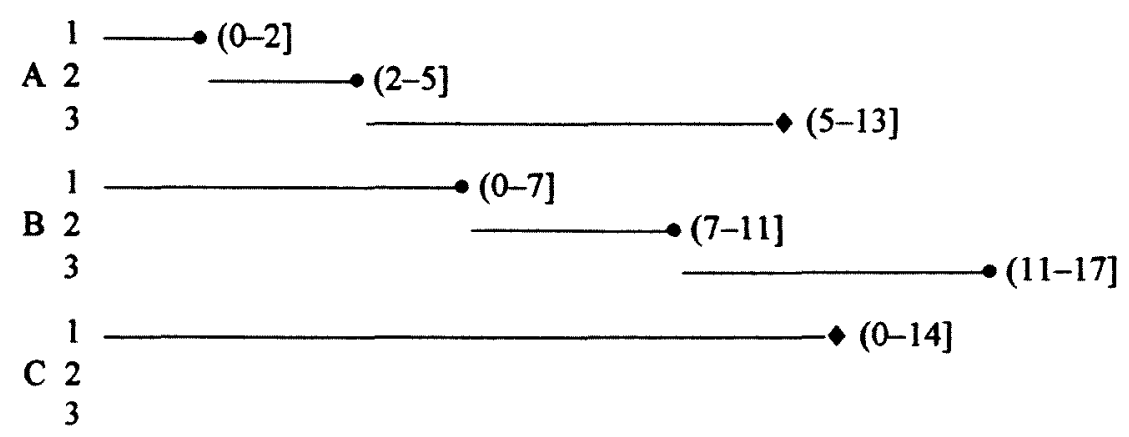


há variações na estrutura de intervalos de risco na análise de dados univariados de sobrevida nem na análise de eventos agrupados, pois nestas duas situações ocorre somente uma falha por indivíduo. Nota-se, também, que os intervalos de risco com processos de contagem e com tempo entre eventos têm as mesmas amplitudes.

$\mathrm{Na}$ análise de falhas múltiplas, para cada indivíduo, há interesse em observar mais de uma falha. As falhas múltiplas podem ser eventos recorrentes e/ou falhas de múltiplos tipos. Neste caso, para cada observação $i$ do indivíduo $j$, há uma função indicadora de risco no tempo $t, Y_{i j}(t),\left(i=1,2, \ldots, n_{j}\right),(j=1,2, \ldots, m)$, que pode ser definida diferentemente, conforme a estrutura do intervalo de risco escolhida. Cada tipo de intervalo de risco altera o valor do indicador de risco, $Y_{i j}(t)$ no tempo $t$. Tem-se que para tempo total

$$
Y_{i j}(t)=\left\{\begin{array}{l}
1, \text { se } t \leq t_{i j} \\
0, \text { caso contrário }
\end{array}\right.
$$

para tempo entre eventos

$$
Y_{i j}(t)=\left\{\begin{array}{l}
1, \text { se } t \leq g_{i j}=t_{i j}-t_{i-1, j} \\
0, \text { caso contrário }
\end{array}\right.
$$

e para processos de contagem

$$
Y_{i j}(t)=\left\{\begin{array}{l}
1, \text { se } t_{i-1, j}<t \leq t_{i j} \\
0, \text { caso contrário }
\end{array}\right.
$$

As Figuras 4.2a a 4.2c mostram, graficamente, os valores do indicador de risco para as observaçōes dos indivíduos A, B e C, em cada estrutura de intervalos de risco, de acordo com as informações da Figura 4.1. O indicador de risco para a $1^{\text {a }}$ falha é a mesma função nas três estruturas de intervalos de risco. Para as demais falhas, considere-se, por exemplo, $Y_{2 B}(6)$, a função indicadora de risco para a $2^{\mathrm{a}}$ observação do indivíduo $\mathrm{B}$ no tempo $t=6$. Conforme as Figuras $4.2 \mathrm{a}$ a 4.2c, tem-se $Y_{2 B}(6)=1$, no intervalo de tempo total, pois o indivíduo B está em risco para a $2^{\mathrm{a}}$ falha no tempo 6 . No entanto, $Y_{2 B}(6)=0$ nos intervalos de tempo entre eventos e de processos de contagem, já que, no tempo entre eventos, o indivíduo $B$ só está em risco para a $2^{a}$ falha até o tempo 4; e em processos de contagem, a partir do tempo 7. 
Figura 4.2a - Função indicadora de risco, $Y_{i}(t)$, para as observaçðes dos indivíduos da Figura 4.1, com tempo total

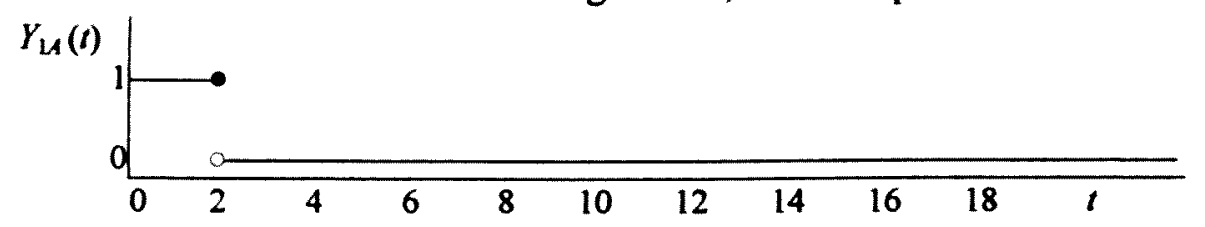

$Y_{24}(t)$

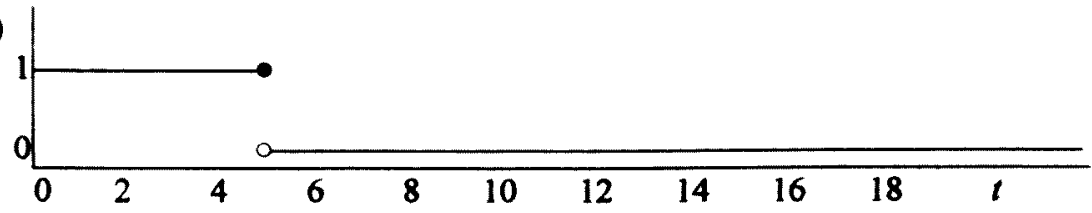

$Y_{34}(t)$

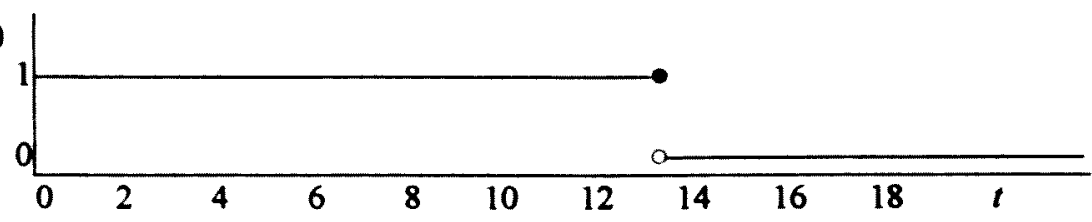

$Y_{1 B}(t)$

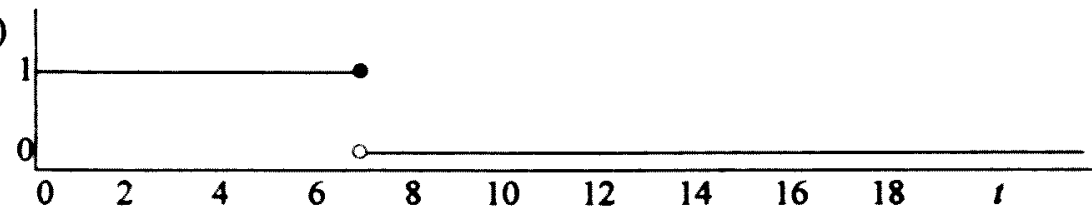

$Y_{2 B}(t)$

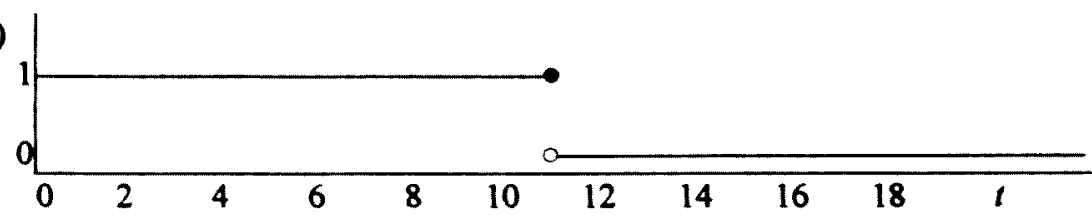

$Y_{3 B}(t)$

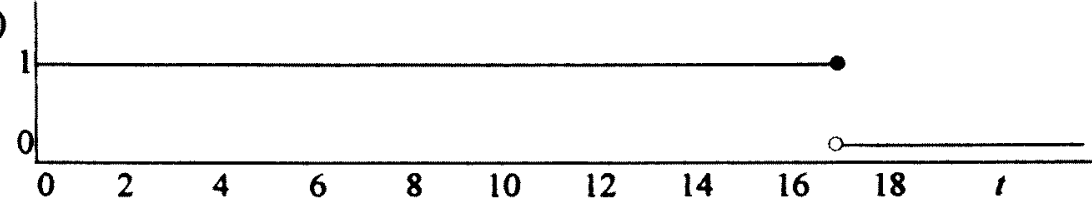

$Y_{1 C}(t)$
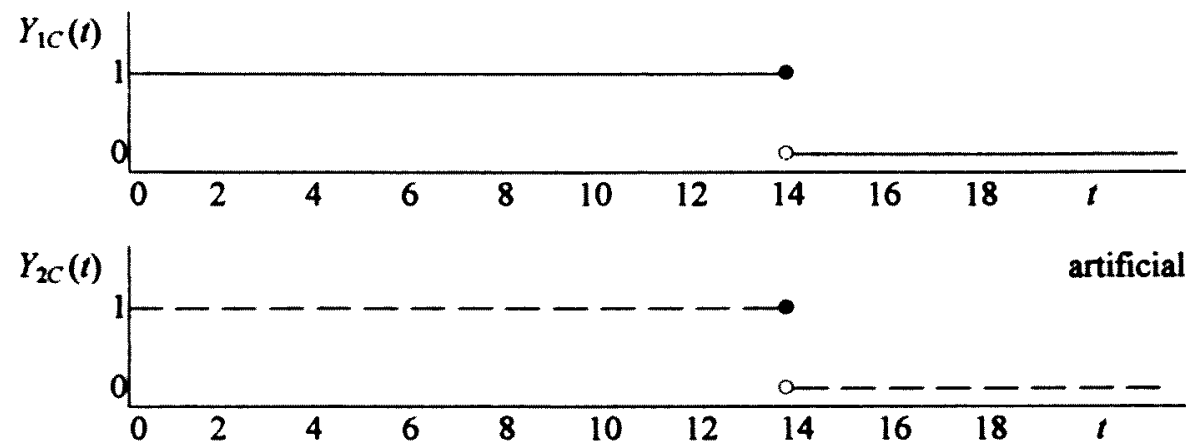

$Y_{3 C}(t)$

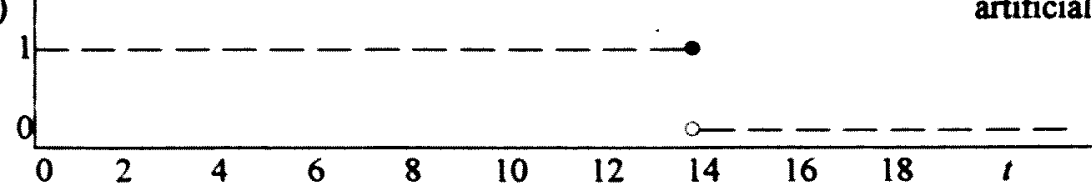


Figura 4.2b - Função indicadora de risco, $Y_{i j}(g)$, para as observações dos indivíduos da Figura 4.1, com tempo entre eventos
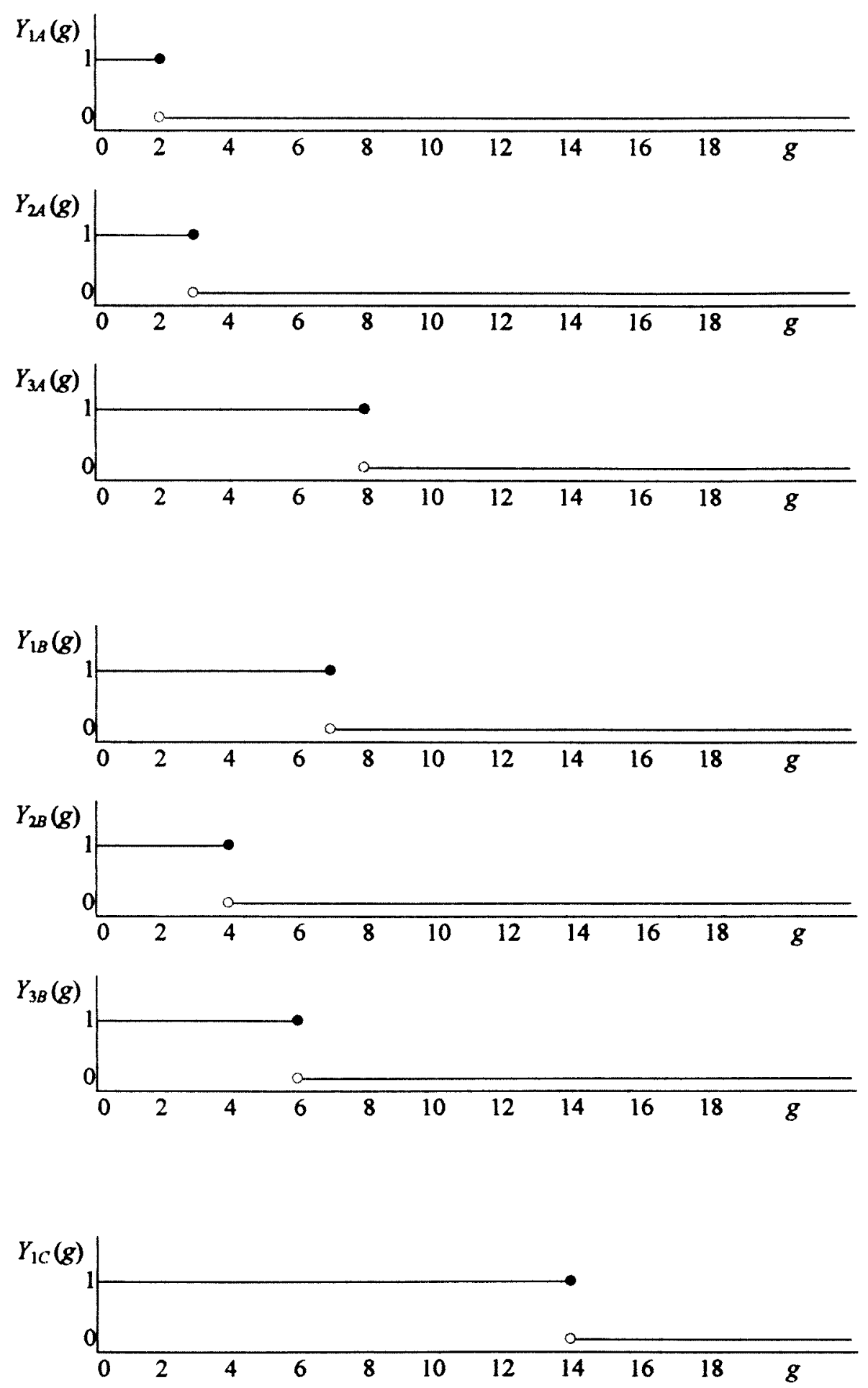
Figura 4.2c - Função indicadora de risco, $Y_{i j}(t)$, para as observações dos individuos da Figura 4.1, com processos de contagem
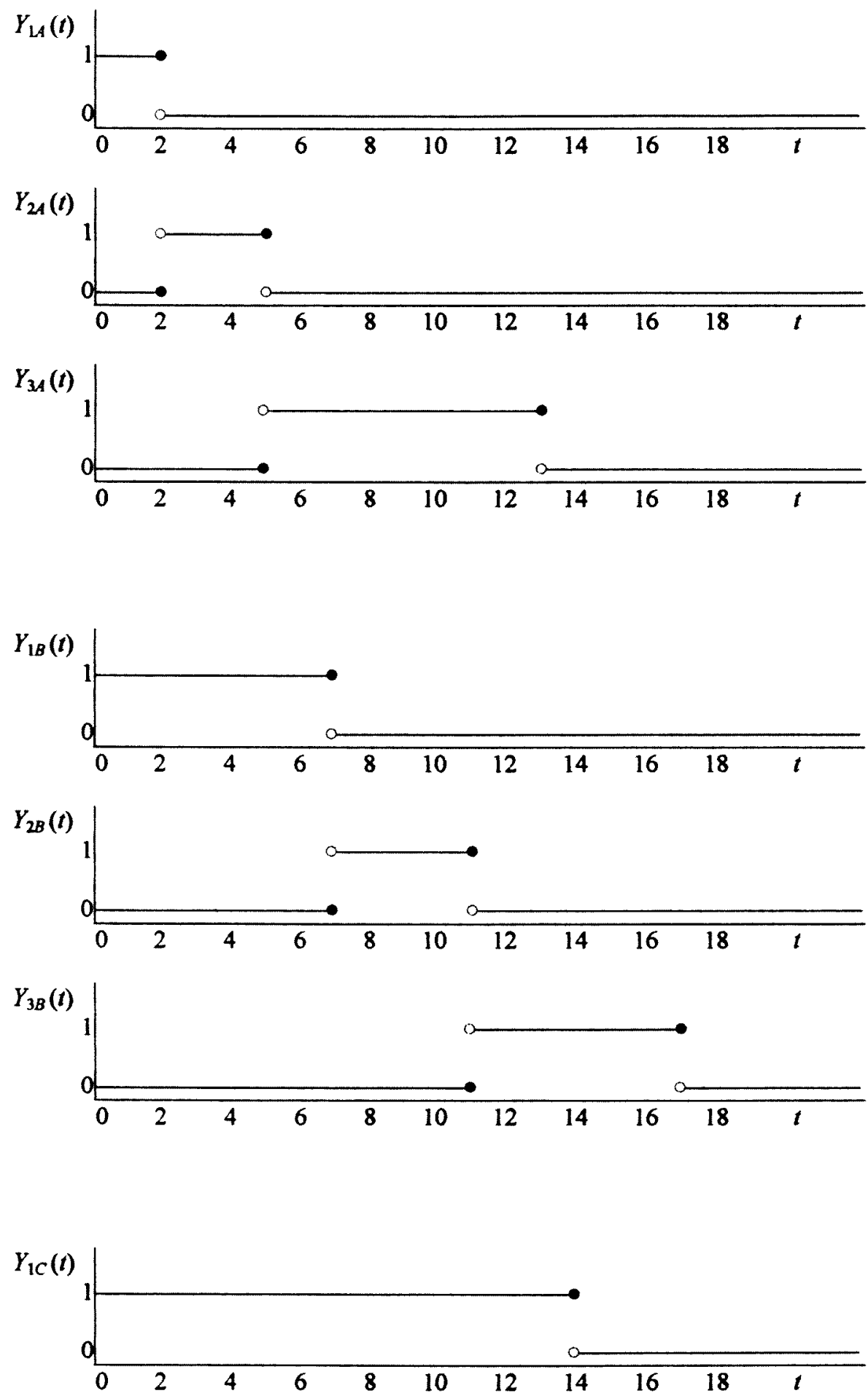
As funções de verossimilhança parcial descritas nas Seções 4.1.2 e 4.1.3, por construção, dependem de $Y_{i j}(t)$ e conseqüentemente, tanto na abordagem de fragilidade como na de variancia robusta, as estimativas dos parâmetros podem ser diferentes quando a definição para $Y_{i j}(t)$ é alterada.

O tipo de conjunto de risco adotado é outra condição que modifica a formulação da verossimilhança parcial. A definição de conjunto de risco, em um dado instante de tempo, depende de quais indivíduos podem ser incluídos, de acordo com a escolha do risco basal, que pode ser comum ou especifico por tipo de falha no caso de eventos de múltiplos tipos e, para eventos recorrentes, é comum ou específico por ordem de recorrência.

Os tipos de conjunto de risco são mais facilmente descritos para eventos recorrentes. Se o risco basal, $h_{0}(t)$, é comum a todas as falhas, o conjunto de risco é do tipo irrestrito, isto é, todos os indivíduos em risco podem contribuir para o conjunto de risco da $i$-ésima falha, qualquer que seja $i$; sem considerar o número de falhas que cada individuo tem. Outro tipo de conjunto de risco é aquele que é restrito para a $i$-ésima falha. Nesta situação, são considerados somente os indivíduos em risco que têm $(i-1)$ falhas. Por exemplo, somente indivíduos que têm 3 falhas podem contribuir para o conjunto de risco restrito à $4^{\mathrm{a}}$ falha. Um conjunto de risco restrito tem um risco basal, $h_{0 i}(t)$, específico para a $i$-ésima falha $\left(i=1,2, \ldots, n_{j}\right),(j=1,2, \ldots, m)$; é semelhante ao modelo de Cox estratificado para dados univariados de sobrevida (Seção 1.2.5) em que foi definido um conjunto de risco restrito a estratos. O conjunto de risco pode ainda ser semi-restrito, que define um risco basal, $h_{0 i}(t)$, específico para $i$-ésima falha, mas admite que indivíduos com menos do que $(i-1)$ falhas estejam sob risco para a $i$-ésima falha criando intervalos de risco artificiais ("dummies"); assim, um individuo que tem uma ou nenhuma falha está em risco para a $4^{\mathrm{a}}$ falha. No entanto, um indivíduo com 4 falhas, por exemplo, não contribui para o conjunto de risco semi-restrito à $3^{\mathrm{a}}$ falha.

A forma da função de verossimilhança parcial dos modelos semiparamétricos é modificada se o risco basal adotado é comum ou específico para a ordem das recorrências ou para o tipo de falha, de maneira que a estrutura da verossimilhança 
parcial a ser maximizada, para conjuntos de risco irrestritos é expressa como

$$
\prod_{j=1}^{m} \prod_{i=1}^{n_{j}}\left[\frac{\varphi_{i j}(\cdot)}{\sum_{l=1}^{m} \sum_{k=1}^{n_{l}} Y_{k l}\left(t_{i j}\right) \varphi_{k l}(\cdot)}\right]^{\delta_{i j}}
$$

e para os conjuntos de risco semi-restrito e restrito à $i$-ésima falha (eventos recorrentes) ou à falha do tipo $i$ (eventos de múltiplos tipos) é expressa como

$$
\prod_{j=1}^{m} \prod_{i=1}^{n_{j}}\left[\frac{\varphi_{i j}(\cdot)}{\sum_{l=1}^{m} Y_{i l}\left(t_{i j}\right) \varphi_{i l}(\cdot)}\right]^{\delta_{i j}}
$$

em que no modelo de fragilidade gama, $\varphi_{i j}(\cdot)$ representa uma das verossimilhanças parciais apresentadas na Seção 4.1.2; e no modelo com variância robusta, $\varphi_{i j}\left(\boldsymbol{\beta}, \mathbf{x}_{i j}\right)=\exp \left(\boldsymbol{\beta}^{\prime} \mathbf{x}_{i j}\right)$.

Retomando o exemplo dos 3 indivíduos da Figura 4.1 para ilustrar o processo de construção da verossimilhança parcial conforme tipo de conjunto de risco, a contribuição para verossimilhança parcial correspondente ao tempo da $2^{\mathrm{a}}$ falha do indivíduo $\mathrm{B}, t_{2 B}=11$, pode ser expressa como

$$
\frac{\varphi_{2 B}(\cdot)}{\sum_{l=1}^{m} \sum_{k=1}^{n} Y_{k l}(11) \varphi_{k l}(\cdot)}
$$

com conjunto de risco irrestrito, e

$$
\frac{\varphi_{2 B}(\cdot)}{\sum_{l=1}^{m} Y_{2 l}(11) \varphi_{2 l}(\cdot)}
$$

com conjuntos de risco semi-restrito e restrito.

Assim, para a formulação de tempo total (Figura 4.2a),

a) com conjunto de risco irrestrito, tem-se que a contribuição para a verossimilhança parcial (4.19) inclui a informação:

- do indivíduo $\mathrm{A}$, devido ao risco para a $3^{\mathrm{a}}$ falha,

- do indivíduo $B$ duas vezes, devido aos riscos para as $2^{\mathrm{a}}$ e $3^{\mathrm{a}}$ falhas e,

- do indivíduo $\mathrm{C}$, devido ao risco para a $1^{\mathrm{a}}$ falha de $\mathrm{C}$;

b) com conjunto de risco restrito à $2^{\mathrm{a}}$ falha, tem-se que a contribuição para (4.20) inclui a informação: 
- do indivíduo B, devido ao risco para a $2^{\mathrm{a}}$ falha,

- mas não inclui a informação dos indivíduos A e C;

c) com conjunto de risco semi-restrito à $2^{\mathbf{a}}$ falha, tem-se que a contribuição para (4.20), inclui a informação:

- do indivíduo $B$, devido ao risco para a $2^{\text {a }}$ falha e,

- do indivíduo $\mathrm{C}$, devido ao risco artificial para a $2^{\mathrm{a}}$ falha.

Para tempo entre eventos (Figura 4.2b), substituindo $t_{2 B}=11$ por $g_{2 B}=4$,

a) com conjunto de risco irrestrito, tem-se que a contribuição para a verossimilhança parcial (4.19) inclui a informação:

- do indivíduo A, devido ao risco para a $3^{\mathrm{a}}$ falha,

- do indivíduo $B$ três vezes, devido ao risco para as $1^{\mathrm{a}}, 2^{\mathrm{a}}$ e $3^{\mathrm{a}}$ falhas e,

- do individuo $\mathrm{C}$, devido ao risco para a $1^{\mathrm{a}}$ falha;

b) com conjunto de risco restrito à $2^{\mathbf{a}}$ falha, tem-se que a contribuição para (4.20) inclui a informação do indivíduo $\mathrm{B}$, devido ao risco para a $2^{\mathrm{a}}$ falha.

Para processos de contagem (Figura 4.2c),

a) com conjunto de risco irrestrito, tem-se que a contribuição para (4.20) inclui a informação dos indivíduos A, B e C uma única vez, devido aos riscos para as $3^{\mathrm{a}}, 2^{\mathrm{a}}$ e $1^{\mathrm{a}}$ falhas, respectivamente;

b) com conjunto de risco restrito à $2^{\mathbf{a}}$ falha, tem-se que a contribuição para a verossimilhança parcial (4.19) inclui a informação do indivíduo $\mathrm{B}$ devido ao risco para $2^{\mathrm{a}}$ falha.

Nas estruturas de tempo entre eventos e de processos de contagem, o conjunto de risco semi-restrito não é aplicável porque intervalos artificiais não podem ser criados com tempo entre eventos; e com processos de contagem, é até possível criar intervalos artificiais, mas é sem sentido, porque processos de contagem são usados para evitar que individuos estejam sob risco antes do prévio evento ocorrer. 
Alguns modelos de sobrevida que estão baseados no modelo semiparamétrico de Cox e foram propostos na literatura para tratar falhas múltiplas adotam uma das estruturas de intervalo de risco em combinação com um dos tipos de conjunto de risco, e é bem conhecido que esses modelos podem chegar a resultados diferentes. Segundo KELLY e LIM (2000), a combinação dos três tipos de intervalo de risco com os três tipos de conjunto de risco produz, conceitualmente, sete modelos possíveis e com sentido, como apresentado no Quadro 4.1. Desses modelos, cinco estão identificados na literatura: no modelo de Andersen-Gill (AG) usa-se processos de contagem com conjunto de risco irrestrito; no modelo de Prentice-Williams-Peterson, um conjunto de risco restrito é usado com em duas versões para os intervalos de risco, uma com tempo entre eventos (PWPte) e outra com processos de contagem (PWP-pc), chamada erroneamente de tempo total, em alguns textos; o modelo de Lee-Wei-Amato (LWA), apresentado na Seção 4.1.3, requer tempo total com conjunto de risco irrestrito; e no modelo de Wei-Lin-Weissfeld (WLW) usa-se tempo total com conjunto de risco semirestrito. Os outros dois modelos variantes, sugeridos por KELLY e LIM (2000), são os modelos para tempo total com conjunto de risco restrito (as vezes tratado como PWP-tt) e para tempo entre eventos com conjunto de risco irrestrito (não encontrado em outras referências).

Quadro 4.1 - Características e nomenclatura dos modelos para falhas múltiplas

\begin{tabular}{l|c|c|c}
\hline \multirow{2}{*}{ Intervalo de risco } & \multicolumn{3}{|c}{ Conjunto de risco } \\
\cline { 2 - 4 } & Irrestrito & Semi-restrito & Restrito \\
\hline Tempo total (TT) & LWA & WLW & possível \\
Tempo entre eventos (TE) & possível & impossivel & PWP-te \\
Processos de contagem (PC) & AG & sem sentido & PWP-pc \\
\hline
\end{tabular}

A escolha de um dos modelos determina a forma da função de verossimilhança parcial e conseqüentemente, determina as estimativas dos parâmetros do modelo. As diferentes estruturas entre os modelos para analisar falhas múltiplas são importantes na escolha de um deles, servindo para sugerir o modelo que seja mais adequado. A escolha do modelo para falhas múltiplas depende, em princípio, do tipo de falha múltipla. Eventos recorrentes têm a característica de que as falhas são ordenadas e que o indivíduo, em um tempo qualquer, pode estar em risco para somente uma falha; nos eventos de múltiplos tipos as falhas não são 
ordenadas e o indivíduo pode estar em risco para vários tipos de falha ao mesmo tempo. Questões de pesquisa também podem determinar a escolha do modelo. Por exemplo, para verificar se o efeito de tratamento varia entre a $1^{\mathrm{a}}$ falha e as demais, é preciso ajustar um modelo estratificado por ordem de ocorrência das falhas e incluir interação entre tratamento e a variável que indica a seqüência das falhas.

LIN (1994) sugeriu que, para eventos recorrentes, seja utilizado o modelo AG, que é o mais simples, principalmente quando houver poucas ocorrências (poucos indivíduos com dois ou mais eventos); e, quando o número de falhas anteriores não influencia na taxa de ocorrência da próxima falha, o modelo AG é suficiente para responder de modo satisfatório às hipóteses da análise, além da facilidade de processamento e interpretação. O modelo de PWP, com tempo entre eventos, pode ser considerado, se houver interesse neste tipo de escala de tempo. Em algumas situações, a estrutura imposta pelo modelo de WLW pode parecer inconsistente quando, por exemplo, a ordem de ocorrência dos eventos é importante, e neste caso, não faz sentido considerar que os indivíduos estão em risco para uma determinada falha sem ter as anteriores.

Nas simulações de BOX-STEFFENSMEIER e DE BOEF (2002), os resultados apontaram que, em uma variedade de condições (com ou sem independência entre eventos e com ou sem heterogeneidade não observada entre indivíduos), as abordagens de variância robusta e de fragilidade com TE - restrito (PWP-te) são os candidatos preferidos na escolha de modelos para analisar eventos recorrentes. BOX-STEFFENSMEIER e DE BOEF (2002) concluíram que a abordagem de variância robusta com PC - irrestrito (AG) tem um desempenho relativamente bom quando há heterogeneidade não observada entre os indivíduos, mas há independência entre eventos. Também concluíram que sem independência entre eventos, são apropriados somente modelos restritos, ou seja, com estratificação por número de falhas. 


\subsection{Aspectos computacionais}

\section{Variância robusta}

Os três programas computacionais escolhidos têm implementada a variância robusta proposta por LIN e WEI (1989) que é adequada para estimação de parâmetros é obtida pela maximização da função de verossimilhança parcial baseada na distribuição marginal dos tempos de falha multivariados. No Stata, é necessário usar a opção "noadjust" para obter estimativas de variancia robusta similares as dos programas SAS e S-PLUS. As opções para aproximações de Breslow-Peto e de Efron e para estratificação estão disponíveis nos três programas.

\section{Fragilidade gama}

No caso da modelagem com fragilidade gama, THERNEAU e GRAMBSCH, em 2000, demonstraram que as estimativas obtidas pela maximização da verossimilhança parcial penalizada coincidem com as estimativas obtidas do algoritmo EM com qualquer valor fixado para $\theta$, a variância da fragilidade gama. Assim, o algoritmo do processo de verossimilhança parcial penalizada, implementado no S-Plus, é preferível por ser mais rápido; no entanto, esta versão do S-Plus não estima a variância de $\hat{\theta}^{3}$ e para testar $\mathrm{H}_{0}: \theta=0$, o programa realiza, equivalentemente, um teste de Wald aproximado para testar $\mathrm{H}_{0}: \boldsymbol{\omega}=\mathbf{0}$, em que $\boldsymbol{\omega}$ é um vetor de efeitos (coeficientes) aleatórios do modelo de fragilidade compartilhada (4.2).

THERNEAU e GRAMBSCH (2000) recomendaram um teste de razão de verossimilhanças para testar $\mathrm{H}_{0}: \boldsymbol{\omega}=\mathbf{0}$, que não é mostrado no "output" e a estatística do teste é dada por

$$
\chi_{L R_{\theta}}^{2}=2\left[\log L_{o b s}\left(\hat{\boldsymbol{\beta}}, \hat{h}_{0}, \hat{\theta}\right)-\log P L\left(\hat{\boldsymbol{\beta}}^{*}\right)\right]
$$

que tem distribuição assintótica qui-quadrado com 1 grau de liberdade $\left(\chi_{1}^{2}\right)$, sob $\mathrm{H}_{0} ; L_{\text {obs }}(\cdot)$ é a verossimilhança parcial observada (4.14), indicada por I-likelihood no "output" do modelo com fragilidade, e $P L(\cdot)$ é a verossimilhança parcial de um modelo sem fragilidade em $\hat{\beta}^{*}$, a estimativa $\operatorname{de} \beta$ sem fragilidade ${ }^{4}$.

\footnotetext{
3 ao menos não está disponível.

4 após ajustar o modelo sem fragilidade, coxs, digitar o comando coxs\$loglik[2].
} 
A fórmula da variância do estimador de $\boldsymbol{\beta}$ usada pela rotina implementada no S-Plus assume um valor fixado para $\theta$, ao invés de tratá-lo como um valor estimado. Apesar disso, THERNEAU e GRAMBSCH (2000) afirmam que parece ser bastante acurado em várias situações; e para muitos problemas, o programa é rápido suficiente, mais do que a maioria das estimativas de variância confiáveis que poderiam ser obtidas via técnicas de reamostragem, tal como o "bootstrap".

No Stata, a implementação atual para o ajuste do modelo de fragilidade gama é também via verossimilhança parcial penalizada de THERNEAU e GRAMBSCH (2000), no qual é estimado a variancia de $\hat{\theta}^{5}$. Dependendo do volume de dados, o número de cálculos matriciais pode ser muito grande no Stata, o que leva a um tempo computacional excepcionalmente grande para a estimação dos parâmetros do modelo e das variâncias dos estimadores. $O$ programa testa $\mathrm{H}_{0}: \theta=0$ por um teste da razão de verossimilhanças modificado, que é calculado como em (4.21), mas é modificado porque leva em consideração o fato do teste ser na borda do espaço paramétrico de $\theta$; assim, para o cálculo do nível descritivo $\mathrm{p}$, a distribuição assintótica da estatística do teste, sob $\mathrm{H}_{0}$, não é a usual distribuição $\chi_{1}^{2}$, mas uma mistura meio-a-meio de um qui-quadrado degenerado no ponto zero e um $\chi_{1}^{2}$. STATA CORPORATION (2003, p.131) sugere ver GUTIERREZ e col. (2001) para mais detalhes.

Como, até o momento, o modelo de fragilidade não está implementado no programa SAS, para obter as estimativas com fragilidade gama foi usada uma macro do SAS, que implementa a proposta de KLEIN (1992) usando o algoritmo EM para maximizar uma verossimilhança completa. Para poder usar a macro, disponivel em http://www.biostat.mcw.edu/software/SoftMenu.html, os tempos de falha precisam estar em ordem crescente, sendo que as falhas vêm antes das censuras, e a variável que identifica os grupos deve tomar valores inteiros consecutivos entre 1 e $m$.

O S-Plus é o programa mais flexível, permitindo introduzir a fragilidade em todos os modelos propostos, inclusive os modelos estratificados para falhas múltiplas e é possível ao usuário especificar um valor para $\theta$, ao invés de estimá-lo. Tanto o Stata como a macro do SAS, até o momento, não permitem modelos com risco basal específico, ou seja, modelos estratificados que permitem conjuntos de

\footnotetext{
${ }^{5}$ No manual do Stata, não está claro como a variância de $\hat{\theta}$ é estimada.
} 
risco restrito e semi-restrito com fragilidade. A macro do SAS é ainda mais limitada, pois também não permite a formulação de processos de contagem para intervalos de risco nem a aproximação Efron para empates.

A versão do S-Plus que foi usada neste trabalho contém um erro no "output", que nos modelos de fragilidade apresenta o valor de $\mathrm{p}$ (nível descritivo do teste) com uma aproximação incorreta para as últimas casas decimais. Este problema é resolvido com uma linha de comando digitada após o ajuste do modelo "coxf". Para obter o valor de $\mathrm{p}$ do teste para a $\mathrm{k}$-ésima covariável incluída no modelo digitar o comando 1-pchisq (coxf $\$ \operatorname{coef}[\mathrm{k}] \sim 2 / \operatorname{coxf} \$ v a r[\mathrm{k}], 1)$. Uma alternativa ao S-Plus, é usar o programa $R$ que é uma versão de código aberto.

Alguns modelos de fragilidade gama não puderam ser ajustados por falhas no processo iterativo. No Stata, a função de log-verossimilhança marginal usada para estimar $\theta$ não é côncava ao aplicar o modelo TT - irrestrito com aproximação Breslow-Peto aos dados do Estudo 4 (Tabela 5.4a). Nos estudos de eventos recorrentes e de $1^{\mathrm{a}}$ falha, ocorreram problemas com a macro do SAS, quando $\theta$ deveria ser próximo de zero (segundo as estimativas dos outros programas).

Em outros modelos de fragilidade gama, o ajuste é feito mas o programa envia uma mensagem de aviso. O Quadro 4.2 esquematiza a ocorrência desses avisos.

Quadro 4.2 - Mensagens de aviso no "output" do programa

\begin{tabular}{|c|c|c|c|}
\hline Programa & Mensagem & Modelo & Estudo \\
\hline \multirow{3}{*}{ Stata } & \multirow{2}{*}{ "backed up" } & \begin{tabular}{|l|l} 
Semiparamétrico de Cox com aproximação \\
Breswlo-Peto para a $1^{\mathbf{a}}$ falha
\end{tabular} & 3 \\
\hline & & $\begin{array}{l}\text { Semiparamétrico de Cox com aproximação Efron } \\
\text { para a } 1^{2} \text { falha }\end{array}$ & 3 \\
\hline & $\begin{array}{l}\text { "numerical derivatives } \\
\text { are approximate flat or } \\
\text { discontinuous region } \\
\text { encountered" }\end{array}$ & $\begin{array}{l}\text { Semiparamétrico com tempo total irrestrito e } \\
\text { aproximação Efron para eventos recorrentes }\end{array}$ & 5 \\
\hline \multirow{3}{*}{ S-Plus } & \multirow{3}{*}{$\begin{array}{l}\text { "inner loop failed to } \\
\text { converge for iterations } \\
+ \text { in coxpenal.fit(.)" }\end{array}$} & $\begin{array}{l}\text { Semiparamétrico com tempo total semi-restrito e } \\
\text { aproximaçăo Breslow-Peto para eventos recor- } \\
\text { rentes }\end{array}$ & 3 e 4 \\
\hline & & $\begin{array}{l}\text { Semiparamétrico com tempo total semi-restrito e } \\
\text { aproximaçăo Efron para eventos recorrentes }\end{array}$ & 3,4 e 5 \\
\hline & & $\begin{array}{l}\text { Semiparamétrico com tempo total restrito e apro- } \\
\text { ximaçăo Efron para eventos recorrentes }\end{array}$ & 3 e 4 \\
\hline
\end{tabular}




\section{Intervalos e conjuntos de risco}

O usuário de pacotes estatísticos pode somente distinguir os sete modelos semiparamétricos possiveis para falhas múltiplas, em parte, com o comando para ajustar o modelo semiparamétrico. Outras diferenciações, como a criação de intervalos de riscos artificiais (para o conjunto de risco semi-restrito), são feitas na fase de estruturação do banco de dados (CLEVES 1999; THERNEAU e GRAMBSCH 2000). As Tabelas 4.1 a 4.4 exemplificam os diferentes formatos dos bancos de dados, de acordo com o modelo a ser ajustado aos dados da Figura 4.1. A diferenciação de dois modelos com mesmo banco de dados (Tabelas 4.1, 4.3 e 4.4) é feita com a opção de estratificação no comando para ajustar o modelo semiparamétrico de Cox, nos modelos com conjunto de risco restrito; e para modelos com processos de contagem é preciso indicar a variável que representa o limite inferior do intervalo de risco ${ }^{6}$.

Tabela 4.1 - Arquivo de dados com as recorrências dos individuos da Figura 4.1 para os modelos com tempo total e conjuntos de riscos irrestrito (LWA) ou restrito

\begin{tabular}{cccc}
\hline id & ordem da falha & tempo & censura \\
\hline A & 1 & 2 & 1 \\
A & 2 & 5 & 1 \\
A & 3 & 13 & 0 \\
B & 1 & 7 & 1 \\
B & 2 & 11 & 1 \\
B & 3 & 17 & 1 \\
C & 1 & 14 & 0 \\
\hline
\end{tabular}

Tabela 4.2 - Arquivo de dados com as recorrências dos indivíduos da Figura 4.1 para o modelo com tempo total e conjunto de risco semi-restrito (WLW)

\begin{tabular}{cccc}
\hline id & ordem da falha & tempo & censura \\
\hline A & 1 & 2 & 1 \\
A & 2 & 5 & 1 \\
A & 3 & 13 & 0 \\
B & 1 & 7 & 1 \\
B & 2 & 11 & 1 \\
B & 3 & 17 & 1 \\
C & 1 & 14 & 0 \\
C & 2 & 14 & 0 \\
C & 3 & 14 & 0 \\
\hline
\end{tabular}

\footnotetext{
${ }^{6}$ Com tempo total e tempo entre eventos, este limite é zero.
} 
Tabela 4.3 - Arquivo de dados com as recorrências dos indivíduos da Figura 4.1 para os modelos com tempo entre eventos e conjunto de risco irrestrito ou restrito (PWP-gt)

\begin{tabular}{cccc}
\hline id & ordem da falha & tempo & censura \\
\hline A & 1 & 2 & 1 \\
A & 2 & 3 & 1 \\
A & 3 & 8 & 0 \\
B & 1 & 7 & 1 \\
B & 2 & 4 & 1 \\
B & 3 & 6 & 1 \\
C & 1 & 14 & 0 \\
\hline
\end{tabular}

Tabela 4.4 - Arquivo de dados com as recorrências dos indivíduos da Figura 4.1 para os modelos com processos de contagem e conjunto de risco irrestrito (AG) ou restrito (PWP-tt)

\begin{tabular}{ccccc}
\hline id & ordem da falha & tempo inicial & tempo final & censura \\
\hline A & 1 & 0 & 2 & 1 \\
A & 2 & 2 & 5 & 1 \\
A & 3 & 5 & 13 & 0 \\
B & 1 & 0 & 7 & 1 \\
B & 2 & 7 & 11 & 1 \\
B & 3 & 11 & 17 & 1 \\
C & 1 & 0 & 14 & 0 \\
\hline
\end{tabular}




\section{COMPARAÇÃO EMPÍRICA}

\subsection{Comparação dos modelos por estudo}

\section{Estudo 1: ninhada de ratos}

Como as unidades de análise estão agrupadas devido ao plano de amostragem, é um exemplo de eventos agrupados, sendo que todos os 50 grupos de ratos têm tamanho igual a três. Foi considerada uma única covariável, $x_{i j}$, indicadora de tratamento, tal que $x_{i j}=1$, se o rato $i$ da ninhada $j$ recebeu a droga e $x_{i j}=0$, se o rato $i$ da ninhada $j$ não recebeu a droga $(i=1,2,3),(j=1,2, \ldots, 50)$.

Nos resultados apresentados na Tabela 5.1, observa-se que $\hat{\theta}<0,5$. E em todos os testes para independência, $\mathrm{H}_{0}: \theta=0$, tem-se que $p>0,05$. Portanto, há evidências de que a variância dos modelos de fragilidade gama não é significativa, indicando que não há correlação entre ratos da mesma ninhada. É razoável, então, ajustar um modelo de Cox, sem fragilidade, e compará-lo com os outros modelos.

As estimativas de $H R$ entre droga e placebo do S-Plus estão representadas na Figura 5.1. Uma comparação visual das estimativas indica que são praticamente iguais e pode-se concluir que a droga é fator de risco para desenvolvimento de tumor.

\section{Estudo 2: retinopatia em diabéticos}

Trata-se de um estudo de eventos agrupados com 197 grupos (pacientes), cada grupo formado pelas duas observações de cada paciente. Duas covariáveis categóricas foram incluídas nos modelos: $x_{i j 1}$, indicadora de tratamento para 0 olho $i$ do indivíduo $j$ e $x_{j 2}$, indicadora de diabetes tipo adulta para o indivíduo $j$ $(i=1,2),(j=1,2, \ldots, 197)$. 
Tabela 5.1 - Estimativas da razão de taxas de falha $(H R)$ entre tratamento e controle e da variância $(\theta)$ da fragilidade gama para o Estudo 1 , segundo alguns modelos semiparamétricos para eventos agrupados e programas computacionais

\begin{tabular}{|c|c|c|c|c|c|c|c|}
\hline \multirow{2}{*}{ Modelo } & \multicolumn{2}{|c|}{ Stata } & \multicolumn{2}{|c|}{ S-Plus } & \multicolumn{3}{|c|}{ SAS } \\
\hline & $\theta$ & $p^{(1)}$ & $\theta$ & $p^{(2)}$ & $\theta$ & $p_{1}^{(2)}$ & $\mathrm{p}_{2}{ }^{(3)}$ \\
\hline $\begin{array}{c}\text { Fragilidade } \\
\text { gama } \\
\text { (Breslow-Peto) }\end{array}$ & 0,4743 & 0,1076 & 0,4736 & 0,2153 & 0,4743 & 0,2153 & 0,3228 \\
\hline $\begin{array}{c}\text { Fragilidade } \\
\text { gama } \\
\text { (Efron) }\end{array}$ & 0,4990 & 0,0975 & 0,4987 & 0,1951 & \multicolumn{3}{|c|}{ não disponivel } \\
\hline Modelo & $H R$ & $\mathrm{IC}(H R)$ & $H R$ & $\mathrm{IC}(H R)$ & $H R$ & & $H R)$ \\
\hline $\begin{array}{c}\text { Cox } \\
\text { (Breslow-Peto) }\end{array}$ & 2,455 & 1,$318 ; 4,574$ & 2,455 & 1,$318 ; 4,574$ & 2,455 & 1,31 & 4,574 \\
\hline $\begin{array}{c}\text { Variância } \\
\text { Robusta } \\
\text { (Breslow-Peto) }\end{array}$ & 2,455 & 1,$363 ; 4,423$ & 2,455 & 1,$363 ; 4,423$ & 2,455 & 1,36 & 4,423 \\
\hline $\begin{array}{c}\text { Fragilidade } \\
\text { gama } \\
\text { (Breslow-Peto) }\end{array}$ & 2,473 & 1,$314 ; 4,654$ & 2,473 & 1,$314 ; 4,654$ & 2,473 & não c & ponivel \\
\hline $\begin{array}{c}\text { Cox } \\
\text { (Efron) }\end{array}$ & 2,471 & 1,$326 ; 4,605$ & 2,471 & 1,$326 ; 4,605$ & 2,471 & 1,32 & 4,605 \\
\hline $\begin{array}{l}\text { Variância } \\
\text { Robusta } \\
\text { (Efron) }\end{array}$ & 2,471 & 1,$366 ; 4,471$ & 2,471 & 1,$366 ; 4,471$ & 2,471 & 1,37 & 4,456 \\
\hline $\begin{array}{c}\text { Fragilidade } \\
\text { gama } \\
\text { (Efron) }\end{array}$ & 2,495 & 1,$325 ; 4,700$ & 2,495 & 1,$325 ; 4,699$ & & Io dispor & \\
\hline
\end{tabular}

(1) Teste da razåo de verossimilhanças (modificado) para $\mathrm{H}_{0}: \theta=0$

(2) Teste da razão de verossimilhanças para $\mathrm{H}_{0}: \theta=0$

(3) Teste de Wald para $\mathrm{H}_{0}: \theta=0$

Estas notas servem para as demais tabelas

Figura 5.1 - Intervalos de confiança da razão de taxas de falha entre tratamento e controle do Estudo 1, segundo alguns modelos semiparamétricos para eventos agrupados, usando o programa S-Plus

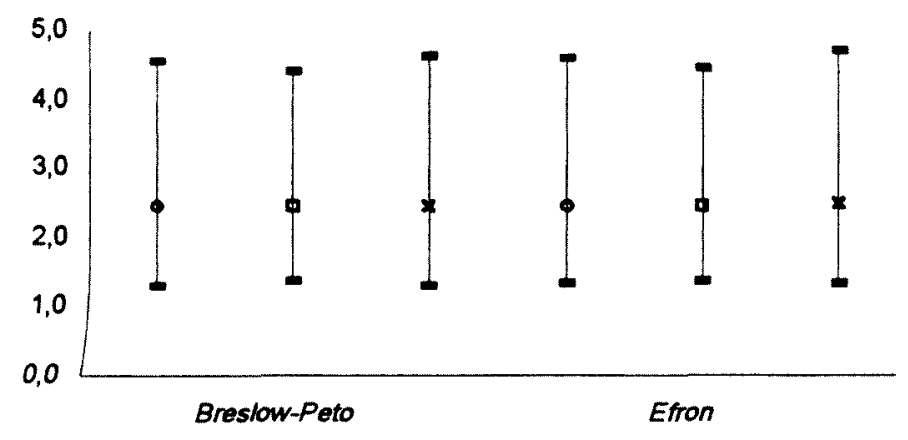


Conforme a Tabela 5.2, verifica-se que a variância da fragilidade gama é estimada em 0,85 e é significativa. Portanto, existe uma correlação intra-indivíduo, sendo adequado ajustar modelos que considerem esta correlação. As estimativas de razão de taxas de falha apresentadas na Tabela 5.2 e na Figura 5.2, dos modelos com fragilidade e variância robusta estão bastante próximas, tanto para tratamento como para tipo de diabetes. Há indicações de que tratamento é fator de proteção para perda de acuidade visual.

Tabela 5.2 - Estimativas da razão de taxas de falha $(H R)$ e da variância $(\theta)$ da fragilidade gama para os dados do Estudo 2, segundo alguns modelos semiparamétricos para eventos agrupados e programas computacionais

\begin{tabular}{|c|c|c|c|c|c|c|c|}
\hline \multirow{2}{*}{ Modelo } & \multicolumn{2}{|c|}{ Stata } & \multicolumn{2}{|c|}{ S-Plus } & \multicolumn{3}{|c|}{ SAS } \\
\hline & $\theta$ & $\mathbf{p}$ & $\boldsymbol{\theta}$ & $\mathbf{p}$ & $\boldsymbol{\theta}$ & $\mathbf{p}_{1}$ & $p_{2}$ \\
\hline $\begin{array}{c}\text { Fragilidade } \\
\text { gama } \\
\text { (Breslow-Peto) }\end{array}$ & 0,8452 & 0,0003 & 0,8418 & 0,0007 & 0,8452 & 0,0007 & 0,0071 \\
\hline $\begin{array}{c}\text { Fragilidade } \\
\text { gama } \\
\text { (Efron) }\end{array}$ & 0,8543 & 0,0003 & 0,8512 & 0,0006 & \multicolumn{3}{|c|}{ não disponivel } \\
\hline & $H R$ & $\mathrm{IC}(H R)$ & $H R$ & $\mathrm{IC}(H R)$ & $H R$ & & $(H R)$ \\
\hline \multicolumn{8}{|c|}{ tratamento versus controle } \\
\hline $\begin{array}{c}\text { Variância } \\
\text { Robusta } \\
\text { (Breslow-Peto) }\end{array}$ & 0,459 & 0,$343 ; 0,614$ & 0,459 & 0,$343 ; 0,614$ & 0,459 & 0,34 & $3 ; 0,614$ \\
\hline $\begin{array}{c}\text { Fragilidade } \\
\text { gama } \\
\text { (Breslow-Peto) }\end{array}$ & 0,403 & 0,$286 ; 0,567$ & 0,403 & 0,$286 ; 0,567$ & 0,403 & não c & isponivel \\
\hline $\begin{array}{c}\text { Variância } \\
\text { Robusta } \\
\text { (Efron) }\end{array}$ & 0,459 & 0,$343 ; 0,614$ & 0,459 & 0,$343 ; 0,614$ & 0,459 & 0,34 & $3 ; 0,614$ \\
\hline $\begin{array}{c}\text { Fragilidade } \\
\text { gama } \\
\text { (Efron) } \\
\end{array}$ & 0,402 & 0,$285 ; 0,566$ & 0,402 & 0,$286 ; 0,566$ & & to dispor & ível \\
\hline \multicolumn{8}{|c|}{ diabetes adulta versus juvenil } \\
\hline $\begin{array}{c}\text { Variância } \\
\text { Robusta } \\
\text { (Breslow-Peto) }\end{array}$ & 1,055 & 0,$744 ; 1,497$ & 1,055 & 0,$744 ; 1,497$ & 1,055 & 0,74 & $4 ; 1,497$ \\
\hline $\begin{array}{l}\text { Fragilidade } \\
\text { gama } \\
\text { (Breslow-Peto) }\end{array}$ & 1,041 & 0,$677 ; 1,602$ & 1,041 & 0,$677 ; 1,603$ & 1,041 & não & isponivel \\
\hline $\begin{array}{c}\text { Variância } \\
\text { Robusta } \\
\text { (Efron) }\end{array}$ & 1,055 & 0,$744 ; 1,498$ & 1,055 & 0,$744 ; 1,498$ & 1,055 & 0,74 & $4 ; 1,497$ \\
\hline $\begin{array}{c}\text { Fragilidade } \\
\text { gama } \\
\text { (Efron) }\end{array}$ & 1,042 & 0,$676 ; 1,605$ & 1,042 & 0,$676 ; 1,606$ & & Lo dispor & ivel \\
\hline
\end{tabular}


Figura 5.2 - Intervalos de confiança da razão de taxas de falha para os dados do Estudo 2, segundo alguns modelos semiparamétricos para eventos agrupados usando o programa S-Plus

a) $H R$ entre tratamento e controle

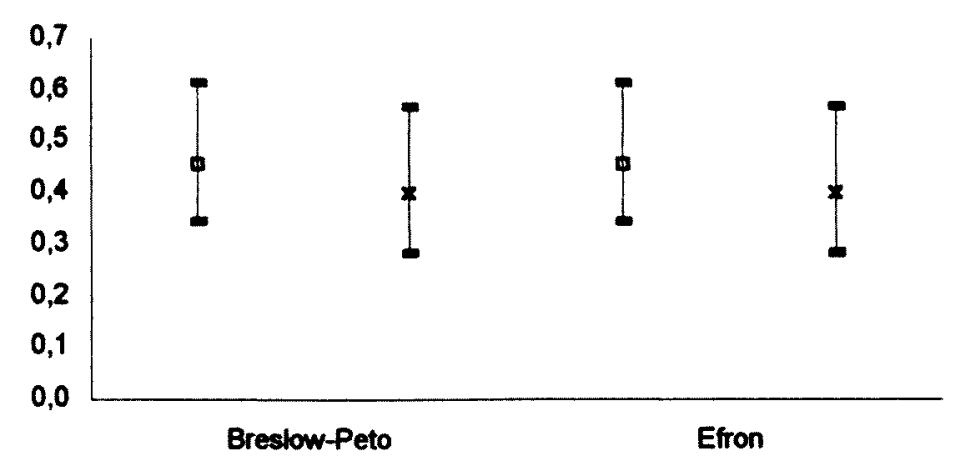

b) $H R$ entre diabetes adulta e juvenil

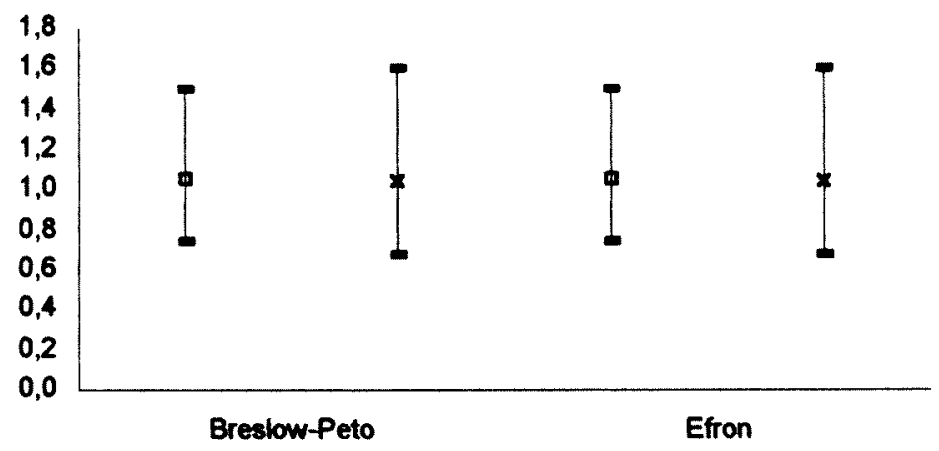

$\square$ Variância Robusta

$\times$ Fragilidade 


\section{Estudo 3: recorrência de tumor em pacientes com câncer de bexiga}

Consiste de repetidos eventos, em que foram observadas até 4 recorrências de tumor por paciente. Foram incluídas nos modelos três covariáveis: $x_{j 1}$, indicadora de tratamento para o indivíduo $j, x_{j 2}=$ tamanho do maior tumor do indivíduo $j$ e $x_{j 3}=$ número de tumores do indivíduo $j(j=1,2, \ldots, 85)$. Os sete modelos possíveis para falhas múltiplas foram ajustados. Como comentado na Seção 4.1.4, diferentes modelos determinam diferentes estimativas, independentemente da abordagem adotada (fragilidade gama ou variância robusta; aproximação de Breslow-Peto (B-P) ou Efron (E)). A Tabela 5.3 mostra que entre os 14 modelos de fragilidade gama, três não convergiram no S-Plus e não estão disponiveis nos outros programas, seis indicaram que $\theta$ não é significativo: $\mathrm{PC}$ - restrito com B-P e E, TT - irrestrito com B-P e E, TE - restrito com B-P e E; em cinco modelos, $\theta$ é significativo, com valores estimados entre 0,45 e 1,58: $\mathrm{PC}$ - irrestrito com B-P e E, TT - semi-restrito com B-P e E, TT - restrito com B-P e E, TE - irrestrito com E, sendo que no modelo com TE - irrestrito com B-P, o teste do Stata diferiu dos demais. O teste que o Stata realiza é o único que leva em consideração o fato do parâmetro ser testado na borda do espaço paramétrico. Desta forma, o valor descritivo que apresenta deve ser o correto; e portanto, por este modelo, há indicações de que $\theta$ é significativo.

Como o indivíduo está em risco somente para uma falha de cada vez, os modelos com processos de contagem e tempo entre eventos são mais apropriados, porque, nestes casos, o intervalo de risco considera o tempo entre falhas. E se houver razões que indiquem falta de independência entre os eventos de um mesmo indivíduo, modelos restritos devem ser usados, conforme comentado na Seção 4.1.4. Se for razoável aceitar que uma recorrência de tumor afeta as demais, pode-se concluir, de acordo com os modelos PC - restrito B-P e E, e GT restrito B-P e E, que $\theta$ não é significativo, indicando que não há correlação intraindivíduo.

A Tabela 5.3b apresenta os resultados das análises com dados univariados de sobrevida, ou seja, era de interesse somente a $1^{a}$ recorrência de tumor nos pacientes. Verifica-se que $\theta$ não é significativo, portanto a heterogeneidade não observada não tem efeito sobre a taxa de recorrência do $1^{\circ}$ tumor, e neste caso, modelos sem fragilidade podem ser adequados. 
Tabela 5.3a - Estimativas da razão de taxas de falha $(H R)$ e da variância $(\theta)$ da fragilidade gama para os dados do Estudo 3, segundo alguns modelos semiparamétricos para eventos recorrentes e programas computacionais

\begin{tabular}{|c|c|c|c|c|c|c|}
\hline Modelo & \multicolumn{2}{|r|}{ Stata } & \multicolumn{2}{|c|}{ S-Plus } & \multicolumn{2}{|c|}{ SAS } \\
\hline \multicolumn{7}{|c|}{ Processos de contagem - irrestrito } \\
\hline & $\theta$ & $\mathbf{p}$ & $\theta$ & $\mathbf{p}$ & $\theta$ & $\mathrm{p}_{2}$ \\
\hline $\begin{array}{c}\text { Fragilidade } \\
\text { gama } \\
\text { (Breslow-Peto) }\end{array}$ & 0,9296 & 0,0000 & 0,9300 & 0,0000 & \multirow{2}{*}{\multicolumn{2}{|c|}{ não disponível }} \\
\hline $\begin{array}{c}\text { Fragilidade } \\
\text { gama } \\
\text { (Efron) }\end{array}$ & 1,0752 & 0,0000 & 1,0776 & 0,0006 & & \\
\hline & $H R$ & $\mathrm{IC}(H R)$ & $H R$ & $\mathrm{IC}(H R)$ & $H R$ & $\mathrm{IC}(H R)$ \\
\hline \multicolumn{7}{|c|}{ tratamento versus controle } \\
\hline $\begin{array}{l}\text { Variância } \\
\text { Robusta } \\
\text { (Breslow-Peto) }\end{array}$ & 0,631 & 0,$381 ; 1,047$ & 0,631 & 0,$381 ; 1,047$ & 0,631 & 0,$381 ; 1,047$ \\
\hline $\begin{array}{c}\text { Fragilidade } \\
\text { gama } \\
\text { (Breslow-Peto) }\end{array}$ & 0,558 & 0,$300 ; 1,038$ & 0,558 & 0,$299 ; 1,039$ & & lisponível \\
\hline $\begin{array}{l}\text { Variância } \\
\text { Robusta } \\
\text { (Efron) }\end{array}$ & 0,628 & 0,$373 ; 1,057$ & 0,628 & 0,$373 ; 1,057$ & 0,628 & 0,$379 ; 1,041$ \\
\hline $\begin{array}{c}\text { Fragilidade } \\
\text { gama } \\
\text { (Efron) }\end{array}$ & 0,545 & 0,$284 ; 1,044$ & 0,545 & 0,$284 ; 1,046$ & & lisponivel \\
\hline \multicolumn{7}{|c|}{ tamanho de tumores } \\
\hline $\begin{array}{c}\text { Variância } \\
\text { Robusta } \\
\text { (Breslow-Peto) }\end{array}$ & 0,958 & 0,$826 ; 1,111$ & 0,958 & 0,$826 ; 1,111$ & 0,958 & 0,$826 ; 1,111$ \\
\hline $\begin{array}{c}\text { Fragilidade } \\
\text { gama } \\
\text { (Breslow-Peto) }\end{array}$ & 0,977 & 0,$792 ; 1,205$ & 0,977 & 0,$790 ; 1,208$ & & lisponivel \\
\hline $\begin{array}{l}\text { Variância } \\
\text { Robusta } \\
\text { (Efron) }\end{array}$ & 0,957 & 0,$822 ; 1,115$ & 0,957 & 0,$822 ; 1,115$ & 0,957 & 0,$826 ; 1,110$ \\
\hline $\begin{array}{l}\text { Fragilidade } \\
\text { gama } \\
\text { (Efron) }\end{array}$ & 0,979 & 0,$785 ; 1,220$ & 0,979 & 0,$783 ; 1,224$ & & lisponivel \\
\hline \multicolumn{7}{|c|}{ números de tumores } \\
\hline $\begin{array}{c}\text { Variância } \\
\text { Robusta } \\
\text { (Breslow-Peto) }\end{array}$ & 1,187 & 1,$053 ; 1,339$ & 1,187 & 1,$053 ; 1,339$ & 1,187 & 1,$053 ; 1,339$ \\
\hline $\begin{array}{l}\text { Fragilidade } \\
\text { gama } \\
\text { (Breslow-Peto) }\end{array}$ & 1,252 & 1,$052 ; 1,490$ & 1,252 & 1,$053 ; 1,489$ & \multicolumn{2}{|c|}{ não disponivel } \\
\hline $\begin{array}{c}\text { Variância } \\
\text { Robusta } \\
\text { (Efron) }\end{array}$ & 1,191 & 1,$053 ; 1,348$ & 1,191 & 1,$053 ; 1,348$ & 1,191 & 1,$056 ; 1,344$ \\
\hline $\begin{array}{c}\text { Fragilidade } \\
\text { gama } \\
\text { (Efron) }\end{array}$ & 1,270 & 1,$056 ; 1,526$ & 1,270 & 1,$058 ; 1,524$ & \multicolumn{2}{|c|}{ não disponível } \\
\hline
\end{tabular}


(continuação da Tabela 5.3a)

\begin{tabular}{|c|c|c|c|c|c|c|}
\hline Modelo & \multicolumn{2}{|c|}{ Stata } & \multicolumn{2}{|c|}{ S-Plus } & \multicolumn{2}{|c|}{ SAS } \\
\hline \multicolumn{7}{|c|}{ Processos de contagem - restrito } \\
\hline & $\theta$ & $\mathrm{p}$ & $\theta$ & $\mathrm{p}$ & $\theta$ & $\mathrm{p}_{2}$ \\
\hline $\begin{array}{c}\text { Fragilidade } \\
\text { gama } \\
\text { (Breslow-Peto) }\end{array}$ & \multirow{2}{*}{\multicolumn{2}{|c|}{ não disponivel }} & 0,0000 & 1,0000 & \multirow{2}{*}{\multicolumn{2}{|c|}{ não disponivel }} \\
\hline $\begin{array}{l}\text { Fragilidade } \\
\text { gama } \\
\text { (Efron) }\end{array}$ & & & 0,0000 & 1,0000 & & \\
\hline & $H R$ & $\mathrm{IC}(H R)$ & $H R$ & $\mathrm{IC}(H R)$ & $H R$ & $\mathrm{IC}(H R)$ \\
\hline \multicolumn{7}{|c|}{ tratamento versus controle } \\
\hline $\begin{array}{c}\text { Variância } \\
\text { Robusta } \\
\text { (Breslow-Peto) }\end{array}$ & 0,716 & 0,$486 ; 1,053$ & 0,716 & 0,$486 ; 1,053$ & 0,716 & 0,$486 ; 1,053$ \\
\hline $\begin{array}{c}\text { Fragilidade } \\
\text { gama } \\
\text { (Breslow-Peto) }\end{array}$ & \multicolumn{2}{|c|}{ não disponivel } & 0,716 & 0,$469 ; 1,093$ & \multicolumn{2}{|c|}{ não disponivel } \\
\hline $\begin{array}{l}\text { Variância } \\
\text { Robusta } \\
\text { (Efron) } \\
\end{array}$ & 0,716 & 0,$480 ; 1,070$ & 0,716 & 0,$480 ; 1,070$ & 0,716 & 0,$487 ; 1,055$ \\
\hline $\begin{array}{c}\text { Fragilidade } \\
\text { gama } \\
\text { (Efron) }\end{array}$ & \multicolumn{2}{|c|}{ não disponível } & 0,716 & 0,$469 ; 1,094$ & \multicolumn{2}{|c|}{ não disponível } \\
\hline \multicolumn{7}{|c|}{ tamanho de tumores } \\
\hline $\begin{array}{c}\text { Variância } \\
\text { Robusta } \\
\text { (Breslow-Peto) }\end{array}$ & 0,992 & 0,$882 ; 1,116$ & 0,992 & 0,$882 ; 1,116$ & 0,992 & 0,$882 ; 1,116$ \\
\hline $\begin{array}{c}\text { Fragilidade } \\
\text { gama } \\
\text { (Breslow-Peto) }\end{array}$ & \multicolumn{2}{|c|}{ não disponivel } & 0,992 & 0,$860 ; 1,144$ & \multicolumn{2}{|c|}{ não disponivel } \\
\hline $\begin{array}{c}\text { Variância } \\
\text { Robusta } \\
\text { (Efron) }\end{array}$ & 0,992 & 0,$879 ; 1,119$ & 0,992 & 0,$879 ; 1,119$ & 0,992 & 0,$881 ; 1,116$ \\
\hline $\begin{array}{c}\text { Fragilidade } \\
\text { gama } \\
\text { (Efron) }\end{array}$ & \multicolumn{2}{|c|}{ não disponível } & 0,992 & 0,$860 ; 1,144$ & \multicolumn{2}{|c|}{ não disponível } \\
\hline \multicolumn{7}{|c|}{ números de tumores } \\
\hline $\begin{array}{c}\text { Variância } \\
\text { Robusta } \\
\text { (Breslow-Peto) }\end{array}$ & 1,123 & 1,$018 ; 1,238$ & 1,123 & 1,$018 ; 1,238$ & 1,123 & 1,$018 ; 1,238$ \\
\hline $\begin{array}{c}\text { Fragilidade } \\
\text { gama } \\
\text { (Breslow-Peto) }\end{array}$ & \multicolumn{2}{|c|}{ não disponivel } & 1,123 & 1,$010 ; 1,247$ & \multicolumn{2}{|c|}{ não disponivel } \\
\hline $\begin{array}{c}\text { Variância } \\
\text { Robusta } \\
\text { (Efron) }\end{array}$ & 1,127 & 1,$019 ; 1,246$ & 1,127 & 1,$019 ; 1,246$ & 1,127 & 1,$022 ; 1,242$ \\
\hline $\begin{array}{c}\text { Fragilidade } \\
\text { gama } \\
\text { (Efron) } \\
\end{array}$ & \multicolumn{2}{|c|}{ não disponivel } & 1,127 & 1,$015 ; 1,251$ & \multicolumn{2}{|c|}{ não disponivel } \\
\hline
\end{tabular}


(continuação da Tabela 5.3a)

\begin{tabular}{|c|c|c|c|c|c|c|}
\hline Modelo & \multicolumn{2}{|r|}{ Stata } & \multicolumn{2}{|c|}{ S-Plus } & \multicolumn{2}{|r|}{ SAS } \\
\hline \multicolumn{7}{|c|}{ Tempo total - irrestrito } \\
\hline & $\theta$ & $\mathrm{p}$ & $\theta$ & $\mathrm{p}$ & $\theta$ & $\mathrm{p}_{2}$ \\
\hline $\begin{array}{c}\text { Fragilidade } \\
\text { gama } \\
\text { (Breslow-Peto) }\end{array}$ & 0,1320 & 0,2433 & 0,1314 & 0,4865 & & \\
\hline $\begin{array}{c}\text { Fragilidade } \\
\text { gama } \\
\text { (Efron) }\end{array}$ & 0,2042 & 0,1507 & 0,1970 & 0,3017 & & disponível \\
\hline & $H R$ & $\mathrm{IC}(H R)$ & $H R$ & $\mathrm{IC}(H R)$ & $H R$ & $\mathrm{IC}(H R)$ \\
\hline \multicolumn{7}{|c|}{ tratamento versus controle } \\
\hline $\begin{array}{c}\text { Variância } \\
\text { Robusta } \\
\text { (Breslow-Peto) }\end{array}$ & 0,632 & 0,$426 ; 0,939$ & 0,632 & 0,$426 ; 0,939$ & 0,632 & 0,$426 ; 0,939$ \\
\hline $\begin{array}{l}\text { Fragilidade } \\
\text { gama } \\
\text { (Breslow-Peto) }\end{array}$ & 0,619 & 0,$396 ; 0,967$ & 0,619 & 0,$396 ; 0,967$ & & \\
\hline $\begin{array}{c}\text { Variância } \\
\text { Robusta } \\
\text { (Efron) }\end{array}$ & 0,629 & 0,$421 ; 0,941$ & 0,629 & 0,$421 ; 0,941$ & 0,629 & 0,$424 ; 0,934$ \\
\hline $\begin{array}{c}\text { Fragilidade } \\
\text { gama } \\
\text { (Efron) } \\
\end{array}$ & 0,610 & 0,$381 ; 0,975$ & 0,610 & 0,$382 ; 0,974$ & & disponível \\
\hline \multicolumn{7}{|c|}{ tamanho de tumores } \\
\hline $\begin{array}{c}\text { Variância } \\
\text { Robusta } \\
\text { (Breslow-Peto) }\end{array}$ & 0,973 & 0,$861 ; 1,100$ & 0,973 & 0,$862 ; 1,100$ & 0,973 & 0,$861 ; 1,100$ \\
\hline $\begin{array}{l}\text { Fragilidade } \\
\text { gama } \\
\text { (Breslow-Peto) }\end{array}$ & 0,980 & 0,$845 ; 0,137$ & 0,980 & 0,$845 ; 1,137$ & & \\
\hline $\begin{array}{c}\text { Variância } \\
\text { Robusta } \\
\text { (Efron) }\end{array}$ & 0,973 & 0,$859 ; 1,101$ & 0,973 & 0,$859 ; 1,101$ & 0,973 & 0,$861 ; 1,099$ \\
\hline $\begin{array}{c}\text { Fragilidade } \\
\text { gama } \\
\text { (Efron) }\end{array}$ & 0,982 & 0,$840 ; 1,148$ & 0,982 & 0,$840 ; 1,147$ & & disponível \\
\hline \multicolumn{7}{|c|}{ números de tumores } \\
\hline $\begin{array}{c}\text { Variância } \\
\text { Robusta } \\
\text { (Breslow-Peto) }\end{array}$ & 1,125 & 1,$018 ; 1,244$ & 1,125 & 1,$018 ; 1,244$ & 1,125 & 1,$018 ; 1,244$ \\
\hline $\begin{array}{l}\text { Fragilidade } \\
\text { gama } \\
\text { (Breslow-Peto) }\end{array}$ & 1,146 & 1,$022 ; 1,286$ & 1,146 & 1,$022 ; 1,285$ & & \\
\hline $\begin{array}{l}\text { Variância } \\
\text { Robusta } \\
\text { (Efron) }\end{array}$ & 1,127 & 1,$018 ; 1,248$ & 1,127 & 1,$018 ; 1,248$ & 1,127 & 1,$019 ; 1,246$ \\
\hline $\begin{array}{c}\text { Fragilidade } \\
\text { gama } \\
\text { (Efron) }\end{array}$ & 1,159 & 1,$025 ; 1,310$ & 1,158 & 1,$025 ; 1,308$ & & disponivel \\
\hline
\end{tabular}

(continua) 
(continuação da Tabela 5.3a)

\begin{tabular}{|c|c|c|c|c|c|c|}
\hline Modelo & \multicolumn{2}{|c|}{ Stata } & \multicolumn{2}{|r|}{ S-Plus } & \multicolumn{2}{|c|}{ SAS } \\
\hline \multicolumn{7}{|c|}{ Tempo total - semi-restrito } \\
\hline & $\theta$ & $\mathrm{p}$ & $\theta$ & $\mathrm{p}$ & $\theta$ & $\mathrm{p}_{2}$ \\
\hline $\begin{array}{c}\begin{array}{c}\text { Fragilidade } \\
\text { gama } \\
\text { (Breslow-Peto) }\end{array} \\
\begin{array}{c}\text { Fragilidade } \\
\text { gama } \\
\text { (Efron) }\end{array} \\
\end{array}$ & \multicolumn{2}{|c|}{ não disponível } & & & \multicolumn{2}{|c|}{ não disponível } \\
\hline & $H R$ & $\mathrm{IC}(H R)$ & $H R$ & $\mathrm{IC}(H R)$ & $H R$ & $\mathrm{IC}(H R)$ \\
\hline \multicolumn{7}{|c|}{ tratamento versus controle } \\
\hline $\begin{array}{c}\text { Variância } \\
\text { Robusta } \\
\text { (Breslow-Peto) }\end{array}$ & 0,560 & 0,$390 ; 1,015$ & \multirow{2}{*}{$\begin{array}{l}0,560 \\
0,557\end{array}$} & \multirow{2}{*}{$\begin{array}{l}0,390 ; 1,015 \\
0,305 ; 1,019\end{array}$} & 0,560 & 0,$390 ; 1,015$ \\
\hline $\begin{array}{c}\text { Variância } \\
\text { Robusta } \\
\text { (Efron) }\end{array}$ & 0,557 & 0,$305 ; 1,019$ & & & 0,557 & 0,$308 ; 1,010$ \\
\hline \multicolumn{7}{|c|}{ tamanho de tumores } \\
\hline $\begin{array}{c}\text { Variância } \\
\text { Robusta } \\
\text { (Breslow-Peto) } \\
\end{array}$ & 0,950 & 0,$792 ; 1,140$ & 0,950 & 0,$792 ; 1,140$ & 0,950 & 0,$792 ; 1,140$ \\
\hline $\begin{array}{c}\text { Variância } \\
\text { Robusta } \\
\text { (Efron) }\end{array}$ & 0,950 & 0,$789 ; 1,143$ & 0,950 & 0,$789 ; 1,143$ & 0,950 & 0,$791 ; 1,140$ \\
\hline \multicolumn{7}{|c|}{ números de tumores } \\
\hline $\begin{array}{c}\text { Variância } \\
\text { Robusta } \\
\text { (Breslow-Peto) }\end{array}$ & 1,232 & 1,$083 ; 1,401$ & 1,232 & 1,$083 ; 1,401$ & 1,232 & 1,$083 ; 1,401$ \\
\hline $\begin{array}{c}\text { Variância } \\
\text { Robusta } \\
\text { (Efron) }\end{array}$ & 1,234 & 1,$083 ; 1,406$ & 1,234 & 1,$083 ; 1,406$ & 1,234 & 1,$085 ; 1,403$ \\
\hline \multicolumn{7}{|c|}{ Tempo total - restrito } \\
\hline & $\theta$ & $\mathrm{p}$ & $\theta$ & $\mathrm{p}$ & $\theta$ & $\mathrm{p}_{2}$ \\
\hline $\begin{array}{c}\text { Fragilidade } \\
\text { gama } \\
\text { (Breslow-Peto) }\end{array}$ & \multirow{2}{*}{\multicolumn{2}{|c|}{ não disponível }} & 1,5769 & 0,0022 & \multirow{2}{*}{\multicolumn{2}{|c|}{ não disponivel }} \\
\hline $\begin{array}{c}\text { Fragilidade } \\
\text { gama } \\
\text { (Efron) }\end{array}$ & & & & & & \\
\hline & $H R$ & $\mathrm{IC}(H R)$ & $H R$ & $\mathrm{IC}(H R)$ & $H R$ & $\mathrm{IC}(H R)$ \\
\hline \multicolumn{7}{|c|}{ tratamento versus controle } \\
\hline $\begin{array}{c}\text { Variância } \\
\text { Robusta } \\
\text { (Breslow-Peto) }\end{array}$ & 0,596 & 0,$392 ; 0,907$ & 0,597 & 0,$392 ; 0,907$ & 0,597 & 0,$392 ; 0,907$ \\
\hline $\begin{array}{c}\text { Fragilidade } \\
\text { gama } \\
\text { (Breslow-Peto) }\end{array}$ & \multicolumn{2}{|c|}{ não disponível } & 0,467 & 0,$213 ; 1,024$ & \multicolumn{2}{|c|}{ não disponível } \\
\hline $\begin{array}{l}\text { Variância } \\
\text { Robusta } \\
\text { (Efron) }\end{array}$ & 0,589 & 0,$384 ; 0,905$ & 0,589 & 0,$384 ; 0,906$ & 0,589 & 0,$387 ; 0,897$ \\
\hline \multicolumn{7}{|c|}{ tamanho de tumores } \\
\hline $\begin{array}{c}\text { Variância } \\
\text { Robusta } \\
\text { (Breslow-Peto) }\end{array}$ & 0,992 & 0,$869 ; 1,133$ & 0,992 & 0,$869 ; 1,133$ & 0,992 & 0,$869 ; 1,133$ \\
\hline $\begin{array}{c}\text { Fragilidade } \\
\text { gama } \\
\text { (Breslow-Peto) }\end{array}$ & & disponível & 1,069 & 0,$815 ; 1,401$ & & disponível \\
\hline $\begin{array}{c}\text { Variância } \\
\text { Robusta } \\
\text { (Efron) }\end{array}$ & 0,992 & 0,$866 ; 1,135$ & 0,992 & 0,$866 ; 1,135$ & 0,992 & 0,$869 ; 1,132$ \\
\hline
\end{tabular}


(continuação da Tabela 5.3a)

\begin{tabular}{|c|c|c|c|c|c|c|}
\hline Modelo & \multicolumn{2}{|c|}{ Stata } & \multicolumn{2}{|c|}{ S-Plus } & \multicolumn{2}{|r|}{ SAS } \\
\hline & $H R$ & $\mathrm{IC}(H R)$ & $H R$ & $\mathrm{IC}(H R)$ & $H R$ & $\mathrm{IC}(H R)$ \\
\hline \multicolumn{7}{|c|}{ números de tumores } \\
\hline $\begin{array}{c}\text { Variancia } \\
\text { Robusta } \\
\text { (Brealow-Peto) }\end{array}$ & 1,108 & 1,$001 ; 1,227$ & 1,108 & 1,$001 ; 1,227$ & 1,108 & 1,$001 ; 1,227$ \\
\hline $\begin{array}{c}\text { Fragilidade } \\
\text { gama } \\
\text { (Brualow-Peto) }\end{array}$ & \multicolumn{2}{|c|}{ não disponivel } & 1,344 & 1,$069 ; 1,690$ & \multicolumn{2}{|c|}{ não disponivel } \\
\hline $\begin{array}{l}\text { Variância } \\
\text { Robusta } \\
\text { (Efron) }\end{array}$ & 1,111 & 1,$000 ; 1,234$ & 1,111 & 1,$000 ; 1,234$ & 1,111 & 1,$004 ; 1,230$ \\
\hline \multicolumn{7}{|c|}{ Tempo entre eventos - irrestrito } \\
\hline & $\theta$ & p & $\theta$ & p & $\theta$ & $p_{2}$ \\
\hline $\begin{array}{c}\text { Fragilidade } \\
\text { gama } \\
\text { (Broslow-Peto) }\end{array}$ & 0,4547 & 0,0251 & 0,4540 & 0,0501 & 0,4547 & $0,0501 \quad 0,1358$ \\
\hline $\begin{array}{c}\text { Fragilidade } \\
\text { gama } \\
\text { (Efroo) }\end{array}$ & 0,6436 & 0,0044 & 0,6439 & 0,0088 & & 0 disponivel \\
\hline & $H R$ & $\mathrm{IC}(H R)$ & $H R$ & $\mathrm{IC}(H R)$ & $H R$ & $\mathrm{IC}(H R)$ \\
\hline \multicolumn{7}{|c|}{ tratamento versus controle } \\
\hline $\begin{array}{c}\text { Variância } \\
\text { Robusta } \\
\text { (Brealow-Peto) }\end{array}$ & 0,693 & 0,$443 ; 1,082$ & 0,693 & 0,$443 ; 1,082$ & 0,693 & 0,$443 ; 1,082$ \\
\hline $\begin{array}{c}\text { Fragilidade } \\
\text { ganna } \\
\text { (Brealow-Peto) }\end{array}$ & 0,651 & 0,$387 ; 1,097$ & 0,651 & 0,$387 ; 1,097$ & 0,651 & nāo disponivel \\
\hline $\begin{array}{c}\text { Variancia } \\
\text { Robusta } \\
\text { (Efron) }\end{array}$ & 0,688 & 0,$434 ; 1,091$ & 0,688 & 0,$434 ; 1,091$ & 0,688 & 0,$440 ; 1,075$ \\
\hline $\begin{array}{c}\text { Fragilidade } \\
\text { gama } \\
\text { (Efon) }\end{array}$ & 0,636 & 0,$361 ; 1,118$ & 0,636 & 0,$362 ; 1,118$ & & 0 disponivel \\
\hline \multicolumn{7}{|c|}{ tamanho de tumores } \\
\hline $\begin{array}{c}\text { Variância } \\
\text { Robusta } \\
\text { (Brealow-Peto) }\end{array}$ & 0,980 & 0,$862 ; 1,115$ & 0,980 & 0,$862 ; 1,115$ & 0,980 & 0,$862 ; 1,115$ \\
\hline $\begin{array}{c}\text { Fragilidade } \\
\text { gama } \\
\text { (Breslow-Peto) }\end{array}$ & 0,995 & 0,$835 ; 1,186$ & 0,995 & 0,$835 ; 1,186$ & 0,995 & não disponível \\
\hline $\begin{array}{c}\text { Variância } \\
\text { Robusta } \\
\text { (Efron) }\end{array}$ & 0,980 & 0,$858 ; 1,119$ & 0,980 & 0,$858 ; 1,119$ & 0,980 & 0,$862 ; 1,115$ \\
\hline $\begin{array}{c}\text { Fragilidade } \\
\text { gama } \\
\text { (Efroa) }\end{array}$ & 1,002 & 0,$829 ; 1,211$ & 1,002 & 0,$828 ; 1,213$ & & o disponivel \\
\hline \multicolumn{7}{|c|}{ números de tumores } \\
\hline $\begin{array}{c}\text { Vaniancia } \\
\text { Robusta } \\
\text { (Brelow-Peto) }\end{array}$ & 1,168 & 1,$055 ; 1,293$ & 1,168 & 1,$055 ; 1,293$ & 1,168 & 1,$055 ; 1,293$ \\
\hline $\begin{array}{c}\text { Fragilidade } \\
\text { gems } \\
\text { (Brealow-Peto) }\end{array}$ & 1,216 & 1,$056 ; 1,399$ & 1,216 & 1,$057 ; 1,398$ & 1,216 & não disponivel \\
\hline $\begin{array}{c}\text { Varifincia } \\
\text { Robusta } \\
\text { (Efroo) }\end{array}$ & 1,172 & 1,$056 ; 1,301$ & 1,172 & 1,$056 ; 1,301$ & 1,172 & 1,$058 ; 1,298$ \\
\hline $\begin{array}{c}\text { Fragilidade } \\
\text { gama } \\
\text { (Efroa) }\end{array}$ & 1,242 & 1,$063 ; 1,452$ & 1,242 & 1,$064 ; 1,450$ & & o disponivel \\
\hline
\end{tabular}


(continuação da Tabela 5.3a)

\begin{tabular}{|c|c|c|c|c|c|c|}
\hline Modelo & \multicolumn{2}{|c|}{ Stata } & \multicolumn{2}{|c|}{ S-Plus } & \multicolumn{2}{|c|}{ SAS } \\
\hline & $H R$ & $\mathrm{IC}(H R)$ & $H R$ & $\mathrm{IC}(H R)$ & $H R$ & $\mathrm{IC}(H R)$ \\
\hline \multicolumn{7}{|c|}{ Tempo entre eventos - restrito } \\
\hline & $\theta$ & $\mathbf{p}$ & $\theta$ & p & $\theta$ & $\mathrm{p}_{2}$ \\
\hline $\begin{array}{c}\text { Fragilidade } \\
\text { gama } \\
\text { (Breslow-Peto) } \\
\ldots .\end{array}$ & \multirow{2}{*}{\multicolumn{2}{|c|}{ não disponivel }} & 0,0000 & 1,0000 & \multirow{2}{*}{\multicolumn{2}{|c|}{ não disponivel }} \\
\hline $\begin{array}{c}\text { Fragilidade } \\
\text { gama } \\
\text { (Efron) } \\
\end{array}$ & & & 0,0000 & 1,0000 & & \\
\hline & $H R$ & $\mathrm{IC}(H R)$ & $H R$ & $\mathrm{IC}(H R)$ & $H R$ & $\mathrm{IC}(H R)$ \\
\hline \multicolumn{7}{|c|}{ tratamento versus controle } \\
\hline $\begin{array}{c}\text { Variância } \\
\text { Robusta } \\
\text { (Breslow-Peto) } \\
\end{array}$ & 0,764 & 0,$508 ; 1,148$ & 0,764 & 0,$508 ; 1,148$ & 0,764 & 0,$508 ; 1,148$ \\
\hline $\begin{array}{c}\text { Fragilidade } \\
\text { gama } \\
\text { (Breslow-Peto) }\end{array}$ & \multicolumn{2}{|c|}{ não disponivel } & 0,764 & 0,$508 ; 1,147$ & \multicolumn{2}{|c|}{ não disponível } \\
\hline $\begin{array}{c}\text { Variância } \\
\text { Robusta } \\
\text { (Efron) }\end{array}$ & 0,757 & 0,$496 ; 1,154$ & 0,757 & 0,$496 ; 1,154$ & 0,757 & 0,$503 ; 1,138$ \\
\hline $\begin{array}{c}\text { Fragilidade } \\
\text { gama } \\
\text { (Efron) }\end{array}$ & \multicolumn{2}{|c|}{ não disponivel } & 0,757 & 0,$504 ; 1,136$ & \multicolumn{2}{|c|}{ não disponível } \\
\hline \multicolumn{7}{|c|}{ tamanho de tumores } \\
\hline $\begin{array}{c}\text { Variância } \\
\text { Robusta } \\
\text { (Breslow-Peto) } \\
\end{array}$ & 1,007 & 0,$891 ; 1,137$ & 1,007 & 0,$891 ; 1,137$ & 1,007 & 0,$891 ; 1,137$ \\
\hline $\begin{array}{c}\text { Fragilidade } \\
\text { gama } \\
\text { (Breslow-Peto) } \\
\end{array}$ & \multicolumn{2}{|c|}{ não disponivel } & 1,007 & 0,$878 ; 1,155$ & \multicolumn{2}{|c|}{ não disponivel } \\
\hline $\begin{array}{l}\text { Variância } \\
\text { Robusta } \\
\text { (Efron) } \\
\end{array}$ & 1,007 & 0,$888 ; 1,143$ & 1,007 & 0,$888 ; 1,143$ & 1,007 & 0,$891 ; 1,139$ \\
\hline $\begin{array}{c}\begin{array}{c}\text { Fragilidade } \\
\text { gama }\end{array} \\
\text { (Efron) } \\
\end{array}$ & \multicolumn{2}{|c|}{ não disponivel } & 1,007 & 0,$878 ; 1,156$ & \multicolumn{2}{|c|}{ não disponivel } \\
\hline \multicolumn{7}{|c|}{ números de tumores } \\
\hline $\begin{array}{c}\text { Variância } \\
\text { Robusta } \\
\text { (Breslow-Peto) } \\
\end{array}$ & 1,166 & 1,$059 ; 1,283$ & 1,166 & 1,$059 ; 1,283$ & 1,166 & 1,$059 ; 1,283$ \\
\hline $\begin{array}{c}\text { Fragilidade } \\
\text { gama } \\
\text { (Breslow-Peto) }\end{array}$ & \multicolumn{2}{|c|}{ não disponivel } & 1,166 & 1,$053 ; 1,291$ & \multicolumn{2}{|c|}{ não disponivel } \\
\hline $\begin{array}{l}\text { Variância } \\
\text { Robusta } \\
\text { (Efron) }\end{array}$ & 1,171 & 1,$060 ; 1,294$ & 1,171 & 1,$060 ; 1,294$ & 1,171 & 1,$064 ; 1,290$ \\
\hline $\begin{array}{c}\text { Fragilidade } \\
\text { gama } \\
\text { (Efron) } \\
\end{array}$ & \multicolumn{2}{|c|}{ não disponivel } & 1,171 & 1,$058 ; 1,297$ & \multicolumn{2}{|c|}{ não disponivel } \\
\hline
\end{tabular}


Tabela 5.3b - Estimativas da razão de taxas de falha $(H R)$ e da variância $(\theta)$ da fragilidade gama, para a $1^{a}$ recorrência de tumor, segundo alguns modelos semiparamétricos para dados univariados e programas computacionais

\begin{tabular}{|c|c|c|c|c|c|c|}
\hline \multirow{2}{*}{ Modelo } & \multicolumn{2}{|r|}{ Stata } & \multicolumn{2}{|c|}{ S-Plus } & \multicolumn{2}{|c|}{ SAS } \\
\hline & $\theta$ & $\mathrm{p}$ & $\theta$ & $\mathrm{p}$ & $\theta$ & $\mathrm{p}_{2}$ \\
\hline $\begin{array}{c}\text { Fragilidade } \\
\text { gama } \\
\text { (Breslow-Peto) }\end{array}$ & & & 0,0000 & 1,0000 & & \\
\hline $\begin{array}{c}\text { Fragilidade } \\
\text { gama } \\
\text { (Efron) }\end{array}$ & & & 0,0000 & 1,0000 & & disponível \\
\hline \multicolumn{2}{|r|}{$H R$} & $\mathrm{IC}(H R)$ & $H R$ & $\mathrm{IC}(H R)$ & $H R$ & $\mathrm{IC}(H R)$ \\
\hline \multicolumn{7}{|c|}{ tratamento versus controle } \\
\hline $\begin{array}{c}\text { Cox } \\
\text { (Breslow-Peto) }\end{array}$ & 0,596 & 0,$321 ; 1,107$ & 0,596 & 0,$321 ; 1,107$ & 0,596 & 0,$321 ; 1,107$ \\
\hline $\begin{array}{c}\text { Variância } \\
\text { Robusta } \\
\text { (Breslow-Peto) }\end{array}$ & 0,596 & 0,$326 ; 1,089$ & 0,596 & 0,$326 ; 1,089$ & 0,596 & 0,$326 ; 1,089$ \\
\hline $\begin{array}{c}\text { Fragilidade } \\
\text { gama } \\
\text { (Breslow-Peto) }\end{array}$ & & & 0,596 & 0,$321 ; 1,107$ & & \\
\hline $\begin{array}{c}\text { Cox } \\
\text { (Efron) }\end{array}$ & 0,591 & 0,$318 ; 1,097$ & 0,591 & 0,$318 ; 1,098$ & 0,591 & 0,$318 ; 1,098$ \\
\hline $\begin{array}{l}\text { Variância } \\
\text { Robusta } \\
\text { (Efron) }\end{array}$ & 0,591 & 0,$319 ; 1,096$ & 0,591 & 0,$319 ; 1,096$ & 0,591 & 0,$323 ; 1,080$ \\
\hline $\begin{array}{l}\text { Fragilidade } \\
\text { gama } \\
\text { (Efron) } \\
\end{array}$ & & & 0,591 & 0,$318 ; 1,097$ & & disponível \\
\hline \multicolumn{7}{|c|}{ tamanho do tumor } \\
\hline $\begin{array}{c}\text { Cox } \\
\text { (Breslow-Peto) }\end{array}$ & 1,070 & 0,$878 ; 1,305$ & 1,070 & 0,$878 ; 1,305$ & 1,070 & 0,$878 ; 1,305$ \\
\hline $\begin{array}{c}\text { Variância } \\
\text { Robusta } \\
\text { (Breslow-Peto) }\end{array}$ & 1,070 & 0,$906 ; 1,265$ & 1,070 & 0,$906 ; 1,265$ & 1,070 & 0,$906 ; 1,265$ \\
\hline $\begin{array}{c}\text { Fragilidade } \\
\text { gama } \\
\text { (Breslow-Peto) }\end{array}$ & & & 1,070 & 0,$878 ; 1,305$ & & \\
\hline $\begin{array}{c}\text { Cox } \\
\text { (Efron) }\end{array}$ & 1,072 & 0,$879 ; 1,308$ & 1,072 & 0,$879 ; 1,308$ & 1,072 & 0,$879 ; 1,308$ \\
\hline $\begin{array}{c}\text { Variância } \\
\text { Robusta } \\
\text { (Efron) }\end{array}$ & 1,072 & 0,$901 ; 1,275$ & 1,072 & 0,$901 ; 1,276$ & 1,072 & 0,$906 ; 1,268$ \\
\hline $\begin{array}{c}\text { Fragilidade } \\
\text { gama } \\
\text { (Efron) }\end{array}$ & & & 1,072 & 0,$879 ; 1,308$ & & disponível \\
\hline \multicolumn{7}{|c|}{ número de tumores } \\
\hline $\begin{array}{c}\text { Cox } \\
\text { (Breslow-Peto) }\end{array}$ & 1,266 & 1,$091 ; 1,470$ & 1,266 & 1,$091 ; 1,470$ & 1,266 & 1,$091 ; 1,470$ \\
\hline $\begin{array}{l}\text { Variância } \\
\text { Robusta } \\
\text { (Breslow-Peto) }\end{array}$ & 1,266 & 1,$099 ; 1,458$ & 1,266 & 1,$099 ; 1,458$ & 1,266 & 1,$099 ; 1,458$ \\
\hline $\begin{array}{c}\text { Fragilidade } \\
\text { gama } \\
\text { (Breslow-Peto) }\end{array}$ & & & 1,266 & 1,$091 ; 1,470$ & & \\
\hline $\begin{array}{l}\text { Cox } \\
\text { (Efron) }\end{array}$ & 1,269 & 1,$094 ; 1,472$ & 1,269 & 1,$094 ; 1,472$ & 1,269 & 1,$094 ; 1,472$ \\
\hline $\begin{array}{c}\text { Variância } \\
\begin{array}{c}\text { Robusta } \\
\text { (Efron) }\end{array} \\
\end{array}$ & 1,269 & 1,$096 ; 1,469$ & 1,269 & 1,$096 ; 1,469$ & 1,269 & 1,$102 ; 1,461$ \\
\hline $\begin{array}{c}\text { Fragilidade } \\
\text { gama } \\
\text { (Efron) } \\
\end{array}$ & & & 1,269 & 1,$094 ; 1,472$ & & lisponível \\
\hline
\end{tabular}


Figura 5.3 - Intervalos de confiança da razão de taxas de falha para os dados do Estudo 3, segundo alguns modelos semiparamétricos para eventos recorrentes e para $1^{\mathrm{a}}$ recorrência, usando a aproximação Efron e o programa S-Plus

a) $H R$ entre tratamento e controle

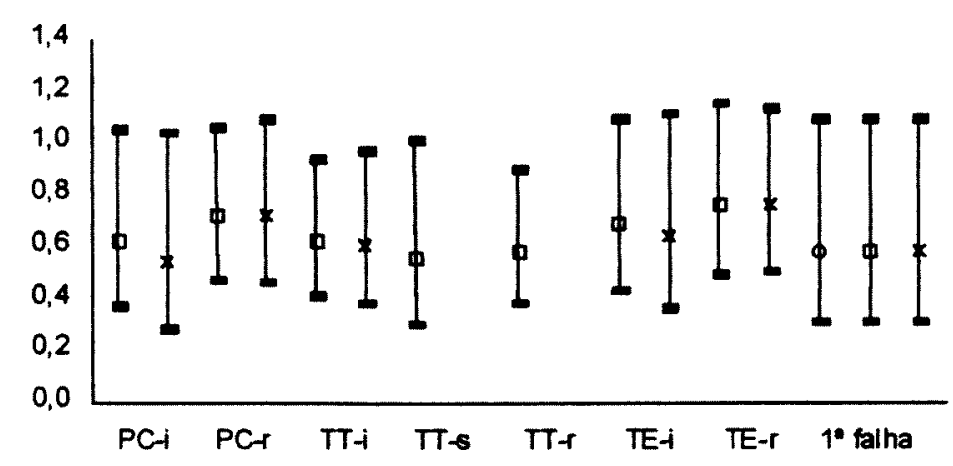

b) $H R$ para tamanhos de tumores

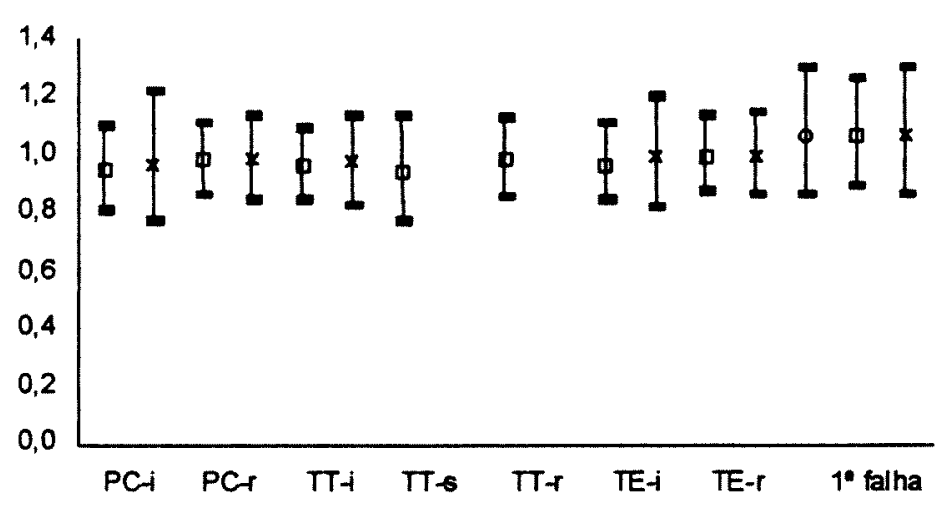

c) $H R$ para números de tumores

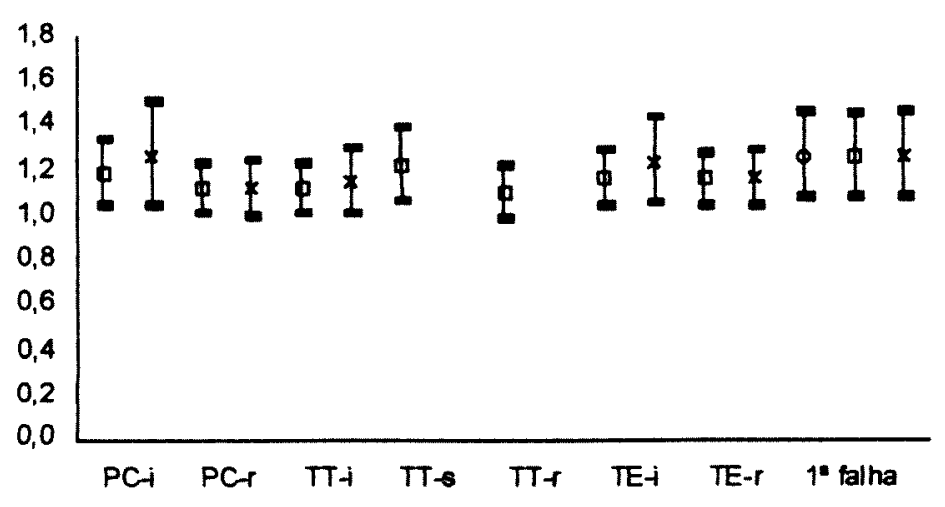

$\circ$ Cox

$\square$ Variância Robusta

$\times$ Fragilidade 
Pela Figura 5.3, que considera somente os resultados do S-Plus com aproximação Efron, verifica-se que as estimativas $H R$ não são acentuadamente diferentes, a não ser para a covariável indicadora de tratamento (a), onde nos modelos TT irrestrito e restrito (que, neste caso, não são os mais indicados), HR é significativo e estimado ser menor que 1 ; nos demais modelos, $H R$ entre tratamento e controle não é significativo. As estimativas de $H R$ para número de tumores (c) indicam que o efeito de número de tumores é significativo, portanto ter vários tumores é fator de risco para recorrências. Pela análise com a $1^{\mathrm{a}}$ recorrência, obtiveram-se resultados semelhantes à análise com eventos recorrentes. Esta semelhança entre as análises para dados univariados e multivariados era esperada, pois pelos modelos mais adequados para eventos recorrentes pode-se concluir que não há correlação intra-indivíduo.

\section{Estudos 4 e 5: febre e morbidades infantis}

Esses dois conjuntos de dados são de uma coorte de 450 crianças e são exemplos de eventos recorrentes. As covariáveis incluídas nos modelos são: $x_{j 1}$, indicadora de parto fórceps para a criança $j, x_{j 2}$, indicadora de parto cesariana para a criança $j$ e $x_{j 3}$, indicadora de mãe fumante, antes da gestação, para a criança $j(j=1,2, \ldots, 450)$.

O Estudo 4 considera todas as ocorrências de febre que foram registradas pela mãe até os 90 dias de idade da criança. De acordo com a Tabela 5.4a, verifica-se, para os modelos de fragilidade gama, que com relação a significância do parâmetro $\theta$, os resultados são semelhantes aos do Estudo 3 . A distinção é no modelo TE - irrestrito com B-P em que um dos dois resultados apresentados pelo SAS diferiu dos resultados do STATA e do S-Plus. Se for razoável aceitar que uma ocorrência de febre afeta as demais (sem independência entre eventos), então, de acordo com os modelos PC - restrito com B-P e E, e GT - restrito com B-P e E, pode-se concluir que $\theta$ não é significativo e portanto não há correlação intra-indivíduo. 
Tabela 5.4a - Estimativas da razão de taxas de falha $(H R)$ e da variância $(\theta)$ da fragilidade gama para os dados do Estudo 4, segundo alguns modelos semiparamétricos para eventos recorrentes e programas computacionais

\begin{tabular}{|c|c|c|c|c|c|c|}
\hline Modelo & \multicolumn{2}{|c|}{ Stata } & \multicolumn{2}{|c|}{ S-Plus } & \multicolumn{2}{|c|}{ SAS } \\
\hline \multicolumn{7}{|c|}{ Processos de contagem - irrestrito } \\
\hline & $\theta$ & $\mathbf{p}$ & $\theta$ & $\mathbf{p}$ & $\theta$ & $\mathrm{p}_{2}$ \\
\hline $\begin{array}{c}\text { Fragilidade } \\
\text { gama } \\
\text { (Breslow-Peto) }\end{array}$ & 0,4374 & 0,0151 & 0,4352 & 0,0302 & \multirow{2}{*}{\multicolumn{2}{|c|}{ não disponivel }} \\
\hline $\begin{array}{c}\text { Fragilidade } \\
\text { gama } \\
\text { (Efron) } \\
\end{array}$ & 0,4766 & 0,0103 & 0,4685 & 0,0206 & & \\
\hline & $H R$ & $\mathrm{IC}(H R)$ & $H R$ & $\mathrm{IC}(H R)$ & $H R$ & $\mathrm{IC}(H R)$ \\
\hline \multicolumn{7}{|c|}{ mãe fumante versus não-fumante } \\
\hline $\begin{array}{c}\text { Variância } \\
\text { Robusta } \\
\text { (Breslow-Peto) }\end{array}$ & 1,180 & 0,$779 ; 1,787$ & 1,180 & 0,$779 ; 1,787$ & 1,180 & 0,$779 ; 1,787$ \\
\hline $\begin{array}{c}\text { Fragilidade } \\
\text { gama } \\
\text { (Breslow-Peto) }\end{array}$ & 1,177 & 0,$781 ; 1,773$ & 1,177 & 0,$781 ; 1,773$ & & lisponivel \\
\hline $\begin{array}{c}\text { Variància } \\
\text { Robusta } \\
\text { (Efron) } \\
\end{array}$ & 1,180 & 0,$777 ; 1,793$ & 1,180 & 0,$777 ; 1,793$ & 1,180 & 0,$779 ; 1,788$ \\
\hline $\begin{array}{c}\text { Fragilidade } \\
\text { gama } \\
\text { (Efron) }\end{array}$ & 1,178 & 0,$779 ; 1,779$ & 1,178 & 0,$780 ; 1,779$ & & disponivel \\
\hline \multicolumn{7}{|c|}{ parto fórceps versus normal } \\
\hline $\begin{array}{c}\text { Variância } \\
\text { Robusta } \\
\text { (Breablow-Peto) }\end{array}$ & 1,572 & 1,$001 ; 2,470$ & 1,573 & 1,$002 ; 2,471$ & 1,572 & 1,$001 ; 2,470$ \\
\hline $\begin{array}{c}\text { Fragilidade } \\
\text { gama } \\
\text { (Brestow-Peto) }\end{array}$ & 1,570 & 1,$032 ; 2,389$ & 1,570 & 1,$032 ; 2,388$ & & disponivel \\
\hline $\begin{array}{c}\text { Variância } \\
\text { Robusta } \\
\text { (Efron) }\end{array}$ & 1,577 & 1,$001 ; 2,484$ & 1,579 & 1,$002 ; 2,486$ & 1,577 & 1,$004 ; 2,478$ \\
\hline $\begin{array}{c}\text { Fragilidade } \\
\text { gama } \\
\text { (Efron) }\end{array}$ & 1,577 & 1,$033 ; 2,407$ & 1,577 & 1,$034 ; 2,405$ & & disponivel \\
\hline \multicolumn{7}{|c|}{ parto cesariana versus normal } \\
\hline $\begin{array}{c}\text { Variância } \\
\text { Robusta } \\
\text { (Brestow-Peto) }\end{array}$ & 1,052 & 0,$707 ; 1,567$ & 1,052 & 0,$707 ; 1,567$ & 1,052 & 0,$707 ; 1,567$ \\
\hline $\begin{array}{c}\text { Fragilidade } \\
\text { gama } \\
\text { (Brealow-Peto) }\end{array}$ & 1,053 & 0,$699 ; 1,586$ & 1,053 & 0,$699 ; 1,586$ & \multicolumn{2}{|c|}{ não disponivel } \\
\hline $\begin{array}{l}\text { Variância } \\
\text { Robusta } \\
\text { (Efron) }\end{array}$ & 1,053 & 0,$706 ; 1,570$ & 1,053 & 0,$706 ; 1,570$ & 1,053 & 0,$707 ; 1,567$ \\
\hline $\begin{array}{c}\text { Fragilidade } \\
\text { gama } \\
\text { (Efron) }\end{array}$ & 1,054 & 0,$698 ; 1,590$ & 1,054 & 0,$698 ; 1,590$ & \multicolumn{2}{|c|}{ não disponivel } \\
\hline
\end{tabular}


(continuação da Tabela 5.4a)

\begin{tabular}{|c|c|c|c|c|c|c|}
\hline Modelo & \multicolumn{2}{|c|}{ Stata } & \multicolumn{2}{|c|}{ S-Plus } & \multicolumn{2}{|r|}{ SAS } \\
\hline \multicolumn{7}{|c|}{ Processos de contagem - restrito } \\
\hline & $\theta$ & $\mathrm{p}$ & $\theta$ & $\mathbf{p}$ & $\theta$ & $p_{2}$ \\
\hline $\begin{array}{c}\text { Fragilidade } \\
\text { gama } \\
\text { (Breslow-Peto) }\end{array}$ & \multirow{2}{*}{\multicolumn{2}{|c|}{ não disponível }} & 0,0000 & 1,0000 & \multirow{2}{*}{\multicolumn{2}{|c|}{ não disponivel }} \\
\hline $\begin{array}{c}\text { Fragilidade } \\
\text { gama } \\
\text { (Efron) }\end{array}$ & & & 0,0000 & 1,0000 & & \\
\hline & $H R$ & $\mathrm{IC}(H R)$ & $H R$ & $\mathrm{IC}(H R)$ & $H R$ & $\mathrm{IC}(H R)$ \\
\hline \multicolumn{7}{|c|}{ mie fumante versus não-fumante } \\
\hline $\begin{array}{c}\text { Variância } \\
\text { Robusta } \\
\text { (Breslow-Peto) }\end{array}$ & 1,199 & 0,$822 ; 1,750$ & 1,199 & 0,$822 ; 1,750$ & 1,199 & 0,$822 ; 1,750$ \\
\hline $\begin{array}{c}\text { Fragilidade } \\
\text { gama } \\
\text { (Breslow-Peto) }\end{array}$ & \multicolumn{2}{|c|}{ não disponivel } & 1,199 & 0,$819 ; 1,756$ & \multicolumn{2}{|c|}{ não disponivel } \\
\hline $\begin{array}{c}\text { Variância } \\
\text { Robusta } \\
\text { (Efron) }\end{array}$ & 1,199 & 0,$820 ; 1,755$ & 1,199 & 0,$820 ; 1,755$ & 1,199 & 0,$822 ; 1,750$ \\
\hline $\begin{array}{c}\text { Fragilidade } \\
\text { gama } \\
\text { (Efron) }\end{array}$ & \multicolumn{2}{|c|}{ não disponível } & 1,199 & 0,$819 ; 1,757$ & \multicolumn{2}{|c|}{ não disponivel } \\
\hline \multicolumn{7}{|c|}{ parto fórceps versus normal } \\
\hline $\begin{array}{c}\text { Variância } \\
\text { Robusta } \\
\text { (Brealow-Peto) }\end{array}$ & 1,442 & 0,$970 ; 2,143$ & 1,442 & 0,$970 ; 2,143$ & 1,442 & 0,$970 ; 2,143$ \\
\hline $\begin{array}{c}\text { Fragilidade } \\
\text { gama } \\
\text { (Breslow-Peto) }\end{array}$ & \multicolumn{2}{|c|}{ não disponível } & 1,442 & 0,$972 ; 2,138$ & \multicolumn{2}{|c|}{ não disponivel } \\
\hline $\begin{array}{c}\text { Variância } \\
\text { Robusta } \\
\text { (Efron) }\end{array}$ & 1,447 & 0,$971 ; 2,157$ & 1,447 & 0,$971 ; 2,157$ & 1,447 & 0,$974 ; 2,151$ \\
\hline $\begin{array}{c}\text { Fragilidade } \\
\text { gama } \\
\text { (Efroa) }\end{array}$ & \multicolumn{2}{|c|}{ não disponível } & 1,447 & 0,$976 ; 2,146$ & \multicolumn{2}{|c|}{ não disponivel } \\
\hline \multicolumn{7}{|c|}{ parto cesariana versus normal } \\
\hline $\begin{array}{c}\text { Variância } \\
\text { Robusta } \\
\text { (Brealow-Peto) }\end{array}$ & 1,015 & 0,$703 ; 1,466$ & 1,015 & 0,$703 ; 1,466$ & 1,015 & 0,$703 ; 1,466$ \\
\hline $\begin{array}{c}\text { Fragilidade } \\
\text { gama } \\
\text { (Brealow-Peto) }\end{array}$ & \multicolumn{2}{|c|}{ não disponivel } & 1,015 & 0,$692 ; 1,490$ & \multicolumn{2}{|c|}{ não disponivel } \\
\hline $\begin{array}{c}\text { Variância } \\
\text { Robusta } \\
\text { (Efron) }\end{array}$ & 1,015 & 0,$702 ; 1,469$ & 1,015 & 0,$702 ; 1,469$ & 1,015 & 0,$703 ; 1,466$ \\
\hline $\begin{array}{c}\text { Fragilidade } \\
\text { gama } \\
\text { (Efron) }\end{array}$ & \multicolumn{2}{|c|}{ não disponivel } & 1,015 & 0,$692 ; 1,490$ & \multicolumn{2}{|c|}{ não disponivel } \\
\hline
\end{tabular}

(continua) 
(continuação da Tabela 5.4a)

\begin{tabular}{|c|c|c|c|c|c|c|}
\hline Modelo & \multicolumn{2}{|r|}{ Stata } & \multicolumn{2}{|c|}{ S-Plus } & \multicolumn{2}{|c|}{ SAS } \\
\hline \multicolumn{7}{|c|}{ Tempo total - irrestrito } \\
\hline & $\theta$ & $\mathrm{p}$ & $\theta$ & $\mathrm{p}$ & $\theta$ & $\mathrm{p}_{2}$ \\
\hline $\begin{array}{c}\text { Fragilidade } \\
\text { gama } \\
\text { (Breslow-Peto) }\end{array}$ & & & 0,0000 & 1,0000 & & \\
\hline $\begin{array}{c}\text { Fragilidade } \\
\text { gama } \\
\text { (Efron) }\end{array}$ & 0,0000 & 0,4978 & 0,0000 & 1,0000 & & lisponível \\
\hline & $H R$ & $\mathrm{IC}(H R)$ & $H R$ & $\mathrm{IC}(H R)$ & $H R$ & $\mathrm{IC}(H R)$ \\
\hline \multicolumn{7}{|c|}{ mãe fumante versus não-fumante } \\
\hline $\begin{array}{c}\text { Variância } \\
\text { Robusta } \\
\text { (Breslow-Peto) }\end{array}$ & 1,113 & 0,$800 ; 1,548$ & 1,113 & 0,$800 ; 1,548$ & 1,113 & 0,$800 ; 1,548$ \\
\hline $\begin{array}{c}\text { Fragilidade } \\
\text { gama } \\
\text { (Breslow-Peto) }\end{array}$ & & & 1,113 & 0,$763 ; 1,623$ & & \\
\hline $\begin{array}{c}\text { Variância } \\
\text { Robusta } \\
\text { (Efron) }\end{array}$ & 1,113 & 0,$798 ; 1,551$ & 1,113 & 0,$798 ; 1,551$ & 1,113 & 0,$800 ; 1,548$ \\
\hline $\begin{array}{c}\text { Fragilidade } \\
\text { gama } \\
\text { (Efron) }\end{array}$ & 1,113 & 0,$763 ; 1,623$ & 1,113 & 0,$763 ; 1,623$ & & lisponível \\
\hline \multicolumn{7}{|c|}{ parto fórceps versus normal } \\
\hline $\begin{array}{c}\text { Variância } \\
\text { Robusta } \\
\text { (Breslow-Peto) }\end{array}$ & 1,494 & 1,$032 ; 2,164$ & 1,495 & 1,$032 ; 2,165$ & 1,495 & 1,$032 ; 2,165$ \\
\hline $\begin{array}{c}\text { Fragilidade } \\
\text { gama } \\
\text { (Breslow-Peto) }\end{array}$ & & & 1,494 & 1,$019 ; 2,193$ & & \\
\hline $\begin{array}{c}\text { Variância } \\
\text { Robusta } \\
\text { (Efron) }\end{array}$ & 1,498 & 1,$033 ; 2,173$ & 1,499 & 1,$033 ; 2,174$ & 1,499 & 1,$035 ; 2,170$ \\
\hline $\begin{array}{c}\text { Fragilidade } \\
\text { gama } \\
\text { (Efron) }\end{array}$ & 1,498 & 1,$021 ; 2,198$ & 1,498 & 1,$021 ; 2,198$ & & lisponível \\
\hline \multicolumn{7}{|c|}{ parto cesariana versus normal } \\
\hline $\begin{array}{c}\text { Variância } \\
\text { Robusta } \\
\text { (Breslow-Peto) }\end{array}$ & 1,049 & 0,$742 ; 1,485$ & 1,049 & 0,$742 ; 1,485$ & 1,049 & 0,$742 ; 1,485$ \\
\hline $\begin{array}{c}\text { Fragilidade } \\
\text { gama } \\
\text { (Breslow-Peto) }\end{array}$ & & & 1,049 & 0,$716 ; 1,537$ & & \\
\hline $\begin{array}{c}\text { Variância } \\
\text { Robusta } \\
\text { (Efron) }\end{array}$ & 1,050 & 0,$741 ; 1,487$ & 1,050 & 0,$741 ; 1,488$ & 1,050 & 0,$742 ; 1,486$ \\
\hline $\begin{array}{c}\text { Fragilidade } \\
\text { gama } \\
\text { (Efron) }\end{array}$ & 1,050 & 0,$717 ; 1,538$ & 1,050 & 0,$717 ; 1,537$ & & lisponivel \\
\hline
\end{tabular}

(continua) 
(continuação da Tabela 5.4a)

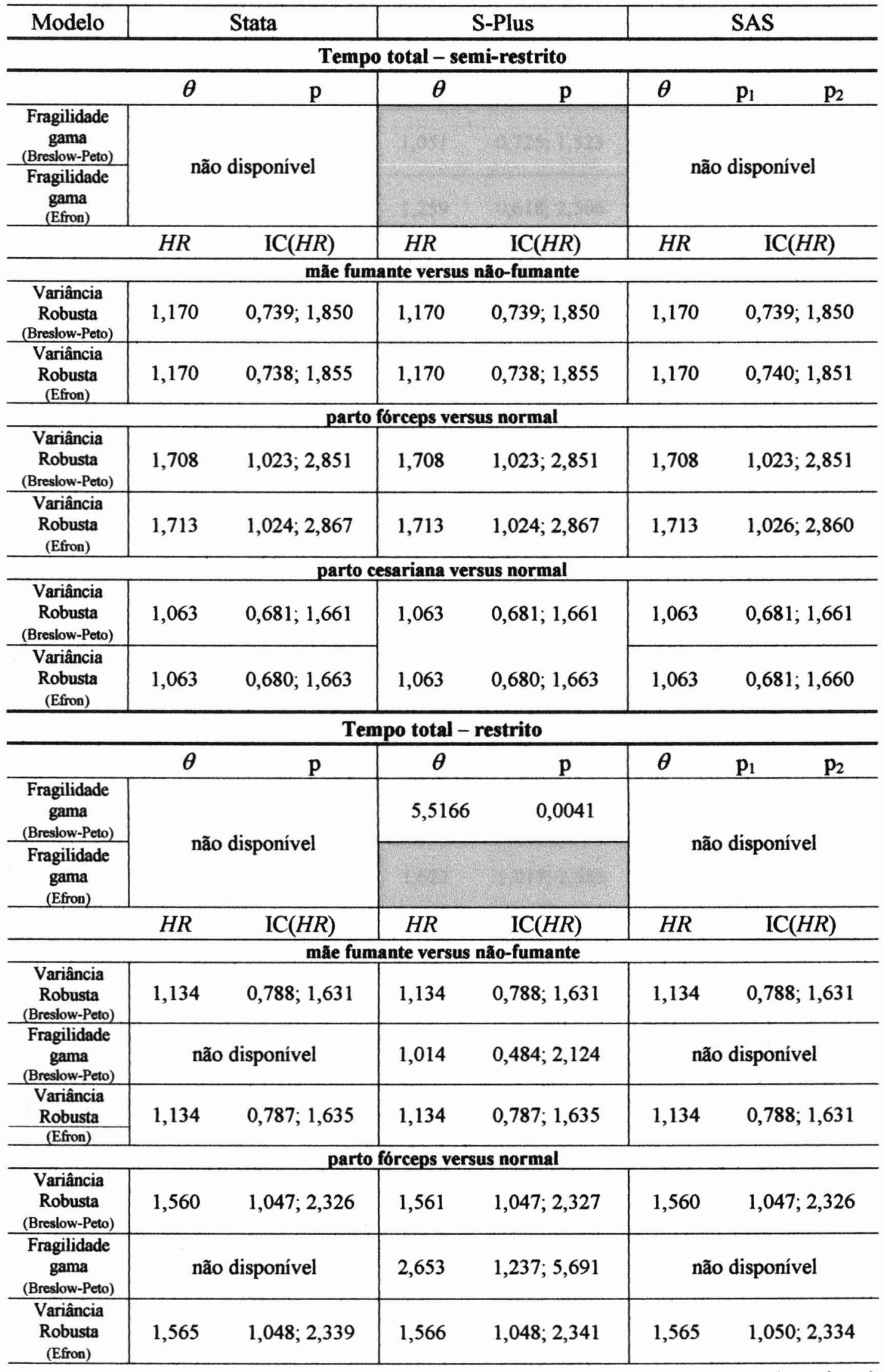


(continuação da Tabela 5.4a)

\begin{tabular}{|c|c|c|c|c|c|c|}
\hline Modelo & \multicolumn{2}{|c|}{ Stata } & \multicolumn{2}{|c|}{ S-Plus } & \multicolumn{2}{|r|}{ SAS } \\
\hline & $H R$ & $\mathrm{IC}(H R)$ & $H R$ & $\mathrm{IC}(H R)$ & $H R$ & $\mathrm{IC}(H R)$ \\
\hline \multicolumn{7}{|c|}{ parto cesariana versus normal } \\
\hline $\begin{array}{c}\text { Variância } \\
\text { Robusta } \\
\text { (Breaslow-Peto) }\end{array}$ & 1,051 & 0,$725 ; 1,523$ & 1,051 & 0,$725 ; 1,523$ & 1,051 & 0,$725 ; 1,523$ \\
\hline $\begin{array}{c}\text { Fragilidade } \\
\text { gama } \\
\text { (Breslow-Peto) }\end{array}$ & \multicolumn{2}{|c|}{ não disponivel } & 1,259 & 0,$618 ; 2,566$ & \multicolumn{2}{|c|}{ não disponivel } \\
\hline $\begin{array}{c}\text { Variância } \\
\text { Robusta } \\
\text { (Efron) }\end{array}$ & 1,051 & 0,$724 ; 1,526$ & 1,051 & 0,$724 ; 1,526$ & 1,051 & 0,$725 ; 1,523$ \\
\hline \multicolumn{7}{|c|}{ Tempo entre eventos - irrestrito } \\
\hline & $\theta$ & $\mathrm{p}$ & $\theta$ & $\mathrm{p}$ & $\boldsymbol{\theta}$ & $\mathbf{p}_{2}$ \\
\hline $\begin{array}{c}\text { Fragilidade } \\
\text { gama } \\
\text { (Brealow-Peto) }\end{array}$ & 1,7113 & 0,0000 & 1,7169 & 0,0000 & 1,7113 & $0,1238 \quad 0,0000$ \\
\hline $\begin{array}{c}\text { Fragilidade } \\
\text { gama } \\
\text { (Efron) } \\
\end{array}$ & 1,9862 & 0,0000 & 1,9881 & 0,0000 & & disponivel \\
\hline & $H R$ & $\mathrm{IC}(H R)$ & $H R$ & $\operatorname{IC}(H R)$ & $H R$ & $\mathrm{IC}(H R)$ \\
\hline \multicolumn{7}{|c|}{ mle fumante versus năo-fumante } \\
\hline $\begin{array}{c}\text { Variância } \\
\text { Robusta } \\
\text { (Breslow-Peto) }\end{array}$ & 1,167 & 0,$762 ; 1,789$ & 1,167 & 0,$762 ; 1,789$ & 1,167 & 0,$762 ; 1,789$ \\
\hline $\begin{array}{c}\text { Fragilidade } \\
\text { gama } \\
\text { (Breslow-Peto) }\end{array}$ & 1,142 & 0,$697 ; 1,871$ & 1,142 & 0,$697 ; 1,872$ & 1,142 & não disponivel \\
\hline $\begin{array}{c}\text { Variância } \\
\text { Robusta } \\
\text { (Efron) }\end{array}$ & 1,169 & 0,$760 ; 1,796$ & 1,169 & 0,$760 ; 1,796$ & 1,169 & 0,$763 ; 1,791$ \\
\hline $\begin{array}{c}\text { Fragilidade } \\
\text { gama } \\
\text { (Efron) } \\
\end{array}$ & 1,140 & 0,$684 ; 1,900$ & 1,140 & 0,$683 ; 1,900$ & & disponivel \\
\hline \multicolumn{7}{|c|}{ parto fórceps versus normal } \\
\hline $\begin{array}{c}\text { Variância } \\
\text { Robusta } \\
\text { (Breslow-Peto) }\end{array}$ & 1,620 & 1,$015 ; 2,584$ & 1,621 & 1,$017 ; 2,586$ & 1,620 & 1,$015 ; 2,584$ \\
\hline $\begin{array}{c}\text { Fragilidade } \\
\text { gama } \\
\text { (Breslow-Peto) }\end{array}$ & 1,770 & 1,$056 ; 2,965$ & 1,770 & 1,$058 ; 2,963$ & 1,770 & não disponivel \\
\hline $\begin{array}{c}\text { Variância } \\
\text { Robusta } \\
\text { (Efron) }\end{array}$ & 1,626 & 1,$016 ; 2,602$ & 1,628 & 1,$017 ; 2,604$ & 1,626 & 1,$019 ; 2,593$ \\
\hline $\begin{array}{c}\text { Fragilidade } \\
\text { gama } \\
\text { (Efron) } \\
\end{array}$ & 1,815 & 1,$062 ; 3,101$ & 1,815 & 1,$064 ; 3,096$ & & disponível \\
\hline \multicolumn{7}{|c|}{ parto cesariana versus normal } \\
\hline $\begin{array}{c}\text { Variância } \\
\text { Robusta } \\
\text { (Breslow-Peto) }\end{array}$ & 1,049 & 0,$695 ; 1,585$ & 1,050 & 0,$695 ; 1,585$ & 1,049 & 0,$695 ; 1,585$ \\
\hline $\begin{array}{c}\text { Fragilidade } \\
\text { gama } \\
\text { (Breslow-Peto) } \\
\end{array}$ & 1,054 & 0,$649 ; 1,712$ & 1,054 & 0,$649 ; 1,713$ & 1,054 & não disponivel \\
\hline $\begin{array}{c}\text { Variância } \\
\text { Robusta } \\
\text { (Efron) }\end{array}$ & 1,049 & 0,$693 ; 1,587$ & 1,049 & 0,$693 ; 1,587$ & 1,049 & 0,$695 ; 1,584$ \\
\hline $\begin{array}{c}\text { Fragilidade } \\
\text { gama } \\
\text { (Efron) } \\
\end{array}$ & 1,053 & 0,$638 ; 1,738$ & 1,053 & 0,$638 ; 1,738$ & & disponivel \\
\hline
\end{tabular}


(continuação da Tabela 5.4a)

\begin{tabular}{|c|c|c|c|c|c|c|}
\hline Modelo & \multicolumn{2}{|c|}{ Stata } & \multicolumn{2}{|c|}{ S-Plus } & \multicolumn{2}{|r|}{ SAS } \\
\hline \multicolumn{7}{|c|}{ Tempo entre eventos - restrito } \\
\hline & $\theta$ & p & $\theta$ & $\mathrm{p}$ & $\theta$ & $\mathbf{p}_{2}$ \\
\hline $\begin{array}{c}\text { Fragilidade } \\
\text { gama } \\
\text { (Breslow-Peto) } \\
\end{array}$ & \multirow{2}{*}{\multicolumn{2}{|c|}{ não disponivel }} & 0,0001 & 1,0000 & \multirow{2}{*}{\multicolumn{2}{|c|}{ não disponivel }} \\
\hline $\begin{array}{c}\text { Fragilidade } \\
\text { gama } \\
\text { (Efron) }\end{array}$ & & & 2,2939 & 0,4124 & & \\
\hline & $H R$ & $\mathrm{IC}(H R)$ & $H R$ & $\mathrm{IC}(H R)$ & $H R$ & $\mathrm{IC}(H R)$ \\
\hline \multicolumn{7}{|c|}{ mãe fumante versus não-fumante } \\
\hline $\begin{array}{c}\text { Variância } \\
\text { Robusta } \\
\text { (Breslow-Peto) } \\
\end{array}$ & 1,173 & 0,$806 ; 1,706$ & 1,173 & 0,$806 ; 1,706$ & 1,173 & 0,$806 ; 1,706$ \\
\hline $\begin{array}{c}\text { Fragilidade } \\
\text { gama } \\
\text { (Breslow-Peto) } \\
\end{array}$ & \multicolumn{2}{|c|}{ não disponivel } & 1,173 & 0,$802 ; 1,713$ & \multicolumn{2}{|c|}{ não disponivel } \\
\hline $\begin{array}{c}\text { Variância } \\
\text { Robusta } \\
\text { (Efron) }\end{array}$ & 1,175 & 0,$804 ; 1,716$ & 1,175 & 0,$804 ; 1,716$ & 1,175 & 0,$807 ; 1,709$ \\
\hline $\begin{array}{c}\text { Fragilidade } \\
\text { gama } \\
\text { (Efron) } \\
\end{array}$ & \multicolumn{2}{|c|}{ não disponível } & 1,137 & 0,$667 ; 1,937$ & \multicolumn{2}{|c|}{ não disponível } \\
\hline \multicolumn{7}{|c|}{ parto fórceps versus normal } \\
\hline $\begin{array}{c}\text { Variância } \\
\text { Robusta } \\
\text { (Breajow-Peto) }\end{array}$ & 1,474 & 0,$994 ; 2,187$ & 1,475 & 0,$994 ; 2,188$ & 1,475 & 0,$994 ; 2,188$ \\
\hline $\begin{array}{c}\text { Fragilidade } \\
\text { gama } \\
\text { (Breslow-Peto) } \\
\end{array}$ & \multicolumn{2}{|c|}{ não disponivel } & 1,474 & 0,$999 ; 2,177$ & \multicolumn{2}{|c|}{ não disponivel } \\
\hline $\begin{array}{c}\begin{array}{c}\text { Variância } \\
\text { Robusta } \\
\text { (Efron) }\end{array} \\
\end{array}$ & 1,481 & 0,$995 ; 2,207$ & 1,482 & 0,$995 ; 2,208$ & 1,482 & 0,$999 ; 2,198$ \\
\hline $\begin{array}{c}\text { Fragilidade } \\
\text { gama } \\
\text { (Efron) } \\
\end{array}$ & \multicolumn{2}{|c|}{ não disponivel } & 1,862 & 1,$062 ; 3,263$ & \multicolumn{2}{|c|}{ não disponivel } \\
\hline \multicolumn{7}{|c|}{ parto cesariana versus normal } \\
\hline $\begin{array}{c}\text { Variância } \\
\text { Robusta } \\
\text { (Breslow-Peto) }\end{array}$ & 1,039 & 0,$715 ; 1,508$ & 1,039 & 0,$715 ; 1,508$ & 1,039 & 0,$715 ; 1,508$ \\
\hline $\begin{array}{c}\text { Fragilidade } \\
\text { gama } \\
\text { (Breslow-Peto) }\end{array}$ & \multicolumn{2}{|c|}{ não disponível } & 1,039 & 0,$709 ; 1,522$ & \multicolumn{2}{|c|}{ não disponivel } \\
\hline $\begin{array}{c}\text { Variância } \\
\text { Robusta } \\
\text { (Efron) }\end{array}$ & 1,038 & 0,$713 ; 1,510$ & 1,038 & 0,$713 ; 1,510$ & 1,038 & 0,$715 ; 1,507$ \\
\hline $\begin{array}{c}\text { Fragilidade } \\
\text { gama } \\
\text { (Efron) } \\
\end{array}$ & \multicolumn{2}{|c|}{ não disponível } & 1,101 & 0,$654 ; 1,854$ & \multicolumn{2}{|c|}{ não disponível } \\
\hline
\end{tabular}


Tabela 5.4b - Estimativas da razão de taxas de falha $(H R)$ e da variância $(\theta)$ da fragilidade gama, para a $1^{\text {a }}$ ocorrência de febre, segundo alguns modelos semiparamétricos para dados univariados e programas computacionais

\begin{tabular}{|c|c|c|c|c|c|c|}
\hline \multirow{2}{*}{ Modelo } & \multicolumn{2}{|c|}{ Stata } & \multicolumn{2}{|c|}{ S-Plus } & \multicolumn{2}{|c|}{ SAS } \\
\hline & $\theta$ & $\mathrm{p}$ & $\theta$ & $\mathrm{p}$ & $\theta$ & $\mathrm{p}_{2}$ \\
\hline $\begin{array}{c}\text { Fragilidade } \\
\text { gama } \\
\text { (Breslow-Peto) }\end{array}$ & 0,0000 & 0,4977 & 0,0001 & 1,0000 & & \\
\hline $\begin{array}{c}\text { Fragilidade } \\
\text { gama } \\
\text { (Efron) } \\
\end{array}$ & 1,8436 & 0,4099 & 1,4396 & 0,8284 & \multicolumn{2}{|c|}{ não disponível } \\
\hline & $H R$ & $\mathrm{IC}(H R)$ & $H R$ & $\mathrm{IC}(H R)$ & $H R$ & $\mathrm{IC}(H R)$ \\
\hline \multicolumn{7}{|c|}{ mãe fumante versus não-fumante } \\
\hline $\begin{array}{c}\text { Cox } \\
\text { (Breslow-Peto) }\end{array}$ & 1,154 & 0,$756 ; 1,762$ & 1,154 & 0,$756 ; 1,762$ & 1,154 & 0,$756 ; 1,762$ \\
\hline $\begin{array}{l}\text { Variância } \\
\text { Robusta } \\
\text { (Breslow-Peto) }\end{array}$ & 1,154 & 0,$768 ; 1,736$ & 1,154 & 0,$767 ; 1,736$ & 1,154 & 0,$768 ; 1,736$ \\
\hline $\begin{array}{c}\text { Fragilidade } \\
\text { gama } \\
\text { (Breslow-Peto) }\end{array}$ & 1,154 & 0,$756 ; 1,762$ & 1,154 & 0,$756 ; 1,762$ & & \\
\hline $\begin{array}{c}\text { Cox } \\
\text { (Efron) }\end{array}$ & 1,155 & 0,$757 ; 1,763$ & 1,155 & 0,$757 ; 1,763$ & 1,155 & 0,$757 ; 1,763$ \\
\hline $\begin{array}{c}\text { Variância } \\
\text { Robusta } \\
\text { (Efron) }\end{array}$ & 1,155 & 0,$766 ; 1,742$ & 1,155 & 0,$766 ; 1,742$ & 1,155 & 0,$768 ; 1,737$ \\
\hline $\begin{array}{c}\text { Fragilidade } \\
\text { gama } \\
\text { (Efron) }\end{array}$ & 1,118 & 0,$643 ; 1,945$ & 1,128 & 0,$667 ; 1,909$ & & disponivel \\
\hline \multicolumn{7}{|c|}{ fórceps versus parto normal } \\
\hline $\begin{array}{c}\text { Cox } \\
\text { (Breslow-Peto) }\end{array}$ & 1,381 & 0,$880 ; 2,167$ & 1,380 & 0,$880 ; 2,167$ & 1,380 & 0,$880 ; 2,167$ \\
\hline $\begin{array}{l}\text { Variância } \\
\text { Robusta } \\
\text { (Breslow-Peto) }\end{array}$ & 1,381 & 0,$879 ; 2,170$ & 1,381 & 0,$879 ; 2,171$ & 1,381 & 0,$879 ; 2,171$ \\
\hline $\begin{array}{c}\text { Fragilidade } \\
\text { gama } \\
\text { (Breslow-Peto) }\end{array}$ & 1,381 & 0,$880 ; 2,167$ & 1,381 & 0,$880 ; 2,167$ & & \\
\hline $\begin{array}{c}\text { Cox } \\
\text { (Efron) }\end{array}$ & 0,387 & 0,$884 ; 2,175$ & 0,387 & 0,$884 ; 2,176$ & 0,387 & 0,$884 ; 2,176$ \\
\hline $\begin{array}{c}\text { Variância } \\
\text { Robusta } \\
\text { (Efron) }\end{array}$ & 1,387 & 0,$879 ; 2,188$ & 1,387 & 0,$879 ; 2,188$ & 1,387 & 0,$883 ; 2,180$ \\
\hline $\begin{array}{c}\text { Fragilidade } \\
\text { gama } \\
\text { (Efron) }\end{array}$ & 1,701 & 0,$926 ; 3,127$ & 1,626 & 0,$916 ; 2,885$ & & disponível \\
\hline \multicolumn{7}{|c|}{ cesariana versus parto normal } \\
\hline $\begin{array}{c}\text { Cox } \\
\text { (Breslow-Peto) }\end{array}$ & 1,006 & 0,$659 ; 1,535$ & 1,006 & 0,$659 ; 1,535$ & 1,006 & 0,$659 ; 1,535$ \\
\hline $\begin{array}{l}\text { Variância } \\
\text { Robusta } \\
\text { (Breslow-Peto) }\end{array}$ & 1,006 & 0,$663 ; 1,527$ & 1,006 & 0,$663 ; 1,527$ & 1,006 & 0,$663 ; 1,527$ \\
\hline $\begin{array}{c}\text { Fragilidade } \\
\text { gama } \\
\text { (Breslow-Peto) }\end{array}$ & 1,006 & 0,$659 ; 1,535$ & 1,006 & 0,$659 ; 1,535$ & & \\
\hline $\begin{array}{c}\text { Cox } \\
\text { (Efron) }\end{array}$ & 1,006 & 0,$661 ; 1,531$ & 1,006 & 0,$661 ; 1,531$ & 1,006 & 0,$661 ; 1,531$ \\
\hline $\begin{array}{c}\text { Variância } \\
\text { Robusta } \\
\text { (Efron) }\end{array}$ & 1,006 & 0,$661 ; 1,530$ & 1,006 & 0,$661 ; 1,530$ & 1,006 & 0,$663 ; 1,527$ \\
\hline $\begin{array}{c}\text { Fragilidade } \\
\text { gama } \\
\text { (Efron) }\end{array}$ & 1,044 & 0,$606 ; 1,800$ & 1,034 & 0,$616 ; 1,735$ & & disponivel \\
\hline
\end{tabular}


Figura 5.4 - Intervalos de confiança da razão de taxas de falha para os dados do Estudo 4, segundo alguns modelos semiparamétricos para eventos recorrentes e para $1^{a}$ recorrência, usando a aproximação Efron e o programa S-Plus

a) $H R$ entre mães fumantes e não-fumantes

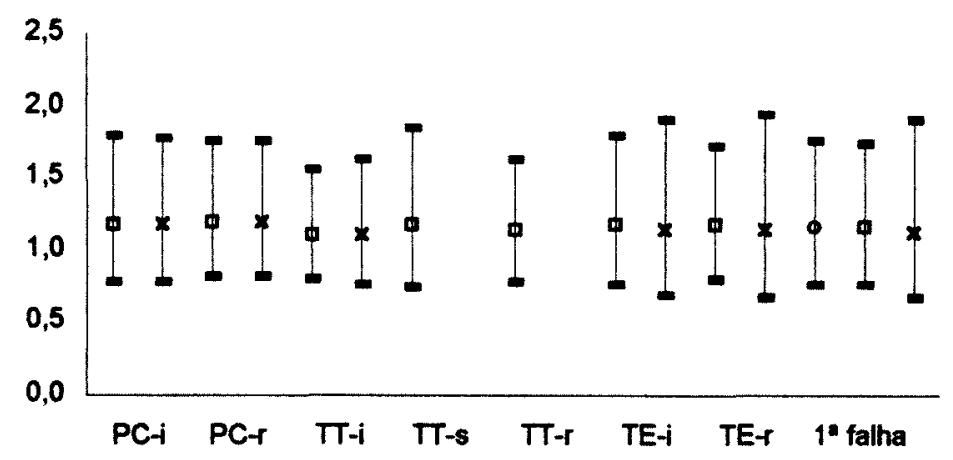

b) $H R$ entre partos fórceps e normais

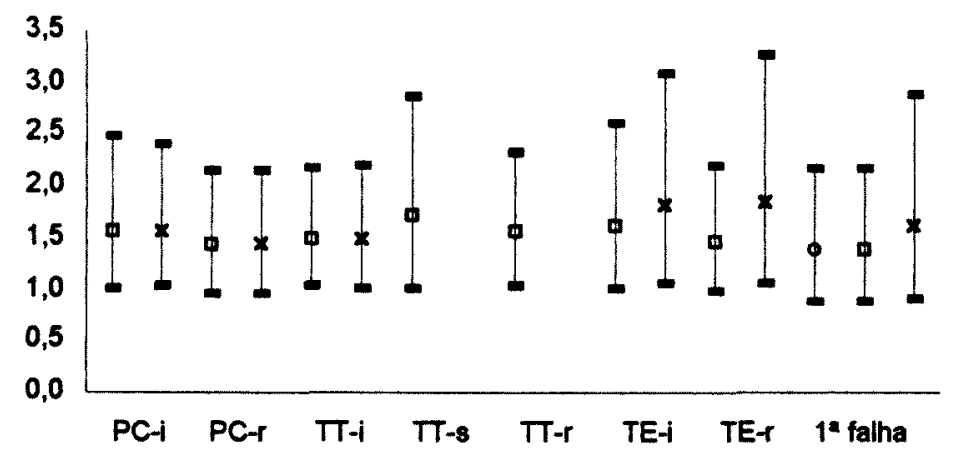

c) $H R$ entre partos cesariana e normais

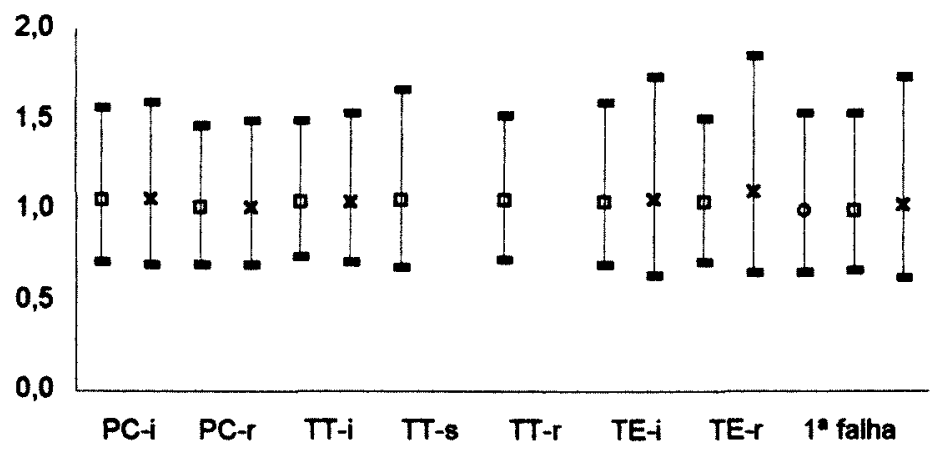

- Cox

$\square$ Variância Robusta

$\times$ Fragilidade 
A Tabela $5.4 \mathrm{~b}$ mostra que a variância $\theta$ da fragilidade gama não é significativa, portanto, a heterogeneidade não observada não está influenciando na $1^{a}$ ocorrência de febre e os modelos sem fragilidade podem ser aplicados a estes dados de sobrevida univariados. Verifica-se que nenhuma das covariáveis tem efeito significativo sobre a taxa de ocorrência do $1^{\circ}$ episódio de febre.

Ao considerar somente as estimativas obtidas no S-Plus com aproximação Efron, pela Figura 5.4, verifica-se que os modelos TT - semi-restrito com variância robusta e TE - irrestrito e restrito com fragilidade apresentam estimativas menos precisas de HR do que em outros modelos, já que os intervalos são maiores para as três covariáveis; e para a covariável indicadora de parto fórceps em (b), as estimativas pontuais nesses três modelos são mais altas. Para essa covariável, não há concordância entre os resultados dos vários modelos, o que pode ser razoável, já que alguns modelos parecem ser inconsistentes quando a ordem de ocorrência dos eventos é importante. Porém, mesmo considerando falta de independência entre eventos, quando é aconselhável usar conjuntos de risco restritos, o modelo $\mathrm{TE}$ - restrito com fragilidade, indica que parto fórceps é fator de risco para ocorrências de febre, o que difere dos modelos TE - restrito com variância robusta, PC - restrito com variância robusta e com fragilidade. Estas divergências talvez possam ser explicadas pela baixa freqüência deste tipo de parto.

O Estudo 5 contém até quatro ocorrências de qualquer tipo de morbidade nos primeiros 90 dias de vida, que foram registradas pela mãe da criança. Pela Tabela 5.5a, verifica-se que entre os 13 modelos de fragilidade gama que convergiram, em 4 modelos o parâmetro $\theta$ não é significativo: $\mathrm{PC}$ - restrito com B-P e E e TT - irrestrito com B-P e E. Os dois modelos mais indicados pela possível falta independência entre eventos, $\mathrm{PC}$ - restrito e $\mathrm{TE}$ - restrito, levam a conclusões diferentes sobre a significância de $\theta$. Se for seguida a sugestão de BOX-STEFFENSMEIER e DE BOEF (2002), TE - restrito é o modelo preferível para analisar eventos recorrentes, pode-se concluir que $\theta$ é significativo e portanto, existe correlação intra-indivíduo. 
Tabela 5.5a - Estimativas da razão de taxas de falha $(H R)$ e da variância $(\theta)$ da fragilidade gama para os dados do Estudo 5, segundo alguns modelos semiparamétricos para eventos recorrentes e programas computacionais

\begin{tabular}{|c|c|c|c|c|c|c|}
\hline Modelo & \multicolumn{2}{|c|}{ Stata } & \multicolumn{2}{|c|}{ S-Plus } & \multicolumn{2}{|r|}{ SAS } \\
\hline \multicolumn{7}{|c|}{ Processos de contagem - irrestrito } \\
\hline & $\theta$ & p & $\theta$ & $\mathbf{p}$ & $\theta$ & $\mathbf{p}_{2}$ \\
\hline $\begin{array}{l}\text { Fragilidade } \\
\text { gama } \\
\text { (Breslow-Peto) }\end{array}$ & 0,4635 & 0,0000 & 0,4666 & 0,0000 & \multirow{2}{*}{\multicolumn{2}{|c|}{ não disponível }} \\
\hline $\begin{array}{c}\text { Fragilidade } \\
\text { gama } \\
\text { (Efron) } \\
\end{array}$ & 0,5067 & 0,0000 & 0,5091 & 0,0000 & & \\
\hline & $H R$ & $\mathrm{IC}(H R)$ & $H R$ & $\mathrm{IC}(H R)$ & $H R$ & $\mathrm{IC}(H R)$ \\
\hline \multicolumn{7}{|c|}{ mãe fumante versus não-fumante } \\
\hline $\begin{array}{c}\text { Variància } \\
\text { Robusta } \\
\text { (Breslow-Peto) }\end{array}$ & 1,085 & 0,$907 ; 1,298$ & 1,085 & 0,$907 ; 1,298$ & 1,085 & 0,$907 ; 1,298$ \\
\hline $\begin{array}{c}\text { Fragilidade } \\
\text { gama } \\
\text { (Breslow-Peto) }\end{array}$ & 1,076 & 0,$866 ; 1,337$ & 1,076 & 0,$866 ; 1,337$ & \multicolumn{2}{|c|}{ não disponivel } \\
\hline $\begin{array}{c}\text { Variância } \\
\text { Robusta } \\
\text { (Efron) }\end{array}$ & 1,089 & 0,$908 ; 1,306$ & 1,089 & 0,$908 ; 1,306$ & 1,089 & 0,$911 ; 1,303$ \\
\hline $\begin{array}{c}\text { Fragilidade } \\
\text { gama } \\
\text { (Efron) }\end{array}$ & 1,077 & 0,$862 ; 1,346$ & 1,077 & 0,$862 ; 1,347$ & \multicolumn{2}{|c|}{ não disponivel } \\
\hline \multicolumn{7}{|c|}{ parto fórceps versus normal } \\
\hline $\begin{array}{c}\text { Variância } \\
\text { Robusta } \\
\text { (Bresslow-Peto) }\end{array}$ & 1,246 & 1,$008 ; 1,539$ & 1,246 & 1,$008 ; 1,539$ & 1,246 & 1,$008 ; 1,539$ \\
\hline $\begin{array}{c}\text { Fragilidade } \\
\text { gama }^{(1)} \\
(\text { Bresow-Peto) }\end{array}$ & 1,341 & 1,$060 ; 1,695$ & 1,341 & 1,$060 ; 1,696$ & \multicolumn{2}{|c|}{ não disponivel } \\
\hline $\begin{array}{c}\text { Variância } \\
\text { Robusta } \\
\text { (Efron) }\end{array}$ & 1,247 & 1,$005 ; 1,547$ & 1,247 & 1,$005 ; 1,547$ & 1,247 & 1,$009 ; 1,541$ \\
\hline $\begin{array}{c}\text { Fragilidade } \\
\text { gama }^{\left({ }^{\prime}\right)} \\
\text { (Efron) }\end{array}$ & 1,356 & 1,$065 ; 1,725$ & 1,356 & 1,$065 ; 1,726$ & \multicolumn{2}{|c|}{ não disponivel } \\
\hline \multicolumn{7}{|c|}{ parto cesariana versus normal } \\
\hline $\begin{array}{c}\text { Variância } \\
\text { Robusta } \\
\text { (Brestow-Peto) }\end{array}$ & 1,037 & 0,$867 ; 1,242$ & 1,037 & 0,$867 ; 1,242$ & 1,037 & 0,$867 ; 1,242$ \\
\hline $\begin{array}{c}\text { Fragilidade } \\
\text { gama (1) } \\
\text { (Brestow-Peto) }\end{array}$ & 1,061 & 0,$862 ; 1,305$ & 1,061 & 0,$862 ; 1,306$ & \multicolumn{2}{|c|}{ não disponivel } \\
\hline $\begin{array}{c}\text { Variância } \\
\text { Robusta } \\
\text { (Efron) } \\
\end{array}$ & 1,039 & 0,$866 ; 1,248$ & 1,039 & 0,$866 ; 1,248$ & 1,039 & 0,$868 ; 1,244$ \\
\hline $\begin{array}{c}\text { Fragilidade } \\
\text { gama (1) } \\
\text { (Efron) }\end{array}$ & 1,067 & 0,$862 ; 1,320$ & 1,067 & 0,$862 ; 1,321$ & \multicolumn{2}{|c|}{ não disponivel } \\
\hline
\end{tabular}


(continuação da Tabela 5.5a)

\begin{tabular}{|c|c|c|c|c|c|c|}
\hline Modelo & \multicolumn{2}{|c|}{ Stata } & \multicolumn{2}{|c|}{ S-Plus } & \multicolumn{2}{|c|}{ SAS } \\
\hline \multicolumn{7}{|c|}{ Processos de contagem - restrito } \\
\hline & $\theta$ & $\mathrm{p}$ & $\theta$ & p & $\theta$ & $\mathbf{p}_{2}$ \\
\hline $\begin{array}{c}\text { Fragilidade } \\
\text { gama } \\
\text { (Breslow-Peto) }\end{array}$ & \multirow{2}{*}{\multicolumn{2}{|c|}{ não disponivel }} & 0,0000 & 1,0000 & \multirow{2}{*}{\multicolumn{2}{|c|}{ não disponivel }} \\
\hline $\begin{array}{c}\text { Fragilidade } \\
\text { gama } \\
\text { (Efron) } \\
\end{array}$ & & & 0,0024 & 0,8508 & & \\
\hline & $H R$ & $\mathrm{IC}(H R)$ & $H R$ & $\mathrm{IC}(H R)$ & $H R$ & $\mathrm{IC}(H R)$ \\
\hline \multicolumn{7}{|c|}{ mãe fumante versus não-fumante } \\
\hline $\begin{array}{c}\text { Variância } \\
\text { Robusta } \\
\text { (Breslow-Peto) }\end{array}$ & 1,031 & 0,$901 ; 1,180$ & 1,031 & 0,$901 ; 1,180$ & 1,031 & 0,$901 ; 1,180$ \\
\hline $\begin{array}{c}\text { Fragilidade } \\
\text { gama } \\
\text { (Breslow-Peto) }\end{array}$ & \multicolumn{2}{|c|}{ não disponivel } & 1,031 & 0,$891 ; 1,193$ & \multicolumn{2}{|c|}{ não disponivel } \\
\hline $\begin{array}{c}\text { Variância } \\
\text { Robusta } \\
\text { (Efron) }\end{array}$ & 1,034 & 0,$900 ; 1,187$ & 1,034 & 0,$900 ; 1,187$ & 1,034 & 0,$903 ; 1,183$ \\
\hline $\begin{array}{c}\text { Fragilidade } \\
\text { gama } \\
\text { (Efron) } \\
\end{array}$ & \multicolumn{2}{|c|}{ não disponível } & 1,034 & 0,$893 ; 1,197$ & \multicolumn{2}{|c|}{ não disponivel } \\
\hline \multicolumn{7}{|c|}{ parto forceps versus normal } \\
\hline $\begin{array}{c}\text { Variância } \\
\text { Robusta } \\
\text { (Breslow-Peto) }\end{array}$ & 1,182 & 1,$012 ; 1,382$ & 1,182 & 1,$012 ; 1,382$ & 1,182 & 1,$012 ; 1,382$ \\
\hline $\begin{array}{c}\text { Fragilidade } \\
\text { gama }^{(1)} \\
\text { (Breslow-Peto) }\end{array}$ & \multicolumn{2}{|c|}{ não disponivel } & 1,182 & 1,$012 ; 1,381$ & \multicolumn{2}{|c|}{ não disponivel } \\
\hline $\begin{array}{c}\text { Variância } \\
\text { Robusta } \\
\text { (Efron) }\end{array}$ & 1,187 & 1,$010 ; 1,395$ & 1,187 & 1,$010 ; 1,395$ & 1,187 & 1,$016 ; 1,387$ \\
\hline $\begin{array}{c}\text { Fragilidade } \\
\text { gama (i) }^{(\text {Efron) }} \\
\end{array}$ & \multicolumn{2}{|c|}{ não disponivel } & 1,188 & 1,$016 ; 1,388$ & \multicolumn{2}{|c|}{ não disponível } \\
\hline \multicolumn{7}{|c|}{ parto cesariana versus normal } \\
\hline $\begin{array}{c}\text { Variância } \\
\text { Robusta } \\
\text { (Brealow-Peto) }\end{array}$ & 1,035 & 0,$901 ; 1,188$ & 1,035 & 0,$901 ; 1,188$ & 1,035 & 0,$901 ; 1,188$ \\
\hline $\begin{array}{c}\text { Fragilidade } \\
\text { gama }^{(1)} \\
\text { (Brestow-Peto) }^{-}\end{array}$ & \multicolumn{2}{|c|}{ não disponivel } & 1,035 & 0,$898 ; 1,192$ & \multicolumn{2}{|c|}{ não disponivel } \\
\hline $\begin{array}{c}\text { Variância } \\
\text { Robusta } \\
\text { (Efron) }\end{array}$ & 1,038 & 0,$901 ; 1,197$ & 1,038 & 0,$901 ; 1,197$ & 1,038 & 0,$904 ; 1,192$ \\
\hline $\begin{array}{c}\text { Fragilidade } \\
\text { gama }^{(1)} \\
\text { (Efron) }\end{array}$ & \multicolumn{2}{|c|}{ não disponivel } & 1,039 & 0,$901 ; 1,197$ & \multicolumn{2}{|c|}{ não disponível } \\
\hline
\end{tabular}


(continuação da Tabela 5.5a)

\begin{tabular}{|c|c|c|c|c|c|c|}
\hline Modelo & \multicolumn{2}{|c|}{ Stata } & \multicolumn{2}{|c|}{ S-Plus } & \multicolumn{2}{|c|}{ SAS } \\
\hline \multicolumn{7}{|c|}{ Tempo total - irrestrito } \\
\hline & $\theta$ & $\mathrm{p}$ & $\theta$ & $\mathrm{p}$ & $\theta$ & $\mathrm{p}_{2}$ \\
\hline $\begin{array}{c}\text { Fragilidade } \\
\text { gama } \\
\text { (Breslow-Peto) }\end{array}$ & 0,0000 & 0,4962 & 0,0001 & 1,0000 & & \\
\hline $\begin{array}{l}\text { Fragilidade } \\
\text { gama } \\
\text { (Efron) }\end{array}$ & & & 0,0001 & 1,0000 & & isponível \\
\hline & $H R$ & $\mathrm{IC}(H R)$ & $H R$ & $\mathrm{IC}(H R)$ & $H R$ & $\mathrm{IC}(H R)$ \\
\hline \multicolumn{7}{|c|}{ mãe fumante versus não-fumante } \\
\hline $\begin{array}{c}\text { Variância } \\
\text { Robusta } \\
\text { (Breslow-Peto) }\end{array}$ & 1,051 & 0,$916 ; 1,206$ & 1,051 & 0,$916 ; 1,206$ & 1,051 & 0,$916 ; 1,206$ \\
\hline $\begin{array}{l}\text { Fragilidade } \\
\text { gama }^{(1)} \\
\text { (Breslow-Peto) }\end{array}$ & 1,051 & 0,$909 ; 1,215$ & 1,051 & 0,$909 ; 1,215$ & & \\
\hline $\begin{array}{c}\text { Variância } \\
\text { Robusta } \\
\text { (Efron) }\end{array}$ & 1,051 & 0,$915 ; 1,207$ & 1,051 & 0,$915 ; 1,207$ & 1,051 & 0,$916 ; 1,206$ \\
\hline $\begin{array}{c}\text { Fragilidade } \\
\text { gama }^{(1)} \\
\text { (Efron) }\end{array}$ & & & 1,051 & 0,$909 ; 1,215$ & & isponível \\
\hline \multicolumn{7}{|c|}{ parto fórceps versus normal } \\
\hline $\begin{array}{c}\text { Variância } \\
\text { Robusta } \\
\text { (Breslow-Peto) }\end{array}$ & 1,182 & 1,$002 ; 1,394$ & 1,182 & 1,$002 ; 1,394$ & 1,182 & 1,$002 ; 1,394$ \\
\hline $\begin{array}{c}\text { Fragilidade } \\
\text { gama }^{(1)} \\
\text { (Breslow-Peto) }\end{array}$ & 1,182 & 1,$012 ; 1,379$ & 1,182 & 1,$012 ; 1,379$ & & \\
\hline $\begin{array}{c}\text { Variância } \\
\text { Robusta } \\
\text { (Efron) }\end{array}$ & 1,182 & 1,$001 ; 1,395$ & 1,182 & 1,$001 ; 1,395$ & 1,182 & 1,$002 ; 1,394$ \\
\hline $\begin{array}{l}\text { Fragilidade } \\
\text { gama }^{(1)} \\
\text { (Efron) }\end{array}$ & & & 1,182 & 1,$012 ; 1,379$ & & isponível \\
\hline \multicolumn{7}{|c|}{ parto cesariana versus normal } \\
\hline $\begin{array}{c}\text { Variância } \\
\text { Robusta } \\
\text { (Breslow-Peto) }\end{array}$ & 1,055 & 0,$921 ; 1,208$ & 1,055 & 0,$921 ; 1,208$ & 1,055 & 0,$921 ; 1,208$ \\
\hline $\begin{array}{l}\text { Fragilidade } \\
\text { gama }^{(1)} \\
\text { (Breslow-Peto) }\end{array}$ & 1,055 & 0,$916 ; 1,214$ & 1,055 & 0,$916 ; 1,214$ & & \\
\hline $\begin{array}{l}\text { Variância } \\
\text { Robusta } \\
\text { (Efron) }\end{array}$ & 1,055 & 0,$920 ; 1,209$ & 1,055 & 0,$920 ; 1,209$ & 1,055 & 0,$921 ; 1,208$ \\
\hline $\begin{array}{c}\text { Fragilidade } \\
\text { gama }^{(1)} \\
\text { (Efron) }\end{array}$ & & & 1,055 & 0,$916 ; 1,214$ & & isponível \\
\hline
\end{tabular}

(continua) 
(continuação da Tabela 5.5a)

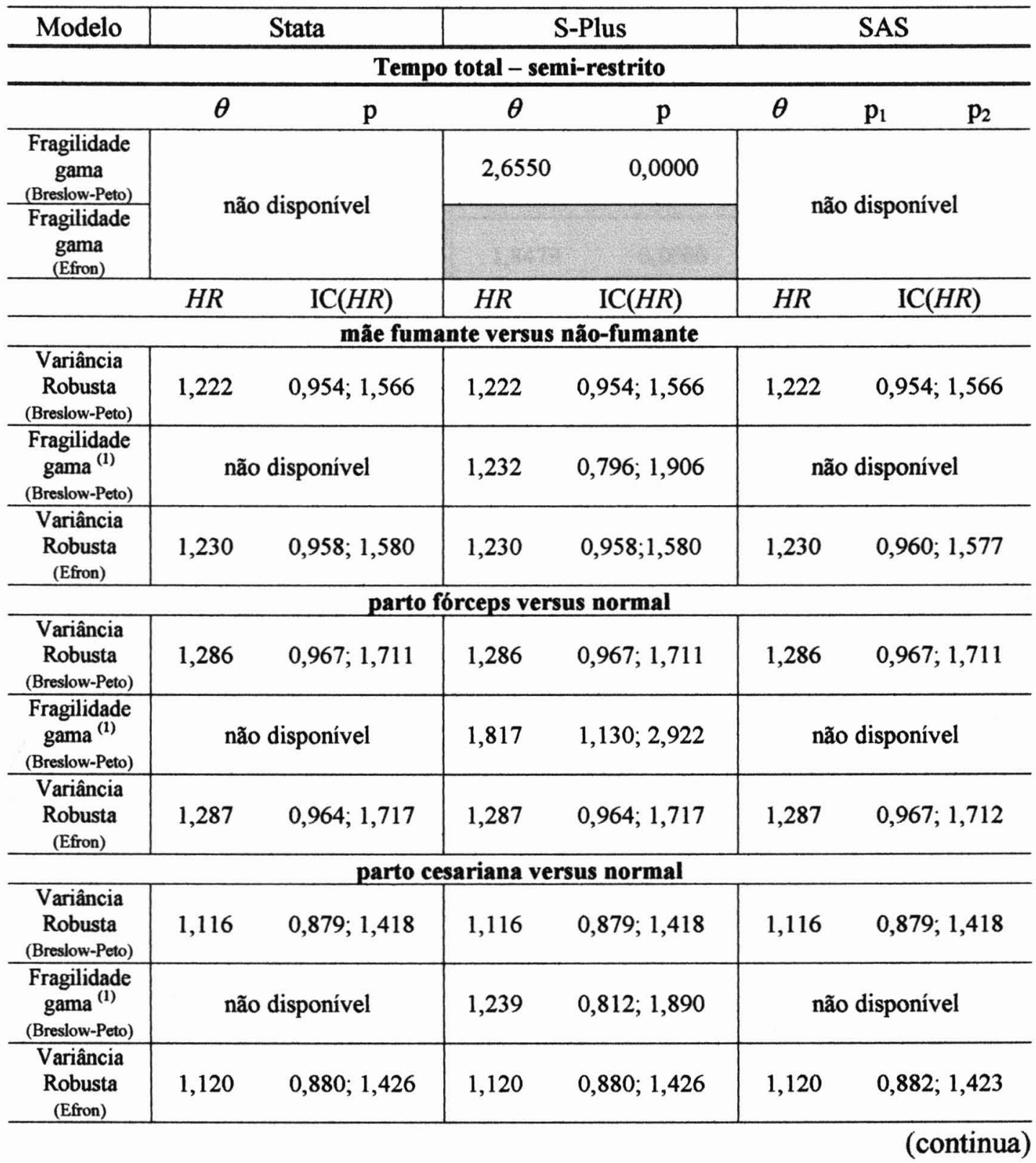


(continuação da Tabela 5.5a)

\begin{tabular}{|c|c|c|c|c|c|c|}
\hline Modelo & & Stata & \multicolumn{2}{|c|}{ S-Plus } & \multicolumn{2}{|c|}{ SAS } \\
\hline \multicolumn{7}{|c|}{ Tempo total - restrito } \\
\hline & $\theta$ & $\mathbf{p}$ & $\theta$ & $\mathrm{p}$ & $\theta$ & $\mathrm{p}_{2}$ \\
\hline $\begin{array}{c}\text { Fragilidade } \\
\text { gama } \\
\text { (Brestow-Peto) }\end{array}$ & \multirow{2}{*}{\multicolumn{2}{|c|}{ não disponível }} & 1,6141 & 0,0000 & \multirow{2}{*}{\multicolumn{2}{|c|}{ não disponivel }} \\
\hline $\begin{array}{c}\text { Fragilidade } \\
\text { gama } \\
\text { (Efron) } \\
\end{array}$ & & & 1,8479 & 0,0000 & & \\
\hline & $H R$ & $\mathrm{IC}(H R)$ & $H R$ & $\mathrm{IC}(H R)$ & $H R$ & $\mathrm{IC}(H R)$ \\
\hline \multicolumn{7}{|c|}{ mãe fumante versus não-fumante } \\
\hline $\begin{array}{c}\text { Variância } \\
\text { Robusta } \\
\text { (Brestow-Peto) }\end{array}$ & 1,092 & 0,$922 ; 1,293$ & 1,092 & 0,$922 ; 1,293$ & 1,092 & 0,$922 ; 1,293$ \\
\hline $\begin{array}{c}\text { Fragilidade } \\
\text { gama } \\
\text { (Breslow-Peto) }\end{array}$ & \multicolumn{2}{|c|}{ não disponivel } & 1,213 & 0,$855 ; 1,722$ & \multicolumn{2}{|c|}{ não disponivel } \\
\hline $\begin{array}{c}\text { Variância } \\
\text { Robusta } \\
\text { (Efron) }\end{array}$ & 1,097 & 0,$924 ; 1,302$ & 1,097 & 0,$924 ; 1,302$ & 1,097 & 0,$926 ; 1,300$ \\
\hline $\begin{array}{c}\text { Fragilidade } \\
\text { gama } \\
\text { (Efroa) }\end{array}$ & \multicolumn{2}{|c|}{ não disponivel } & 1,225 & 0,$844 ; 1,778$ & \multicolumn{2}{|c|}{ não disponível } \\
\hline \multicolumn{7}{|c|}{ parto fórceps versus normal } \\
\hline $\begin{array}{c}\text { Variância } \\
\text { Robusta } \\
\text { (Breslow-Peto) }\end{array}$ & 1,221 & 0,$997 ; 1,495$ & 1,221 & 0,$997 ; 1,495$ & 1,221 & 0,$997 ; 1,495$ \\
\hline $\begin{array}{c}\text { Fragilidade } \\
\text { gama }^{(1)} \\
\text { (Breslow-Peto) }^{2}\end{array}$ & \multicolumn{2}{|c|}{ não disponível } & 1,680 & 1,$145 ; 2,465$ & \multicolumn{2}{|c|}{ não disponível } \\
\hline $\begin{array}{c}\text { Variância } \\
\text { Robusta } \\
\text { (Efron) }\end{array}$ & 1,223 & 0,$996 ; 1,501$ & 1,223 & 0,$996 ; 1,501$ & 1,223 & 0,$999 ; 1,497$ \\
\hline $\begin{array}{c}\text { Fragilidade } \\
\text { gama }^{(1)} \\
\text { (Efron) }\end{array}$ & \multicolumn{2}{|c|}{ não disponível } & 1,740 & 1,$158 ; 2,614$ & \multicolumn{2}{|c|}{ não disponível } \\
\hline \multicolumn{7}{|c|}{ parto cesariana versus normal } \\
\hline $\begin{array}{c}\text { Variância } \\
\text { Robusta } \\
\text { (Breslow-Peto) }\end{array}$ & 1,083 & 0,$919 ; 1,276$ & 1,083 & 0,$919 ; 1,276$ & 1,083 & 0,$919 ; 1,276$ \\
\hline $\begin{array}{c}\text { Fragilidade } \\
\text { gama (1) } \\
\text { (Breslow-Peto) }\end{array}$ & \multicolumn{2}{|c|}{ não disponível } & 1,204 & 0,$860 ; 1,685$ & \multicolumn{2}{|c|}{ não disponível } \\
\hline $\begin{array}{c}\text { Variância } \\
\text { Robusta } \\
\text { (Efron) }\end{array}$ & 1,086 & 0,$919 ; 1,283$ & 1,086 & 0,$919 ; 1,283$ & 1,086 & 0,$921 ; 1,280$ \\
\hline $\begin{array}{c}\text { Fragilidade } \\
\text { gama (1) } \\
\text { (Efron) }\end{array}$ & \multicolumn{2}{|c|}{ não disponível } & 1,247 & 0,$871 ; 1,787$ & \multicolumn{2}{|c|}{ não disponível } \\
\hline
\end{tabular}


(continuação da Tabela 5.5a)

\begin{tabular}{|c|c|c|c|c|c|c|c|}
\hline Modelo & \multicolumn{2}{|c|}{ Stata } & \multicolumn{2}{|c|}{ S-Plus } & \multicolumn{3}{|c|}{ SAS } \\
\hline & \multicolumn{7}{|c|}{ Tempo entre eventos - irrestrito } \\
\hline & $\theta$ & $\mathrm{p}$ & $\theta$ & p & $\theta$ & $\mathrm{p}_{1}$ & $\mathbf{p}_{2}$ \\
\hline $\begin{array}{l}\text { Fragilidade } \\
\text { gama } \\
\text { (Breslow-Peto) }\end{array}$ & 0,2478 & 0,0000 & 0,2458 & 0,0000 & 0,2478 & 0,0001 & 0,0000 \\
\hline $\begin{array}{c}\text { Fragilidade } \\
\text { gama } \\
\text { (Efron) }\end{array}$ & 0,3103 & 0,0000 & 0,3100 & 0,0000 & \multicolumn{3}{|c|}{ não disponivel } \\
\hline & $H R$ & $\mathrm{IC}(H R)$ & $H R$ & $\mathrm{IC}(H R)$ & $H R$ & IC & $(H R)$ \\
\hline \multicolumn{8}{|c|}{ mãe fumante versus não-fumante } \\
\hline $\begin{array}{c}\text { Variância } \\
\text { Robusta } \\
\text { (Breslow-Peto) }\end{array}$ & 1,076 & 0,$924 ; 1,252$ & 1,076 & 0,$924 ; 1,252$ & 1,076 & 0,92 & $4 ; 1,252$ \\
\hline $\begin{array}{c}\text { Fragilidade } \\
\text { gama } \\
\text { (Breslow-Peto) }\end{array}$ & 1,080 & 0,$896 ; 1,301$ & 1,080 & 0,$896 ; 1,301$ & 1,080 & não d & isponivel \\
\hline $\begin{array}{l}\text { Variância } \\
\text { Robusta } \\
\text { (Efron) }\end{array}$ & 1,077 & 0,$923 ; 1,257$ & 1,077 & 0,$923 ; 1,257$ & 1,077 & 0,92 & $6 ; 1,254$ \\
\hline $\begin{array}{c}\text { Fragilidade } \\
\text { gama } \\
\text { (Efron) } \\
\end{array}$ & 1,080 & 0,$888 ; 1,314$ & 1,080 & 0,$888 ; 1,314$ & & o dispon & ivel \\
\hline \multicolumn{8}{|c|}{ parto fórceps versus normal } \\
\hline $\begin{array}{c}\text { Variância } \\
\text { Robusta } \\
\text { (Breslow-Peto) }\end{array}$ & 1,209 & 1,$008 ; 1,451$ & 1,209 & 1,$008 ; 1,451$ & 1,209 & 1,00 & $8 ; 1,451$ \\
\hline $\begin{array}{l}\text { Fragilidade } \\
\text { gama (1) } \\
\text { (Breslow-Peto) }\end{array}$ & 1,276 & 1,$044 ; 1,560$ & 1,276 & 1,$044 ; 1,558$ & 1,276 & não d & isponivel \\
\hline $\begin{array}{l}\text { Variância } \\
\text { Robusta } \\
\text { (Efron) }\end{array}$ & 1,214 & 1,$007 ; 1,463$ & 1,214 & 1,$007 ; 1,463$ & 1,214 & 1,01 & $2 ; 1,456$ \\
\hline $\begin{array}{c}\text { Fragilidade } \\
\text { gama (1) } \\
\text { (Efron) }\end{array}$ & 1,300 & 1,$053 ; 1,606$ & 1,300 & 1,$053 ; 1,606$ & & o dispon & Ivel \\
\hline \multicolumn{8}{|c|}{ parto cesariana versus normal } \\
\hline $\begin{array}{c}\text { Variância } \\
\text { Robusta } \\
\text { (Breslow-Peto) }\end{array}$ & 1,033 & 0,$887 ; 1,204$ & 1,033 & 0,$887 ; 1,204$ & 1,033 & 0,88 & $7 ; 1,204$ \\
\hline $\begin{array}{l}\text { Fragilidade } \\
\text { gama (1) } \\
\text { (Breslow-Peto) }\end{array}$ & 1,045 & 0,$874 ; 1,250$ & 1,045 & 0,$874 ; 1,250$ & 1,045 & não d & isponivel \\
\hline $\begin{array}{l}\text { Variância } \\
\text { Robusta } \\
\text { (Efron) }\end{array}$ & 1,034 & 0,$884 ; 1,209$ & 1,034 & 0,$884 ; 1,209$ & 1,034 & 0,88 & $7 ; 1,204$ \\
\hline $\begin{array}{l}\text { Fragilidade } \\
\text { gama (1) } \\
\text { (Efroa) }\end{array}$ & 1,049 & 0,$869 ; 1,266$ & 1,049 & 0,$869 ; 1,266$ & & o dispon & ivel \\
\hline
\end{tabular}


(continuação da Tabela 5.5a)

\begin{tabular}{|c|c|c|c|c|c|c|}
\hline Modelo & \multicolumn{2}{|c|}{ Stata } & \multicolumn{2}{|c|}{ S-Plus } & \multicolumn{2}{|c|}{ SAS } \\
\hline & \multicolumn{6}{|c|}{ Tempo entre eventos - restrito } \\
\hline & $\theta$ & $\mathrm{p}$ & $\theta$ & p & $\theta$ & $\mathrm{p}_{2}$ \\
\hline $\begin{array}{c}\text { Fragilidade } \\
\text { gama } \\
\text { (Breslow-Peto) }\end{array}$ & \multirow{2}{*}{\multicolumn{2}{|c|}{ não disponivel }} & 0,1503 & 0,0333 & \multirow{2}{*}{\multicolumn{2}{|c|}{ não disponivel }} \\
\hline $\begin{array}{c}\text { Fragilidade } \\
\text { gama } \\
\text { (Efron) } \\
\end{array}$ & & & 0,3268 & 0,0001 & & \\
\hline & $H R$ & $\mathrm{IC}(H R)$ & $H R$ & $\mathrm{IC}(H R)$ & $H R$ & $\mathrm{IC}(H R)$ \\
\hline \multicolumn{7}{|c|}{ mãe fumante versus não-fumante } \\
\hline $\begin{array}{c}\text { Variância } \\
\text { Robusta } \\
\text { (Breslow-Peto) }\end{array}$ & 1,062 & 0,$924 ; 1,220$ & 1,062 & 0,$924 ; 1,220$ & 1,062 & 0,$924 ; 1,220$ \\
\hline $\begin{array}{c}\text { Fragilidade } \\
\text { gama } \\
\text { (Breslow-Peto) }\end{array}$ & \multicolumn{2}{|c|}{ não disponivel } & 1,079 & 0,$908 ; 1,283$ & \multicolumn{2}{|c|}{ não disponivel } \\
\hline $\begin{array}{c}\text { Variância } \\
\text { Robusta } \\
\text { (Efron) }\end{array}$ & 1,067 & 0,$925 ; 1,230$ & 1,067 & 0,$925 ; 1,230$ & 1,067 & 0,$929 ; 1,226$ \\
\hline $\begin{array}{c}\text { Fragilidade } \\
\text { gama } \\
\text { (Efron) } \\
\end{array}$ & \multicolumn{2}{|c|}{ não disponivel } & 1,101 & 0,$902 ; 1,344$ & \multicolumn{2}{|c|}{ não disponivel } \\
\hline \multicolumn{7}{|c|}{ parto fórceps versus normal } \\
\hline $\begin{array}{c}\text { Variância } \\
\text { Robusta } \\
\text { (Breslow-Peto) }\end{array}$ & 1,208 & 1,$021 ; 1,428$ & 1,208 & 1,$021 ; 1,428$ & 1,208 & 1,$021 ; 1,428$ \\
\hline $\begin{array}{c}\text { Fragilidade } \\
\text { gama }^{(1)} \\
\text { (Breslow-Peto) }\end{array}$ & \multicolumn{2}{|c|}{ não disponivel } & 1,254 & 1,$043 ; 1,507$ & \multicolumn{2}{|c|}{ não disponivel } \\
\hline $\begin{array}{l}\text { Variância } \\
\text { Robusta } \\
\text { (Efron) }\end{array}$ & 1,213 & 1,$020 ; 1,442$ & 1,213 & 1,$020 ; 1,442$ & 1,213 & 1,$026 ; 1,434$ \\
\hline $\begin{array}{c}\text { Fragilidade } \\
\text { gama }^{(1)} \\
\text { (Efron) }\end{array}$ & \multicolumn{2}{|c|}{ não disponivel } & 1,309 & 1,$056 ; 1,622$ & \multicolumn{2}{|c|}{ não disponivel } \\
\hline \multicolumn{7}{|c|}{ parto cesariana versus normal } \\
\hline $\begin{array}{c}\text { Variância } \\
\text { Robusta } \\
\text { (Braslow-Peto) }\end{array}$ & 1,041 & 0,$903 ; 1,201$ & 1,041 & 0,$903 ; 1,201$ & 1,041 & 0,$903 ; 1,201$ \\
\hline $\begin{array}{c}\text { Fragilidade } \\
\text { gama }^{(1)} \\
\text { (Breslow-Peto) }\end{array}$ & \multicolumn{2}{|c|}{ não disponível } & 1,059 & 0,$897 ; 1,250$ & \multicolumn{2}{|c|}{ não disponivel } \\
\hline $\begin{array}{c}\text { Variância } \\
\text { Robusta } \\
\text { (Efron) }\end{array}$ & 1,046 & 0,$903 ; 1,211$ & 1,046 & 0,$903 ; 1,211$ & 1,046 & 0,$907 ; 1,206$ \\
\hline $\begin{array}{c}\text { Fragilidade } \\
\text { gama }^{(1)} \\
\text { (Efroa) }\end{array}$ & \multicolumn{2}{|c|}{ não disponivel } & 1,083 & 0,$894 ; 1,312$ & \multicolumn{2}{|c|}{ não disponivel } \\
\hline
\end{tabular}


Tabela 5.5b - Estimativas da razão de taxas de falha $(H R)$ e da variância $(\theta)$ da fragilidade gama, para a $1^{\text {a }}$ ocorrência de qualquer morbidade, segundo alguns modelos semiparamétricos para dados univariados e programas computacionais

\begin{tabular}{|c|c|c|c|c|c|c|}
\hline \multirow{2}{*}{ Modelo } & \multicolumn{2}{|c|}{ Stata } & \multicolumn{2}{|c|}{ S-Plus } & \multicolumn{2}{|c|}{ SAS } \\
\hline & $\theta$ & $\mathrm{p}$ & $\theta$ & $\mathrm{p}$ & $\theta$ & $\mathrm{p}_{2}$ \\
\hline $\begin{array}{c}\text { Fragilidade } \\
\text { gama } \\
\text { (Breslow-Peto) }\end{array}$ & 0,0000 & 0,4971 & 0,0000 & 1,0000 & & \\
\hline $\begin{array}{c}\text { Fragilidade } \\
\text { gama } \\
\text { (Efron) } \\
\end{array}$ & 0,1059 & 0,4040 & 0,0037 & 0,9496 & \multicolumn{2}{|c|}{ não disponível } \\
\hline & $H R$ & $\mathrm{IC}(H R)$ & $H R$ & $\mathrm{IC}(H R)$ & $H R$ & $\mathrm{IC}(H R)$ \\
\hline \multicolumn{7}{|c|}{ mãe fumante versus não-fumante } \\
\hline $\begin{array}{c}\text { Cox } \\
\text { (Breslow-Peto) }\end{array}$ & 1,426 & 1,$115 ; 1,823$ & 1,426 & 1,$115 ; 1,824$ & 1,426 & 1,$115 ; 1,824$ \\
\hline $\begin{array}{l}\text { Variância } \\
\text { Robusta } \\
\text { (Breslow-Peto) }\end{array}$ & 1,426 & 1,$116 ; 1,821$ & 1,426 & 1,$117 ; 1,821$ & 1,426 & 1,$117 ; 1,821$ \\
\hline $\begin{array}{c}\text { Fragilidade } \\
\text { gama } \\
\text { (Breslow-Peto) }\end{array}$ & 1,426 & 1,$115 ; 1,823$ & 1,426 & 1,$115 ; 1,823$ & & \\
\hline $\begin{array}{c}\text { Cox } \\
\text { (Efron) }\end{array}$ & 1,456 & 1,$138 ; 1,863$ & 1,457 & 1,$139 ; 1,863$ & 1,457 & 1,$139 ; 1,863$ \\
\hline $\begin{array}{c}\text { Variância } \\
\text { Robusta } \\
\text { (Efron) }\end{array}$ & 1,456 & 1,$127 ; 1,882$ & 1,457 & 1,$127 ; 1,882$ & 1,457 & 1,$138 ; 1,864$ \\
\hline $\begin{array}{c}\text { Fragilidade } \\
\text { gama } \\
\text { (Efron) } \\
\end{array}$ & 1,505 & 1,$154 ; 1,964$ & 1,458 & 1,$139 ; 1,866$ & & lisponível \\
\hline \multicolumn{7}{|c|}{ forceps versus parto nomal } \\
\hline $\begin{array}{c}\text { Cox } \\
\text { (Breslow-Peto) }\end{array}$ & 1,168 & 0,$895 ; 1,525$ & 1,168 & 0,$895 ; 1,525$ & 1,168 & 0,$895 ; 1,525$ \\
\hline $\begin{array}{c}\text { Variância } \\
\text { Robusta } \\
\text { (Breslow-Peto) }\end{array}$ & 1,168 & 0,$909 ; 1,501$ & 1,168 & 0,$909 ; 1,501$ & 1,168 & 0,$909 ; 1,501$ \\
\hline $\begin{array}{c}\text { Fragilidade } \\
\text { gama } \\
\text { (Breslow-Peto) }\end{array}$ & 1,168 & 0,$895 ; 1,525$ & 1,168 & 0,$895 ; 1,525$ & & \\
\hline $\begin{array}{c}\text { Cox } \\
\text { (Efron) }\end{array}$ & 1,169 & 0,$895 ; 1,526$ & 1,169 & 0,$895 ; 1,526$ & 1,169 & 0,$895 ; 1,526$ \\
\hline $\begin{array}{c}\text { Variância } \\
\text { Robusta } \\
\text { (Efron) }\end{array}$ & 1,169 & 0,$902 ; 1,515$ & 1,169 & 0,$902 ; 1,515$ & 1,169 & 0,$909 ; 1,502$ \\
\hline $\begin{array}{c}\text { Fragilidade } \\
\text { gama } \\
\text { (Efron) } \\
\end{array}$ & 1,174 & 0,$882 ; 1,564$ & 1,169 & 0,$895 ; 1,527$ & & lisponível \\
\hline \multicolumn{7}{|c|}{ cesareana versus parto normal } \\
\hline $\begin{array}{c}\text { Cox } \\
\text { (Breslow-Peto) }\end{array}$ & 1,337 & 1,$056 ; 1,692$ & 1,337 & 1,$056 ; 1,692$ & 1,337 & 1,$056 ; 1,692$ \\
\hline $\begin{array}{c}\text { Variância } \\
\text { Robusta } \\
\text { (Breslow-Peto) }\end{array}$ & 1,337 & 1,$064 ; 1,680$ & 1,337 & 1,$064 ; 1,680$ & 1,337 & 1,$064 ; 1,680$ \\
\hline $\begin{array}{c}\text { Fragilidade } \\
\text { gama } \\
\text { (Breslow-Peto) }\end{array}$ & 1,337 & 1,$056 ; 1,692$ & 1,337 & 1,$056 ; 1,692$ & & \\
\hline $\begin{array}{c}\text { Cox } \\
\text { (Efron) }\end{array}$ & 1,354 & 1,$069 ; 1,714$ & 1,354 & 1,$069 ; 1,714$ & 1,354 & 1,$069 ; 1,714$ \\
\hline $\begin{array}{c}\text { Variância } \\
\text { Robusta } \\
\text { (Efron) }\end{array}$ & 1,354 & 1,$067 ; 1,717$ & 1,354 & 1,$067 ; 1,717$ & 1,354 & 1,$077 ; 1,702$ \\
\hline $\begin{array}{c}\text { Fragilidade } \\
\text { gama } \\
\text { (Efron) }\end{array}$ & 1,384 & 1,$074 ; 1,783$ & 1,355 & 1,$069 ; 1,716$ & & lisponível \\
\hline
\end{tabular}


Figura 5.5 - Intervalos de confiança da razão de taxas de falha para os dados do Estudo 5, segundo alguns modelos semiparamétricos para eventos recorrentes e para $1^{\mathrm{a}}$ recorrência, usando aproximação Efron e o programa S-Plus

a) $H R$ entre mães fumantes e não-fumantes

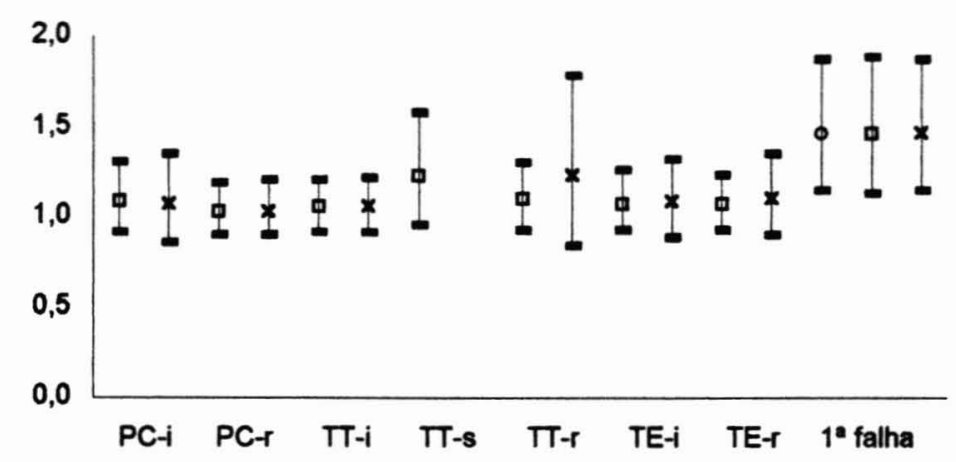

b) $H R$ entre partos fórceps e normais

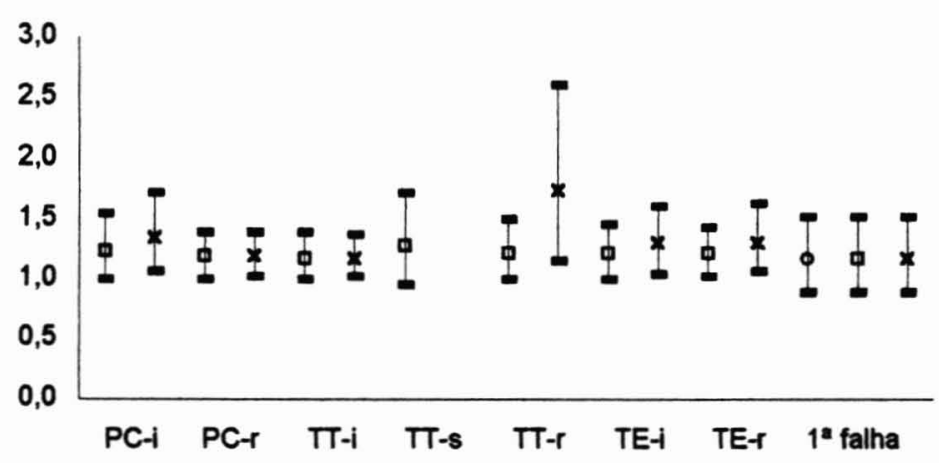

c) $H R$ entre partos cesárea e normais

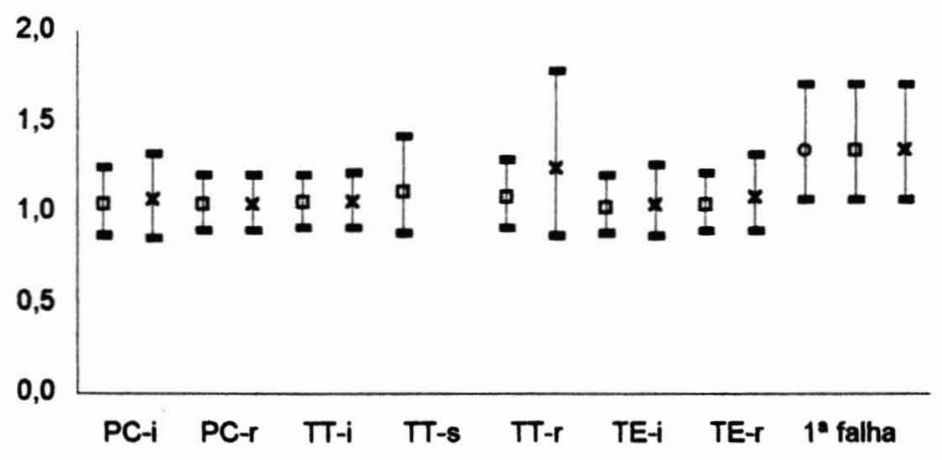

$\circ$ Cox

$\square$ Variância Robusta

$\times$ Fragilidade 
$\mathrm{Na}$ análise com dados univariados (Tabela $5.5 \mathrm{~b}$ ), que considera somente o primeiro episódio de morbidade, o parâmetro $\theta$ não é significativo, portanto, o efeito da heterogeneidade sobre a $1^{\mathrm{a}}$ ocorrência de morbidade parece ser nulo e modelos sem fragilidade podem ser ajustados. As estimativas por intervalo de $H R$ indicam que mãe fumante e parto cesariana são fatores de risco para a $1^{\mathrm{a}}$ ocorrência de morbidade.

Ao comparar os modelos ajustados no S-Plus com aproximação Efron (Figura $5.5)$, verifica-se que as estimativas de $H R$ para $1^{\mathrm{a}}$ falha, nos três gráficos, são diferentes das estimativas para eventos recorrentes. Para as covariáveis indicadoras de mãe fumante e parto cesariana, as estimativas dos modelos para dados univariados são mais altas, enquanto que para parto fórceps foram um pouco mais baixas. Os modelos TT - restrito com fragilidade apresentam estimativas pouco precisas, comparadas com a de outros modelos. Para a covariável indicadora de parto fórceps (b), os resultados mostram-se inconclusivos, devido provavelmente a baixa freqüência deste tipo de parto.

\subsection{Comparação dos programas computacionais}

$\mathrm{Na}$ abordagem de variância robusta, os desempenhos são muito próximos nos três programas com relação ao número de iterações até a convergência e ao tempo de computador. Os resultados dos ajustes dos modelos também foram semelhantes, sobretudo na estimação pontual das razões de taxas de falha nos modelos com aproximação de Breslow-Peto. Quando usando a aproximação por Efron, os correspondentes resultados do programa SAS diferiram um pouco dos demais.

Quanto aos modelos de fragilidade, o desempenho dos programas foi muito diferente. O Quadro 5.1 apresenta as resoluções com modelos irrestritos; não foram relacionados os modelos semi-restritos e restritos porque somente o programa S-Plus ajusta esses modelos com a fragilidade. O programa Stata, na versão que foi usada, tem, em geral, um tempo computacional muito maior, comparado ao S-Plus. A macro do SAS está em uma posição intermediária, principalmente nos casos em que o Stata é extremamente mais lento, mas, por outro lado, a macro do SAS teve um mal desempenho por problemas no processo de estimação, não 
fornece um intervalo de confiança para a razão de taxas de falha e não está disponível o ajuste de modelos com processos de contagem, com conjunto de risco restrito e com aproximação Efron.

Quadro 5.1 - Tempo computacional ${ }^{(1)}$ para o ajuste de alguns modelos com fragilidade gama irrestritos

\begin{tabular}{|c|c|c|c|c|c|c|}
\hline \multirow{3}{*}{ Modelo } & \multicolumn{6}{|c|}{ Programa } \\
\hline & \multicolumn{2}{|c|}{ Stata } & \multicolumn{2}{|c|}{ S-Plus } & \multicolumn{2}{|c|}{ SAS } \\
\hline & Breslow-Peto & Efron & Breslow-Peto & Efron & Breslow-Peto & Efron \\
\hline \multicolumn{7}{|c|}{ Eventos agrupados - Estudo 1} \\
\hline Único & $1 \mathrm{~s}$ & $2 s$ & $2 \mathrm{~s}$ & $2 \mathrm{~s}$ & $16 \mathrm{~s}$ & não disponivel \\
\hline \multicolumn{7}{|c|}{ Eventos agrupados - Estudo 2} \\
\hline Único & $4 \mathrm{~m} 8 \mathrm{~s}$ & $4 \mathrm{~m} 20 \mathrm{~s}$ & $7 \mathrm{~s}$ & $4 s$ & $4 \mathrm{~m} 23 \mathrm{~s}$ & não disponivel \\
\hline \multicolumn{7}{|c|}{ Eventos recorrentes- Estudo 3} \\
\hline Processos de Contagem & $9 \mathrm{~s}$ & $15 \mathrm{~s}$ & $3 \mathrm{~s}$ & $2 \mathrm{~s}$ & não disponivel & não disponivel \\
\hline Tempo total & $17 \mathrm{~s}$ & $24 \mathrm{~s}$ & $3 \mathrm{~s}$ & $3 \mathrm{~s}$ & & não disponivel \\
\hline Tempo entre eventos & $5 \mathrm{~s}$ & $15 \mathrm{~s}$ & $2 \mathrm{~s}$ & $3 \mathrm{~s}$ & $21 \mathrm{~s}$ & não disponivel \\
\hline \multicolumn{7}{|c|}{ Eventos recorrentes- Estudo 4} \\
\hline Processos de Contagem & $1 \mathrm{~h} 27 \mathrm{~m} 50 \mathrm{~s}$ & $1 \mathrm{~h} 30 \mathrm{~m} 57 \mathrm{~s}$ & $11 \mathrm{~s}$ & $19 \mathrm{~s}$ & não disponivel & não disponivel \\
\hline Tempo total & & $49 \mathrm{~m} 43 \mathrm{~s}$ & $11 \mathrm{~s}$ & $13 \mathrm{~s}$ & & não disponivel \\
\hline Tempo entre eventos & $51 \mathrm{~m} 13 \mathrm{~s}$ & $1 \mathrm{~h} 16 \mathrm{~m} 11 \mathrm{~s}$ & $12 \mathrm{~s}$ & $13 \mathrm{~s}$ & $3 \mathrm{~m} 20 \mathrm{~s}$ & não disponivel \\
\hline \multicolumn{7}{|c|}{ Eventos recorrentes- Estudo 5} \\
\hline Processos de Contagem & $1 \mathrm{~h} 35 \mathrm{~m} 17 \mathrm{~s}$ & $12 \mathrm{~h} 35 \mathrm{~m} 58 \mathrm{~s}$ & $23 \mathrm{~s}$ & $22 \mathrm{~s}$ & não disponivel & não disponivel \\
\hline Tempo total & $2 \mathrm{~h} 33 \mathrm{~m} 42 \mathrm{~s}$ & $35 \mathrm{~h} 37 \mathrm{~m} 8 \mathrm{~s}$ & $13 \mathrm{~s}$ & $12 \mathrm{~s}$ & & não disponivel \\
\hline Tempo entre eventos & $1 \mathrm{~h} 35 \mathrm{~m} 38 \mathrm{~s}$ & $17 \mathrm{~h} 59 \mathrm{~m} 33 \mathrm{~s}$ & $17 \mathrm{~s}$ & $17 \mathrm{~s}$ & $7 \mathrm{~m} 28 \mathrm{~s}$ & não disponivel \\
\hline \multicolumn{7}{|c|}{$1^{\text {a }}$ falha- Estudo 3} \\
\hline Único & $5 s$ & & $3 \mathrm{~s}$ & $3 \mathrm{~s}$ & & não disponivel \\
\hline \multicolumn{7}{|c|}{$1^{\text {a }}$ falha- Estudo 4} \\
\hline Único & $40 \mathrm{~m} 58 \mathrm{~s}$ & $54 \mathrm{~m} 19 \mathrm{~s}$ & $9 \mathrm{~s}$ & $13 \mathrm{~s}$ & & não disponivel \\
\hline \multicolumn{7}{|c|}{$1^{\text {a }}$ falha- Estudo 5} \\
\hline Único & $35 \mathrm{~m} 39 \mathrm{~s}$ & $5 \mathrm{~h} 7 \mathrm{~m} 13 \mathrm{~s}$ & $14 \mathrm{~s}$ & $13 \mathrm{~s}$ & & não disponivel \\
\hline
\end{tabular}

(1) Memória $=120 \mathrm{MB}$ de RAM; Velocidade do Processador $=1200 \mathrm{MHz}$

Células sombreadas indicam problemas no processo iterativo 


\section{DISCUSSÃO}

Enquanto as técnicas de regressão para analisar dados univariados de sobrevida, como os modelos de riscos proporcionais, são bem aceitas e bastante usadas, os modelos para analisar dados multivariados de sobrevida, ainda merecem muita discussão. A fragilidade gama e a variância robusta são duas abordagens aplicadas na modelagem de funções de taxas de falha como uma extensão do modelo semiparamétrico de Cox para dados univariados de sobrevida.

\section{Enfoque metodológico}

Por controlarem de forma diferenciada a falta de independência entre tempos de falha multivariados, os coeficientes de regressão e conseqüentemente a razão de taxas de falha dos modelos com variância robusta e com fragilidade têm interpretações distintas. Quando a fragilidade é compartilhada pelo grupo, a razão de taxas de falha estimada pelo modelo com fragilidade é especifica para grupos com um mesmo nivel de fragilidade; enquanto que o modelo com variância robusta apresenta uma razão de taxas de falha geral (THERNEAU e GRAMBSCH 2000).

Os modelos com fragilidade, consideram explicitamente as correlações entre os tempos de falha, incluindo efeitos aleatórios no modelo (em contrapartida com o modelo com variância robusta que não modela essa correlação). Com fragilidade, é possível testar independência intra-grupo, além de predizer a fragilidade de cada grupo. Por ser um modelo sofisticado, sua implementação é mais complexa.

THERNEAU e GRAMBSCH (2000) afirmam que o vetor $\boldsymbol{\beta}$ pode ser estimado mais precisamente que o parâmetro da distribuição de fragilidade gama e MASSONET e col. (2003) comentam que, em geral, obter a variabilidade dos estimadores dos parâmetros do modelo com fragilidade é uma tarefa complexa, 
principalmente de $\hat{\theta}$. KLEIN e MOESCHBERGER (2003) declaram que as estimativas da variabilidade dos parâmetros estimados com o algoritmo EM são obtidas invertendo a matriz de informação observada. Esta matriz de informação é quadrada com dimensão $d+p+1$, em que $d$ é o número de tempos de falha distintos, $p$ é o número de covariáveis e por causa do parâmetro da fragilidade gama é somado 1 à dimensão da matriz e, assim, para conjuntos de dados grandes, este processo torna-se inapropriado. Com verossimilhança parcial penalizada, a variância de $\hat{\theta}$ parece que não é estimada pelo S-Plus, já que o programa não o disponibiliza e as inferências sobre $\beta$ são condicionadas a um valor fixo de $\theta$; e o Stata apresenta uma estimativa para variancia de $\hat{\theta}$, mas não está claro como é obtida. As propostas encontradas na literatura para estimação das variancias são por meio de esquemas de reamostragem com bootstrap (MASSONET e col. 2003).

A observação de uma maior estabilidade no processo de estimação com a função de verossimilhança parcial penalizada em programas como o S-Plus, têm popularizado os modelos de fragilidade gama. Mas o modelo apresenta algumas desvantagens com relação a sua aplicação. Uma delas é a escolha arbitrária da distribuição para a fragilidade. Nem a teoria ou mesmo o próprio conjunto de dados podem prover alguma pista para que uma distribuição seja imposta sobre a fragilidade. Além do mais, estudos com simulações têm mostrado que as estimativas dos parâmetros são bastante sensíveis quanto à forma paramétrica assumida para a fragilidade (HOUGAARD 2000). Mesmo assim, a fragilidade gama é historicamente a mais usada, por conveniência matemática. Outras distribuições têm sido sugeridas na literatura e podem ser encontradas em HOUGAARD (2000) como a fragilidade log-normal implementada na versão 6.1 do S-Plus. Este trabalho é restrito à análise da fragilidade gama, para ser comparável a outros trabalhos como os de KELLY e LIM (2000) e BOX-STEFFENSMEIER e DE BOEF (2002).

Como discutido nas Seções (1.3) e (4.1.4), BOX-STEFFENSMEIER e DE BOEF (2002) destacaram duas possíveis fontes de correlação intra-grupo: a falta de independência entre os eventos e a falta de independência entre grupos, devido a heterogeneidade não observada. Neste aspecto, o modelo de fragilidade compartilhada modela simultaneamente a dependência entre eventos e a heterogeneidade não observada, sendo que no caso da fragilidade gama, um único parâmetro, $\theta$, 
representa ambas propriedades. Além disso, uma suposição dos modelos de fragilidade compartilhada é que a fragilidade é independente das covariáveis incluídas no modelo. Partindo deste pressuposto, a fragilidade pode somente captar as fontes de variação que são independentes das covariáveis incluídas no modelo.

Com relação aos avanços na teoria de modelos de fragilidade, encontram-se na literatura extensões do modelo de fragilidade compartilhada, algumas delas podem ser encontradas em LIANG e col. (1995), como fragilidade dependente do tempo, relaxando a suposição de que a associação entre as observações de um grupo é constante ao longo do tempo. No entanto, a rotina para a estimação dos parâmetros desses modelos mais gerais não está implementada em programas "amigáveis".

De um modo geral, os modelos com variância robusta apresentam a vantagem de um bom desempenho computacional. Por sua simplicidade, não apresentam tantos problemas de convergência como nos modelos de fragilidade gama.

Ao analisar falhas múltiplas, um modelo deve ser assumido, entre os sete modelos possíveis apresentados por KELLY e LIM (2000), além de escolher a forma com que a correlação intra-grupo vai ser tratada, com fragilidade ou variancia robusta. A diferenciação detalhada das sete variações de modelos semiparamétricos para falhas múltiplas é de utilidade por facililitar a opção por uma das alternativas que se julgar mais aplicável aos dados, já que as rotinas para estimação destes modelos estão implementadas em programas computacionais acessíveis a usuários da área biomédica. A principal dificuldade da parte computacional desses modelos para falhas múltiplas talvez seja a estruturação do banco de dados. Nos arquivos originais dos bancos de dados, em geral, cada linha corresponde a um indivíduo e todas as informações individuais estão dispostas nas colunas desses arquivos. No caso de falhas múltiplas, cada indivíduo contribui com várias linhas, cada linha correspondendo a uma observação (falha ou censura) do indivíduo. Mediante alguma programação, é possivel a partir do banco de dados original modificar o formato do arquivo de forma conveniente para aplicar o modelo escolhido. Entretanto, quando não há domínio de programação, transformar o arquivo manualmente pode ser um processo bastante trabalhoso. 


\section{Enfoque empírico}

Em geral, não é esperado que as estimativas dos coeficientes sejam semelhantes, já que estão sendo estimadas quantidades diferentes, a menos que a correlação entre observações do mesmo grupo seja igual a zero: se existe correlação entre as observações do grupo, o modelo de fragilidade estima um $H R$ para grupos com mesmo nível de fragilidade; e o modelo de variância robusta estima um $H R$ geral. No contexto epidemiológico, as razões de taxas de falha estimadas com e sem fragilidade provavelmente são interpretadas igualmente, já que a fragilidade não é observada. Se a estimativa de $\theta$ não é significativa, os modelos sem fragilidade podem ser ajustados. Quando é significativa, pode-se buscar a causa para um valor elevado da variância da fragilidade gama.

THERNEAU e GRAMBSCH (2000) afirmaram que um $\theta=2$ leva a um grande efeito biológico e um $\theta=0,85$ indica um efeito aleatório substancial. Nos ajustes dos modelos, constatou-se um $\hat{\theta}=5,5$, no ajuste do modelo com tempo total restrito e aproximação Breslow-Peto aos dados do Estudo 4, provocando um efeito aleatório extremamente grande, que leva a intervalos de confiança muito grandes para as estimativas de $H R$.

Quando analisando falhas múltiplas, as sete estruturas possíveis (baseadas na escolha do tipo de intervalo de risco e conjunto de risco) para determinação do modelo, resultaram em estimativas diferentes para os parâmetros em $\beta$, mas principalmente de $\theta$. A escolha do modelo depende da característica de falha múltipla (eventos recorrentes ou eventos de múltiplos tipos) e dos interesses da pesquisa, como ajustar um modelo estratificado por ordem de ocorrência das falhas e incluir interação entre tratamento e a variável que indica a seqüencia das falhas para verificar se o efeito de tratamento varia entre a $1^{\mathrm{a}}$ falha e as demais. Verificou-se também que os modelos com fragilidade e com variância robusta foram afetados igualmente por estas diferentes estruturas. Portanto, parece que a opção por um dos modelos independe de qual abordagem é usada para tratar tempos de falha correlacionados; diferentemente do que foi apontado pelo trabalho de BOX-STEFFENSMEIER e DE BOEF (2002), que por simulação concluiram que os modelos tempo entre eventos - restrito com variância robusta e os modelos processos de contagem - restrito com fragilidade são os preferíveis para analisar eventos recorrentes. 


\section{Programas computacionais}

Com relação ao ajuste de modelos com fragilidade gama, o programa Stata, na versão que foi usada, tem, em geral, um tempo computacional muito maior, comparado ao S-Plus; questão que na prática pode ser decisiva para escolha do programa a ser utilizado. A macro do SAS está em uma posição intermediária quanto ao tempo de computador, mas é o programa mais limitado tanto nas opções de modelos que podem ser ajustados (modelos com tempo total ou tempo entre evento; conjunto de risco irrestrito; aproximação Breslow-Peto) como na necessidade de organização do banco de dados (ordenação crescente dos tempos de falha, sendo que as falhas vêm antes das censuras; a variável identificadora de grupo deve tomar valores inteiros consecutivos). Mas a maior desvantagem encontra-se no fato da macro funcionar poucas vezes. O S-Plus é o programa mais flexível, permitindo todos os modelos propostos, e falhando poucas vezes no processo de estimação. O Stata, com relação à flexibilidade, está numa posição intermediária, porém tem facilidades para programação envolvendo montagem de bancos de dados apropriados para análise de dados multivariados de sobrevida.

Considerando os critérios de desempenho e flexibilidade conjuntamente, o melhor programa dentre os três que foram comparados, é atualmente o S-Plus, que aparentemente conta com o suporte de dois pesquisadores interessados em fragilidade, Terry Therneau e Patricia Grambsch. 


\section{CONCLUSÕES}

As estimativas por intervalos de confiança da razão de taxas de falha na análise de eventos recorrentes, quando há várias opções de estruturas de intervalos e de conjuntos de risco, podem ser diferentes, ao ajustar-se modelos com fragilidade gama ou com variância robusta.

A não ser que haja interesse em testar independência, o modelo de variância robusta parece ser o mais indicado para analisar tempos de falha multivariados, enquanto não estiverem disponíveis programas estatísticos flexíveis, com bom desempenho computacional para o uso de modelos de fragilidade.

A abordagem de variância robusta apresentou um melhor desempenho computacional comparada à de fragilidade. O programa S-Plus é o melhor para analisar modelos com fragilidade gama, por ser, no momento, o que oferece mais opções e por usar menos tempo de computador comparado ao programa Stata, que está em posição intermediária, ficando por último a macro do SAS, que tem sérios problemas de convergência. Os três programas são equivalentes para analisar modelos de variância robusta. 


\section{$8 \quad$ REFERENNCIAS}

Allison PD. Event history analysis: regression for longitudinal event data. Bervely Hills: Sage; 1984.

Andersen PK, Gill RD. Cox's regression model for counting process: a large sample study. Ann Statist 1982; 10:1100-20.

Andersen PK, Borgan O, Gill RD, Keiding, N. Statistical models based on counting process. New York: Springer-Verlag; 1993.

Box-Steffensmeier JM, De Boef S. A Monte Carlo analysis for recurrent events data [presentation at the Annual Political Methodology Meetings July 2002, in Seatle, WA] Available from <URL:http://psweb.sbs.ohio-state.edu/presm/working papers/repeatedevents.pdf $>$ [2003 May 04].

Breslow NE. Contribution to the discussion of paper by D. R. Cox. J Roy Statist Soc Ser B 1972; 34:216-7.

Breslow NE. Covariance analysis of censured survival data. Biometrics 1974; 30:89-99.

Bueno MB, Souza JMP, Souza SB, Paz SMRS, Gimeno SGA, Siqueira AAF. Riscos associados ao processo de desmame entre crianças nascidas em hospital universitário de São Paulo, entre 1988 e 1999: estudo de coorte prospectivo do primeiro ano de vida. Cad. Saúde Pública 2003; 19:1453-60. 
Chicarino MPZ. Modelo semiparamétrico de fragilidade gama. São Paulo; 1999 [Dissertação de Mestrado - Instituto de Matemática e Estatística da USP].

Cleves M. Analysis of multiple failure-time data with Stata. Stata Technical Bull 1999; 49: 30-9.

Collett D. Modelling survival data in medical research. $2^{\text {nd }}$ ed. Boca Rota: Chapman e Hall/CRC; 2003.

Colosimo EA. A note on the stratified proportional hazards model. Internat J Math Statist Sci 1997; 6:201-09.

Cox DR. Regression models and life tables (with discussion). J Roy Statist Soc Ser B 1972; 34:187-220.

Cox DR. Partial likelihood. Biometrika 1975; 62:269-76.

Cox DR, Oakes D. Analysis of survival data. London: Chapman \& Hall; 1984.

Cutler SJ, Ederer F. Maximum utilization of the life table method in analyzing survival. J Chronic Dis 1958; 8:699-712.

Duchateau L, Janssen P, Lindsey P, Legrand C, Nguti R, Sylvester R. The shared frailty model and the power for heterogeneity test um multicenter trials. Comp Statist Data Analysis 2002; 40:603-20.

Efron B. Efficiency of Cox's likelihood function for censured data. J Amer Statist Assoc 1977; 72:557-65.

Fleming TR, Harrington DP. Counting process and survival analysis. New York: Wiley; 1991.

Fleming TR, Lin DY. Survival analysis in clinical trials: past developments and future directions. Biometrics 2000; 56:971-83. 
Hougaard P. Analysis of multivariate survival data. New York: SpringerVerlag; 2000.

Huster WJ, Brookmeyer R, Self SG. Modelling paired survival data with covariates. Biometrics 1989; 45:145-56.

Ibrahim JG, Chen M-H, Sinha D. Bayesian survival analysis. New York: Springer-Verlag; 2001.

Kalbfleisch JD, Prentice RL. The statistical analysis of failure time data. $2^{\text {nd }}$ ed. New York: Wiley; 2002.

Kaplan EL, Meier P. Nonparametric estimation from incomplete observation. J Am Statist Assoc 1958; 53:457-81.

Kelly PJ, Lim LL-Y. Survival analysis for recurrent event data: an application to childhood infections diseases. Statist Med 2000; 19:13-33.

Klein JP. Semiparametric estimation of random effects using the Cox model based on the EM algorithm Biometrics 1992; 48:795-806.

Klein JP, Moeschberger M. Survival analysis: techniques for censured end truncated data. $2^{\text {nd }}$ ed. New York: Springer-Verlag; 2003.

Lachin JM. Biostatistical methods: the assessment of relative risks. New York: Wiley; 2000.

Lawless JF. Statistical models and methods for lifetime data. New York: Wiley; 1982.

Lee ET e Wang JW. Statistical methods for survival data analysis. $3^{\text {th }}$ ed. New York: Wiley; 2003. 
Lee EW, Wei LJ, Amato DA. Cox-type regression analysis for larger numbers of small groups of correlated failure time observations. In: Klein JP, Goel PK, editors. Survival analysis: state of the art. Norwell (Mass.): Kluwer Academic; 1992. p.237-47.

Liang K-Y, Self SG, Bandeen-Roche KJ, Zeger SL. Some recent developments for regression analysis of multivariate failure time data. Lifetime Data Anal $1995 ; 1: 403-15$.

Lin DY, Wei LJ. The robust inference for the Cox proportional hazards model. J Amer Statist Assoc 1989; 84:1074-78.

Lin DY. Cox regression analysis of multivariate failure time data: marginal approach. Statist Med 1994; 13:2233-47.

Mantel N. Evaluation of survival data and two new rank order statistics in its consideration. Cancer Chemother Rep 1966; 50: 163-70.

Mantel N, Bohidar NR, Ciminera JL. Mantel-Haenszel analysis of litter-matched time-to-response data, with modifications for recovery of interlitter information. Cancer Res 1977; 37:3863-68.

Massonet G, Burzykowski T, Janssen P Resampling plans for frailty models. Louvainla-Neuve; 2003 (Technical Report 0348) Available from <URL:http:// www.stat.ucl.ac.be/IAP > [2004 Apr 10]

Matuda NS. Heterogeneidade não-observada na análise da história de eventos. Campinas; 1998 [Dissertação de Mestrado - Instituto de Matemática, Estatística e Computação da UNICAMP].

Miller Jr. RG; Gong G, Muñoz A. Survival Analysis. New York: Wiley; 1981.

Murphy AS. Asymptotic theory for the frailty model Ann Statist 1995; 23:182- 
98.

Nielsen GG, Gill RD, Andersen PK, Sørensen TIA. A counting process approach to maximum likelihood estimation in frailty models Scand J Statist 1992;19:2443.

Peto R. Contribution to the discussion of paper by D. R. Cox. J Roy Statist Soc Ser B 1972; 34:205-7.

Pickles A, Crouchley R. A comparison of frailty models for multivariate survival data. Statisc Med 1995; 14:1447-61.

Prentice RL, Williams BJ, Peterson AV. On the regression analysis of multivariate time data. Biometrika $1981 ; 68: 373-79$.

Stata Corporation Stata survival analysis and epidemiological tables. College Station: Stata Press ; 2003 (Reference Manual release 8).

Szklo M, Nieto FJ. Epidemiology: beyond the basics. Annapolis: Aspen Publishers; 2000.

Therneau TM, Grambsch PM. Modeling survival data: extending the Cox model. New York: Springer-Verlag; 2000.

Vaupel JW, Maton KG, Stallard E. The impact of heterogeneity in individual frailty on the dynamics of mortality. Demography $1979 ; 16: 439-54$.

Wei LJ Lin DY, Weissfeld L. Regression analysis of multivariate incomplete failure time data by modeling marginal distribution. J Amer Statist Assoc 1989; 84:1065-73. 